\title{
Reversible Ionic Liquids as Double-Action Solvents for Efficient $\mathrm{CO}_{2}$ Capture
}

\author{
DE-NT0005287
}

October 2008 - September 2011

Dr. Charles A. Eckert, Dr. Charles L. Liotta

\section{Final Scientific/Technical Report}

December 2011

Georgia Tech Research Corporation

Atlanta, GA 30332 


\section{Disclaimer}

This report was prepared as an account of work sponsored by an agency of the United States Government. Neither the United States Government nor any agency thereof, nor any of their employees, makes any warranty, express or implied, or assumes any legal liability or responsibility for the accuracy, completeness, or usefulness of any information, apparatus, product, or process disclosed, or represents that its use would not infringe privately owned rights. Reference herein to any specific commercial product, process, or service by trade name, trademark, manufacturer, or otherwise does not necessarily constitute or imply its endorsement, recommendation, or favoring by the United States Government or any agency thereof. The views and opinions of authors expressed herein do not necessarily state or reflect those of the United States Government or any agency thereof. 


\begin{abstract}
We have developed a novel class of $\mathrm{CO}_{2}$ capture solvents, Reversible Ionic Liquids (RevILs), that offer high absorption capacity through two modes of capture: chemical reaction (chemisorption) and physical solubility (physisorption). These solvents are silicon containing alkaline compounds such as silylamines that form a liquid salt (ionic liquid) upon reaction with $\mathrm{CO}_{2}$. Subsequently, modest elevations in temperature reverse the reaction and yield pure $\mathrm{CO}_{2}$ for sequestration. By incorporating $\mathrm{Si}$ in the molecules we have reduced the viscosity, thereby improving the mass transfer rates of $\mathrm{CO}_{2}$ absorption/desorption and decreasing the processing costs for pumping the solvent. In this project, we have made systematic changes to the structure of these compounds to improve several physical and thermodynamic properties important for $\mathrm{CO}_{2}$ capture. Through these structure-property paradigms, we have obtained a RevIL which requires only a third of the energy required by conventional aqueous MEA process for $90 \% \mathrm{CO}_{2}$ capture.
\end{abstract}




\section{Table of Contents}

Executive Summary

1. Introduction

1.1 Reversible Ionic Liquids: $\mathrm{CO}_{2}$ Capture Solvents with Dual Capture Mechanism

2. Synthesis and Characterization of RevILs

3. Analysis of RevIL Properties

3.1 Methodology (Theory and Experimental)

a) Capacity: Overall, Chemisorption, and Physisorption 15

b) Thermodynamics: Enthalpy of Mixing (Physisorption), Reaction Enthalpy 18 (Chemisorption), Reversal Temperature

c) Viscosity

d) Effect of Water 20

e) Density and Refractive Index

f) Kinetics and Mass Transfer

g) Process Modeling and Economic Analysis

3.2 Results

a) Guanidine based RevILs 22

b) Silylamine based RevILs 23

c) Capacity: Chemisorption, Physisorption, and Overall 25

d) Thermodynamics 30

e) Viscosity 33

f) Effect of Water 34

g) Kinetics and Mass Transfer 35

h) Density and Refractive Index 39

i) Recyclability 41

j) Optimum Single Component RevIL for $\mathrm{CO}_{2}$ capture

k) Scale-up of Synthesis Process $\quad 44$

l) Process Modeling and Economic Analysis $\quad 45$

4. Milestones Appraisal $\quad 50$

5. Conclusions 253 Appendices

a) Design of Custom-built ATR cell $\quad 54$ 
b) Synthesis and Characterization of Molecular and Ionic Liquids 56

c) List of Publications and Presentations 68

$\begin{array}{ll}\text { d) List of Symbols } & 75\end{array}$

\section{List of Figures}

Figure 1: Nile red experiments for illustrating the switch from molecular to ionic species

> Figure 2: ATR_FTIR spectrum for TPSA (a) blue: molecular liquid (b) red: ionic liquid + physisorbed $\mathrm{CO}_{2}$

> Figure 3: Specac heated golden gate ATR sample accessory (left) and reactor cell view 1from bottom (right)

Figure 4: DSC of revIL showing reversion temperature and regeneration enthalpy

Figure 5: van't Hoff plot of TPSA

Figure 6: Mole fraction of $\mathrm{CO}_{2}$ in TPSA as a function of pressure at $35^{\circ} \mathrm{C}$

Figure 7: $\mathrm{CO}_{2}$ uptake comparison for select revILs using both diffuser tube and needle $\mathrm{CO}_{2}$ introduction methods. $25^{\circ} \mathrm{C}, 200 \mathrm{ml} / \mathrm{min}$ pure $\mathrm{CO}_{2}$.

Figure 8 : Enthalpy of reaction $\Delta \mathrm{Hr}_{\mathrm{xn}}$ in $\mathrm{kJ} / \mathrm{mol}$ of $\mathrm{CO}_{2}$ for alkyl-substituted silylamines

> figure 9: reversal temperature of ionic liquids of alkyl-substituted silylamines

Figure 10: Plot of $\mathrm{CO}_{2}$ solubilities $\left(\mathrm{x}_{\mathrm{CO} 2}\right)$ as a function of $\mathrm{CO}_{2}$ pressure $\left(\mathrm{P}_{\mathrm{CO} 2}\right)$ for TEtSA at $35^{\circ} \mathrm{C}$ and $50^{\circ} \mathrm{C}$

Figure 11: Relationship between viscosity \& conversion of molecular liquid to ionic liquid

Figure 12: Water content (a) in saturated molecular liquid (solubility of water in molecular liquid) (b) in distilled molecular liquid (for determination of purity)

Figure 13: Competing processes affecting the overall absorption times

- Figure 14: $\mathrm{CO}_{2}$ uptake in TPSA in 60 sec as a function of $\mathrm{CO}_{2}$ flowrate. Conditions: $25^{\circ} \mathrm{C}$, pure $\mathrm{CO}_{2}$, needle. Theoretical maximum chemisorption at $2.32 \mathrm{~mol} \mathrm{CO} / / \mathrm{kg} \mathrm{ML}$ indicated by dashed line.

$>$ Figure 15: Comparison of diffuser tube (red diamonds) and needle (blue circles) $\mathrm{CO}_{2}$ introduction methods as a function of time in TPSA. $200 \mathrm{ml} / \mathrm{min}$ pure $\mathrm{CO}_{2}, 25^{\circ} \mathrm{C}$. Green dashed line indicates theoretical maximum chemisorption for TPSA. A) 15-seconds - 12 minutes. B) 15 seconds - 75 minutes

$>$ Figure 16:. The silylamine molecular liquid densities as a function of temperature

Figure 17: The silylamine ionic liquid densities as a function of temperature

Figure 18: Relationship between refractive index and extent of conversion from molecular liquid to ionic liquid for TPSA. 
Figure 19: Recyclability of TPSA explored using Refractive Index

> Figure 20: Recyclability of THSA explored using Refractive Index

- Figure 21: Process Flow Diagram of $\mathrm{CO}_{2}$ capture using neat TPSA

Figure 22: Schematic of the custom built high pressure ATR IR reactor for use with the Specac, Ltd. Heated Golden Gate ATR accessory.

\section{List of Tables}

Table 1: List of silylamines $\quad 11$

$>$ Table 2: Physical form of silylamine after bubbling $\mathrm{CO}_{2} \quad 24$

$>$ Table 3: Experimental values of Kc for TPSA $\quad 25$

$>$ Table 4: Values of $\boldsymbol{K} \boldsymbol{\gamma}$ for TPSA estimated Using COSMO-RS 26

$>$ Table 5: Henry's Law constants for ionic liquids at $35^{\circ} \mathrm{C} \quad 28$

$>$ Table 6: Comparison of viscosity of silylamine ionic liquids 33

$>$ Table 7: Comparison of properties of trialkylsilylamines 44

> Table 8: $\mathrm{CO}_{2}$ Capture Calculations $\quad 47$ 


\section{Executive Summary}

In this project we have used Reversible Ionic Liquids (RevILs) as $\mathrm{CO}_{2}$ capture solvents with dual mode of $\mathrm{CO}_{2}$ capture (chemisorption and physisorption). In the original proposal we had proposed two categories of RevILs: silylamines and silylguanidines (Task 3). However, it was found that silylamines, owing to their ease of synthesis and lower molecular weight were superior to silylguanidines. Therefore, the focus of this project has been to use a structureproperty relationships based approach for designing silylamines with optimum $\mathrm{CO}_{2}$ capture properties.

We have studied eight silylamine compounds, as opposed to three silylamine and three silylguanadines proposed initially. At the beginning of the project, the focus was on commercially available trialkoxy silylamines ((3-aminopropyl) trimethoxysilane and (3aminopropyl) triethoxysilane). However, these were unstable under air and moisture and hence unsuitable for $\mathrm{CO}_{2}$ capture application. Six other silylamines ((3-aminopropyl) triethylsilane, (3aminopropyl) tripropylsilane, (3-aminopropyl) trihexylsilane, (3-aminopropyl) diisopropyl $(1 \mathrm{H}, 1 \mathrm{H}, 2 \mathrm{H}, 2 \mathrm{H}$-perfluoropentyl)silane, (3-aminopropyl) cyclohexyldimethylsilane and (3-aminopropyl) phenyldimethylsilane) were synthesized in our laboratory. These were synthesized by hydrosilylation reaction of trialkylsilane with allylamine. In these compounds, the alkyl groups were altered to improve the properties such as capacity, viscosity, reaction enthalpy and reversal temperature. Through systematic studies, it was found that the silylamine with propyl groups attached to the Si ((3-aminopropyl) tripropylsilane) gave the right balance of properties.

Our major contributions in this project include:

a) Synthesis of six new silylamines (Task 2)

b) Determination of $\mathrm{CO}_{2}$ capture capacity of silylamines (Task 5)

i. $\quad$ Chemisorption (equilibrium constants through FT-IR and COSMO-RS)

ii. Physisorption (FT-IR)

iii. Overall (gravimetric)

c) Determination of thermodynamics of silylamines (Task 4) 
i. Reversal temperature (DSC)

ii. Reaction enthalpy (DSC)

iii. Enthalpy of mixing associated with physisorption (FT-IR)

d) Analysis of physical properties of silylamines (Task 5)

i. $\quad$ Viscosity (pre- and post-capture)

ii. Refractive index as a measure for conversion

iii. Density (pre- and post-capture)

e) Analysis of structure-property relationships for determining the solvent with optimum $\mathrm{CO}_{2}$ capture properties (Task 5)

f) Proposal for an industrial scale synthesis route for the optimum silylamine (Task 6)

g) Process simulation in HYSYS of $\mathrm{CO}_{2}$ capture process using our optimum silylamine RevIL (Task 6)

Process simulation of the $\mathrm{CO}_{2}$ capture process using this compound showed that for capturing $90 \% \mathrm{CO}_{2}$, our compound requires a third of the energy cost required by the conventional aq. MEA based process. Therefore, our RevILs provide an extremely promising technology for accomplishing DOE's goal of $90 \% \mathrm{CO}_{2}$ capture with no more than $35 \%$ increase in the process costs by the year 2020 . 


\section{Introduction}

The Eckert-Liotta group has a long-standing history of developing novel smart solvents such

as Organic Aqueous Tunable Solvents (OATS) ${ }^{1,2}$, Gas Expanded Liquids (GXLs) ${ }^{3,4}$, and Piperylene Sulfone as a switchable dimethyl sulfoxide (DMSO) substitute ${ }^{5,6}$. The enormous success of the group in this field is attributed to the collaboration between chemists and chemical engineers, working together to synthesize new molecules that have optimum properties for the specific applications. In this project we have explored a novel class of solvents known as Reversible Ionic Liquids (RevILs). The main objective of this project is to use structure-property relationships to obtain a RevIL with optimum thermodynamic and physical properties for postcombustion recovery of $\mathrm{CO}_{2}$ from fossil fuel-fired power plants. The relationship between molecular structure and physical and thermodynamic properties has been a cornerstone of physical-organic chemistry for more than half a century. It allows us to establish a series of paradigms for predicting how various chemical structures will result in a plethora of physical properties, based on both enthalpic and entropic effects.

\subsection{Reversible Ionic Liquids: $\mathrm{CO}_{2}$ Capture Solvents with Dual Capture Mechanism}

Replacing the existing ethanolamine based $\mathrm{CO}_{2}$ capture systems in coal-fired power plants requires new technologies that offer significant economic advantage through high capture capacity, minimum capital cost and energy requirement, and the feasibility of retrofit application to the existing power plants. There have been several approaches to address this issue - physical and chemical absorption using solvents, swing adsorption with metal organic frameworks (MOF's) and zeolites, membrane technology, and chemical looping to name a few. Our proposed solvents, RevILs, aim at providing a viable alternative to these approaches through high capture capacity, minimum regeneration energy requirement, and easy processability through low viscosity.

RevILs are alkaline compounds such as amines (or equimolar mixtures of guanadines and alcohols) that in molecular liquid form react with $\mathrm{CO}_{2}$ to form ionic liquids. Subsequently, heating or sparging with an inert gas reverses the reaction to give back $\mathrm{CO}_{2}$ and the molecular 
liquid. Our RevILs capture additional $\mathrm{CO}_{2}$ through physisorption thus providing dual capture mechanism.

We had proposed two sets of RevILs: (a) silylamine and (b) silylguanidine. During the course of the project, our focus shifted to silylamines as they showed much more promise as compared to the guanidine based compounds. The details of this are discussed later in the report. Silylamines are silicon containing amines that form RevILs with much lower viscosity due to the lewis acid character of silicon ${ }^{1}$. Lower viscosity minimizes the water requirement thus in turn reducing the parasitic sensible heat required for taking the $\mathrm{CO}_{2}$ rich solvent to the reversal temperature. We have further reduced the viscosity through structural changes in the silylamine. Apart from viscosity, systematic structural changes are also introduced to the enhance capacity (chemisorption and physisorption) and reduce the energy requirement for regenerating $\mathrm{CO}_{2}$.

Organization of this report is as follows. The next section lists the various compounds studied in this project and describes their synthesis and characterization. This is followed by the section describing the experimental techniques used for analyzing the physical and thermodynamic properties. Description of the results and their relationships to the structure of the compounds is given in the section following that. In the last two sections of the report, we have discussed the milestones and our concluding remarks.

\footnotetext{
${ }^{1} \mathrm{H}$. Shirota, J. Edward W. Castner, Why are viscosities lower for ionic liquids with $-\mathrm{CH}_{2} \mathrm{Si}\left(\mathrm{CH}_{3}\right)_{3}$ vs $-\mathrm{CH}_{2} \mathrm{C}\left(\mathrm{CH}_{3}\right)_{3}$ substitutions on the imidazolium cations?, Journal of Physical Chemistry B, 109 (2005) 21576-21585.
} 


\section{Synthesis and Characterization of RevILs}

The silylamines studied in this project are listed in Table 1. Two commercially available alkoxy silylamines, (3-aminopropyl) trimethoxysilane and (3-aminopropyl) triethoxysilane (TMSA and TESA), were used in the beginning of the project. However these compounds degrade when exposed to air or moisture making them unsuitable for the $\mathrm{CO}_{2}$ capture application. The second set of compounds was trialkylsilylamines, TEtSA, TPSA, and THSA. Chemical names of these are given in Table 7. TEtSA is short for triethylsilylamine with three ethyl groups attached to the Si. Similarly TPSA and THSA are acronyms for compounds with three propyl and three hexyl groups attached to the $\mathrm{Si}$, respectively. In all three compounds there is a propyl group between the $\mathrm{Si}$ and the amine. The next compound, (3-aminopropyl) diisopropyl $(1 \mathrm{H}, 1 \mathrm{H}, 2 \mathrm{H}, 2 \mathrm{H}-$ perfluoropentyl)silane or FSA for short, was synthesized to improve the physisorption of $\mathrm{CO}_{2}$ in the ionic liquid as fluorine (F) atoms are known to be $\mathrm{CO}_{2}$-phillic. The two compounds in the table with cyclohexyl and phenyl groups attached to Si were synthesized to study the effects of one bulky side group on Si. The synthesis for compounds 3-8 is given in Scheme 1.

Table 1: List of silylamines

\begin{tabular}{|c|c|c|c|}
\hline \multirow{2}{*}{ Compound } & Molecular liquid & Structure & Acronym \\
\hline 1 & $\begin{array}{c}\text { (3-aminopropyl) } \\
\text { trimethoxysilane }\end{array}$ & (3-aminopropyl) & TMSA \\
\hline 2 & triethoxysilane & 2 & TESA \\
\hline
\end{tabular}




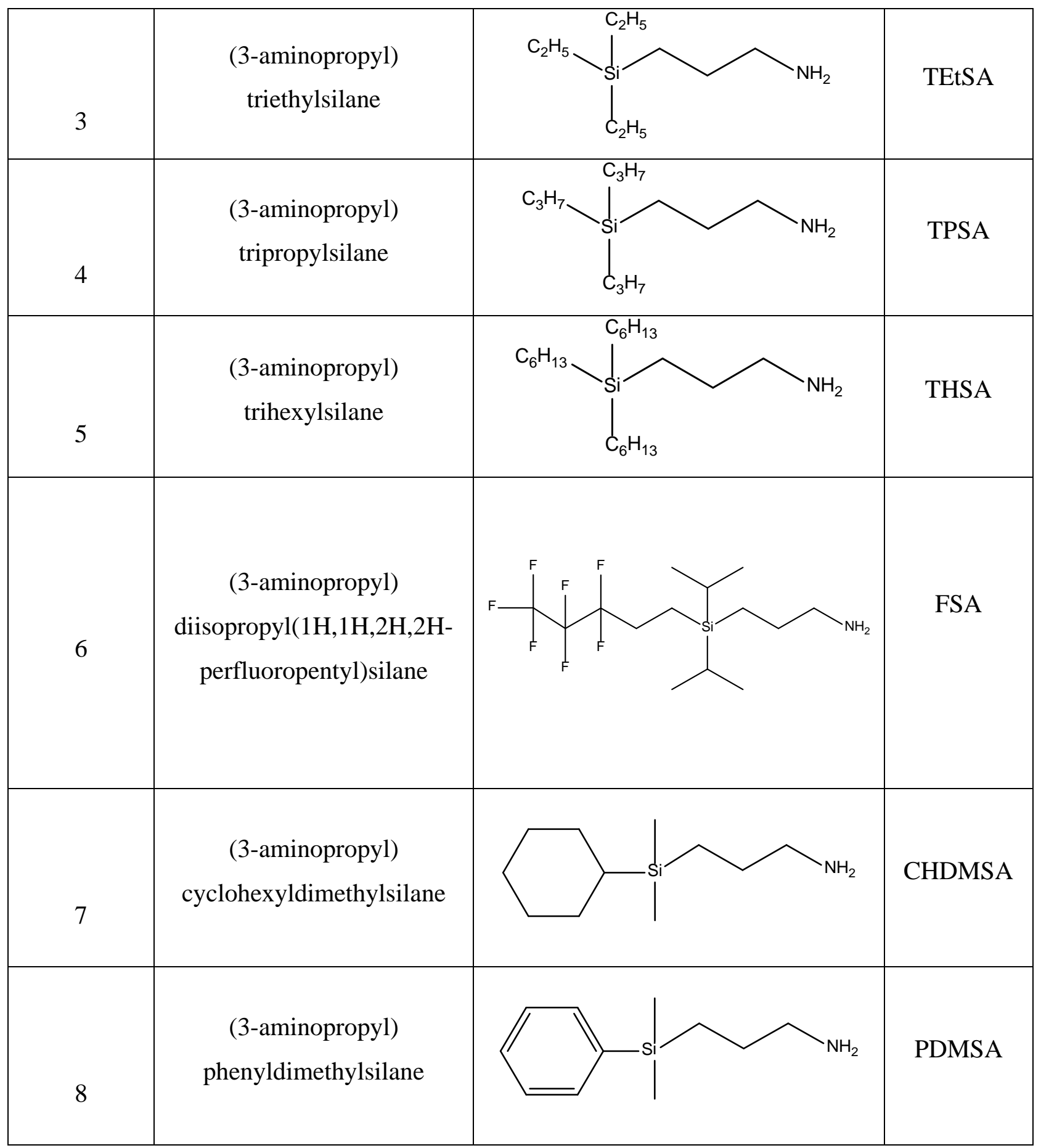

One of the important requirements of a good $\mathrm{CO}_{2}$ capture solvent is a simple synthesis route which can be easily scaled up to provide adequate capture fluid for the high volumes of $\mathrm{CO}_{2}$ released from power plants. The primary scheme (Scheme 1) that used for the synthesis of our silylamine based molecular solvent is: 


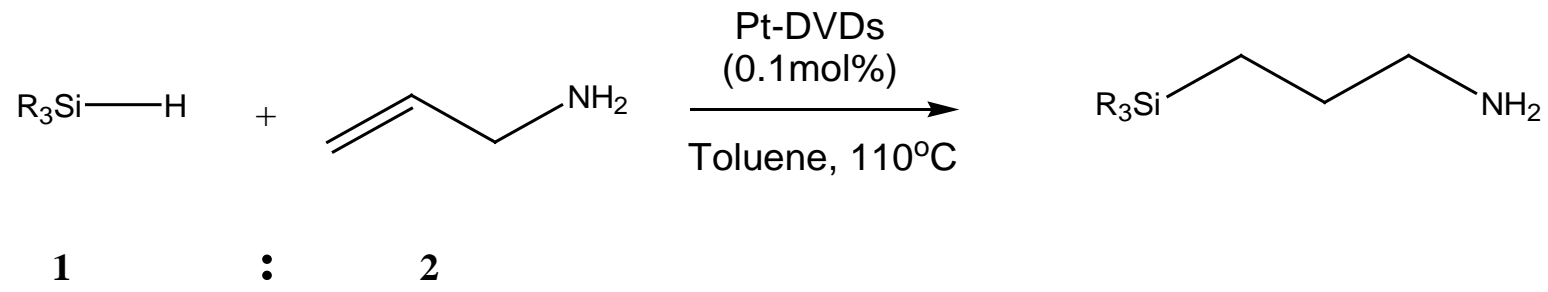

Scheme 1: One-step synthetic scheme for silylamine based RevILs

The above synthetic scheme offers two main benefits for the production of RevILs for $\mathrm{CO}_{2}$ capture from flue gas: (1) the synthesis is simple and efficient and (2) the structure can be easily modified by simply changing the substitution on the starting silane. This allows us to systematically introduce changes to the structure to improve the properties.

After synthesis and isolation, each compound was thoroughly characterized via ${ }^{1} \mathrm{H},{ }^{13} \mathrm{C}$ nuclear magnetic resonance (NMR), Elemental Analysis, Fourier-transform infrared (FT-IR) spectroscopy, and differential scanning calorimetry (DSC)/thermogravimetric analysisi (TGA) thermograms. Then, each molecular liquid was reacted with $\mathrm{CO}_{2}$ to produce an ionic liquid (Scheme 2). All of the characterization data are given in the Appendix $b$ to this report.

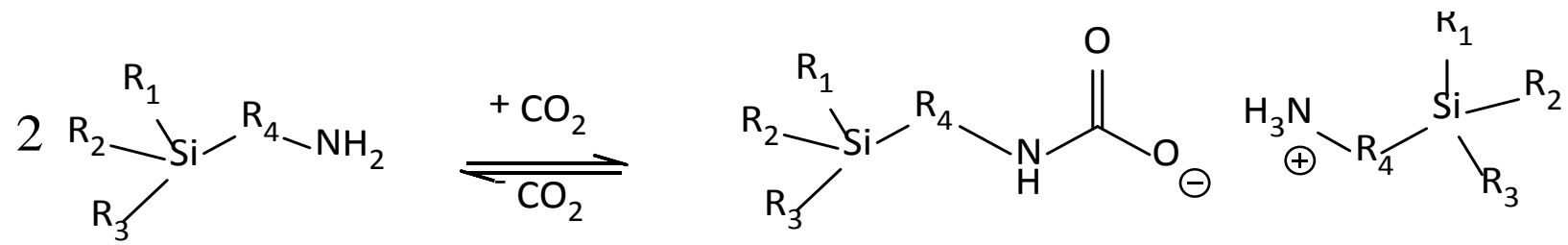

Scheme 2: Reaction of silylamine molecular liquid with $\mathrm{CO}_{2}$ to form RevIL

The resulting ionic species (liquid or solid) was characterized by ${ }^{1} \mathrm{H}$ and ${ }^{13} \mathrm{C}$ NMR, melting point (if applicable), DSC, FT-IR, and solvatochromatic measurements. The solvatochromatic polarity measurements were performed using an HP $8453 \mathrm{UV}$-Vis Spectrophotometer and the polarity probe Nile Red. The wavelength of maximum absorption $\left(\lambda_{\max }\right)$ for the probe in a given solvent is a good measure of the polarity of the solvent. The $\lambda_{\max }$ of Nile Red has been found and reported for hundreds of solvents, making this an efficient approach for determination of solvent 
polarity. Polarity switch of five different silylamine molecular liquids upon reaction with $\mathrm{CO}_{2}$ (to form RevIL) is given in Figure 1.

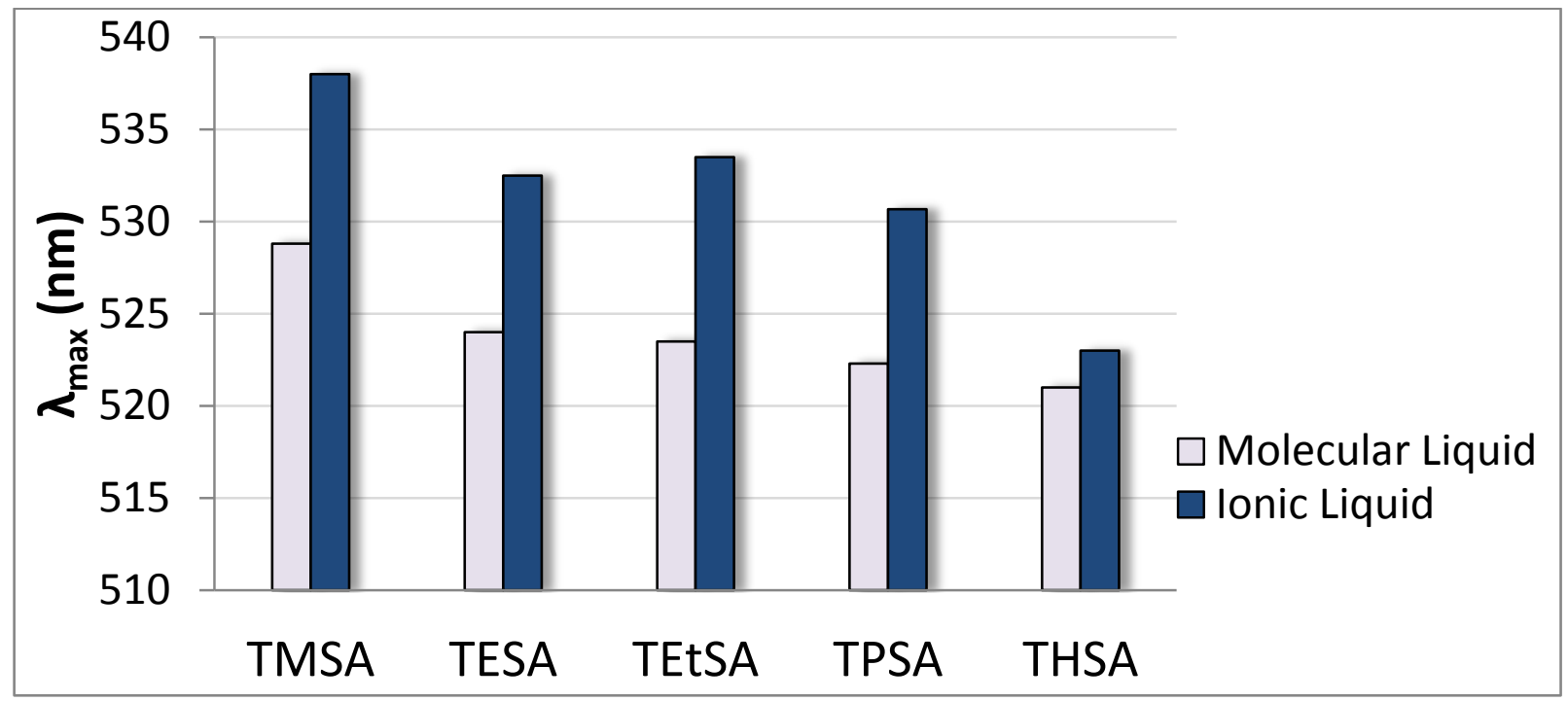

Figure 1: Nile red experiments for illustrating the switch from molecular to ionic species

The loss of $\mathrm{CO}_{2}$ upon heating and thermal stability of the amines was explored using DSC. The DSC experiments were performed on a Q20 TA Intruments machine, with a temperature profile of $5^{\circ} \mathrm{C} / \mathrm{min}$ from an initial temperature of $-40^{\circ} \mathrm{C}$ to a final temperature of $400^{\circ} \mathrm{C}$.

Stability tests were performed by exposing the chemicals to ambient air for a period of two months. NMR analyses of the molecular liquids prior to exposure and after two months of exposure were performed to determine their stability. These tests showed that the trialkylsubstituted precursors were stable over a period of two months in both water- and oxygencontaining environments, while the commercially available TMSA and TESA were not. 


\section{Analysis of RevIL properties}

\subsection{Methodology (Theory and Experimental):}

\section{a) Capacity: Overall, Chemisorption, and Physisorption}

Our objective in this project is to develop new $\mathrm{CO}_{2}$ capture solvents with enhanced $\mathrm{CO}_{2}$ capture capacities through chemisorption and physisorption, with minimal increase in the process costs. The amount of $\mathrm{CO}_{2}$ captured through chemisorption (reaction with the amine) depends on the stoichiometry and the equilibrium constant $(\mathrm{K})$ at the reaction temperature. All the silylamines studied in this project contain single amine functionality, hence at complete conversion two moles of these compounds react with a single mole of $\mathrm{CO}_{2}$. The physisorption, on the other hand, depends on the intermolecular void space in these silylamines, their van der Waals attractions with $\mathrm{CO}_{2}$, and the partial pressure of the $\mathrm{CO}_{2}$ gas stream in contact with the compound. We have systematically altered the structure of our compounds to enhance the physisorption capacities.

We have employed a gravimetric technique for determining the overall capture capacity of each compound. For these experiments, $\mathrm{CO}_{2}$ at 1 bar total pressure was sparged through the molecular liquid (silylamine) at room temperature. The overall capture capacity is determined by the net weight gain at the end of sparging. This, for a given temperature, would ideally represent the combined chemisorption at maximum conversion and the physisorption corresponding to 1 bar pressure of $\mathrm{CO}_{2}$. We have used two methods of sparging: 18 gauge needle and a diffuser tube. The diffuser tube is $1 \mathrm{~cm}$ in diameter, and consists of fritted glass with 24-50 $\mu \mathrm{m}$ porosity. The use of a diffuser tube instead of a needle allows for a better dispersion of the $\mathrm{CO}_{2}$ throughout the liquid sample than what a needle can provide at a similar flowrate.

Additionally, we used attenuated total reflectance (ATR) FT-IR spectroscopy to differentiate between chemical and physical $\mathrm{CO}_{2}$ absorption capacity.

The equilibrium constant, $\mathrm{K}(\mathrm{T})$, representative of the chemisorption of $\mathrm{CO}_{2}$ is found by measuring the equilibrium concentrations of the reactants (molecular liquid and $\mathrm{CO}_{2}$ ), and the 
product (ionic liquid) at a given temperature, and then correcting for the non-ideal behavior of these species.

$$
K=\frac{a_{L L}}{a_{M L}{ }^{2} a_{C O 2}}=\frac{x_{I L} \gamma_{I L}}{\left(x_{M L} \gamma_{M L}\right)^{2} \cdot \frac{f_{C O 2}}{f_{C O 2}^{c}}}=\frac{x_{I L} \gamma_{I L}}{\left(x_{M L} \gamma_{M L}\right)^{2}}
$$

where $x_{i}$ is the mole fraction of the species and $\gamma_{i}$ the activity coefficient, and $f_{\mathrm{CO} 2}$ and $f^{\circ} \mathrm{CO}$ are the fugacity and standard state fugacity of $\mathrm{CO}_{2}$. Since $f^{\circ}{ }_{\mathrm{CO}}=1 \mathrm{bar}$, for $\mathrm{K}$ evaluated at $1 \mathrm{bar}$ (hence $f_{\mathrm{CO} 2}=1 \mathrm{bar}$ ), the equation reduces to the ratio of activities of IL and the square of activities of ML. For evaluating $x_{i}$, we have used the conversion of the molecular liquid to ionic liquid found by ATR FT-IR. Ionic liquid was prepared by sparging $\mathrm{CO}_{2}$ at one bar pressure in a vial containing the solvent maintained at a constant temperature in a sand bath. Post equilibrium conversion, a small sample was placed at the same temperature and pressure in the ATR cell. There are two regions in the IR spectrum that were used for determining molecular and ionic liquid mole fractions: the broad ammonium stretch vibration between $3100-2600 \mathrm{~cm}^{-1}$ and the $\mathrm{C}=\mathrm{O}$ stretch from the carbamate between $1740-1520 \mathrm{~cm}^{-1}$. These are represented as regions I and III in the Figure 2, respectively.

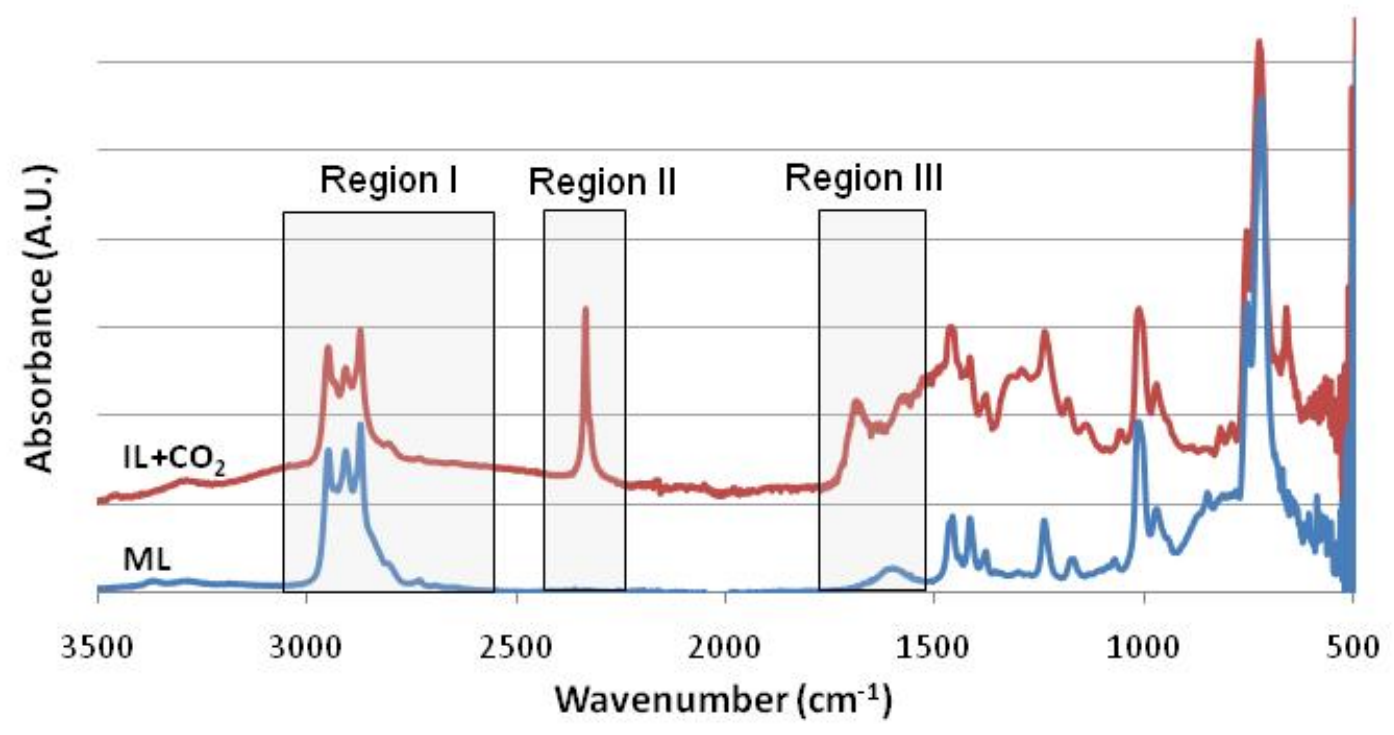

Figure 2: ATR-FTIR spectrum for TPSA (a) Blue: molecular liquid (b) Red: ionic liquid + physisorbed $\mathrm{CO}_{2}$ 
To account for the nonideality $\left(\gamma_{\mathrm{i}}\right)$ of the mixture (deviations from Raoult's Law) i.e. to reflect the highly polar nature of the liquid phase and the dissimilarity of the molecules in the system, we have used data from one of our collaborations outside this project. COSMO-RS approach $^{2,3}$, which assesses the thermodynamic properties of a system through a combination of statistical mechanics calculations and unimolecular quantum chemistry, was used for this purpose. These calculations were jointly performed by researchers from the Eckert-Liotta group at Georgia Institute of Technology and Palomar and Rodriguez group from Universidad Complutense de Madrid and Universidad Autónoma de Madrid. The collaboration is not part of this DOE-funded project, however the data is used as from an external source to compliment the FT-IR experiments.

For physisorption measurements, a preformed RevIL sample was placed in a customdesigned ATR cell, and equilibrated at constant temperature and $\mathrm{CO}_{2}$ pressure. $\mathrm{CO}_{2}$ concentration was measured by evaluating absorbance of the asymmetric $\mathrm{CO}_{2}$ stretch between 2400-2200 $\mathrm{cm}^{-1}$ (region II in Figure 2). The Beer-Lambert Law was used to relate the absorbance to the concentration of the physisorbed $\mathrm{CO}_{2}$. Physisorption $x_{\mathrm{CO} 2}$ is reported in terms of Henry's Law constants:

$$
y_{\mathrm{CO}_{2}} \mathrm{P}=x_{\mathrm{CO}_{2}} \mathrm{H}
$$

The ATR FT-IR optics bench used for data collection is a Heated Golden Gate ATR sample accessory supplied by (Specac, See Figure 3), with a working temperature range up to $300^{\circ} \mathrm{C}$ and pressure rating for the tungsten carbide embedded diamond being 15,000psi. Equilibrium measurements were performed by using a custom-designed and built ATR FT-IR high pressure reactor. Consultation for the design was offered by Prof. Sergei Kazarian of Imperial College London. We have used a custom designed and built Generation 3 stainless steel reactor (see Figure 3), which has been successfully tested at temperatures to $150^{\circ} \mathrm{C}$ and pressures to 1500 psi.

\footnotetext{
${ }^{2}$ Klamt, A. The COSMO and COSMO-RS solvation models. Comput. Mol. Sci. Res. 2011 (DOI: 10.1002/wcms.56)

${ }^{3}$ Diedenhofen, M.; Klamt, A. COSMO-RS as a tool for property prediction of IL mixtures-A review. Fluid Phase Equilibria 2010, 294, 31-38.
} 

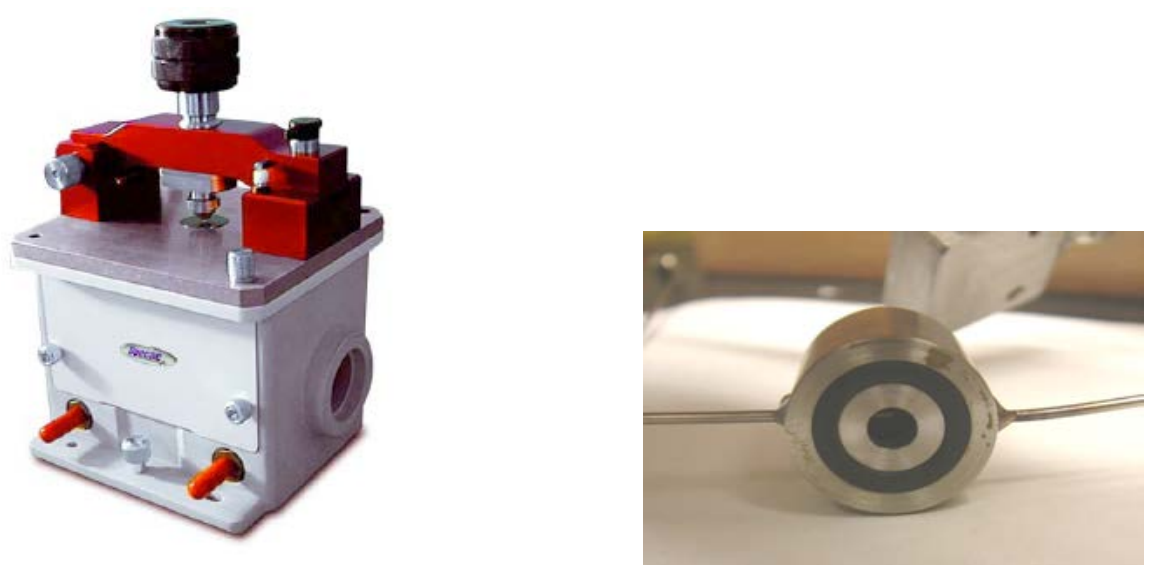

Figure 3: Specac Heated Golden Gate ATR sample accessory (left) and reactor cell view from bottom (right).

b) Thermodynamics: Enthalpy of Mixing (Physisorption), Reaction Enthalpy (Chemisorption), and Reversal Temperature

Thermodynamics of RevILs consists of:

(a) the sensible heat required to raise the temperature of the $\mathrm{CO}_{2}$ rich solvent from the capture temperature to the reversal temperature,

$$
Q=m C_{p} \Delta T
$$

(b) latent heat of the reaction between $\mathrm{CO}_{2}$ and silylamine, $\Delta \mathrm{H}_{\mathrm{rxn}}$

(c) Enthalpy of mixing/demixing of $\mathrm{CO}_{2}$ in the reversible ionic liquid, $\Delta \mathrm{H}_{\text {dissolution }}$

In Equation 3, $\mathrm{m}$ is the mass of the $\mathrm{CO}_{2}$ rich solvent and depends on the $\mathrm{CO}_{2}$ capture capacity. $\mathrm{C}_{\mathrm{p}}$ is the heat capacity estimated using the group contribution method by Ruzicka and Domalski ${ }^{4}$. At $40^{\circ} \mathrm{C}, \mathrm{C}_{\mathrm{p}}$ of our molecular liquids was found to be $2.1 \mathrm{~J} / \mathrm{g}-\mathrm{K}$ while that of our ionic liquids was found to be $2.3 \mathrm{~J} / \mathrm{g}-\mathrm{K} . \Delta \mathrm{T}=\mathrm{T}_{\text {rev }}-\mathrm{T}_{\text {cap }}$, is the difference between the reversal and the capture temperature. In the actual absorber unit, $\mathrm{T}_{\text {cap }}$ will be dictated by the temperature of flue gas stream and hence we will choose $40^{\circ} \mathrm{C}$ as the basis $\mathrm{T}_{\text {cap }}$ for all our compounds. The quantity that will change with the choice of molecular liquid is $\mathrm{T}_{\text {rev }}$. To minimize the heat input for heating the ionic liquid, we would prefer lower values of $\mathrm{T}_{\text {rev. }}$ However, very low values of

\footnotetext{
${ }^{4}$ B.E. Poling, The properties of gases and liquids, 5th ed. ed., McGraw-Hill, New York :, 2001.
} 
$\mathrm{T}_{\text {rev }}$ would leave very small window for operating the absorber and the stripper. Therefore, we are looking for compounds that give optimum values of $\mathrm{T}_{\text {rev. }}$.

We have used Differential Scanning Calorimetery (DSC) for calculation of $\Delta \mathrm{H}_{\mathrm{rxn}}$ and $\mathrm{T}_{\text {rev }}$. As before, the preformed ionic liquid is heated in a DSC pan from $-40^{\circ} \mathrm{C}$ to $400^{\circ} \mathrm{C}$ at a rate of $5^{\circ} \mathrm{C} / \mathrm{min}$. DSC thermogram (as shown in Figure 4) consists of two events: (a) reversion of RevIL to molecular liquid and (b) evaporation of molecular liquid. $\Delta \mathrm{H}_{\mathrm{rxn}}$ is measured by calculating the total heat flow during the reversal event, while $T_{\text {rev }}$ is measured as the onset point of reversion event.

$\Delta \mathrm{H}_{\text {dissolution }}$ is the enthalpy associated with the physical solubility of $\mathrm{CO}_{2}$ in RevIL and is found using Clausius-Clapeyron relation:

$$
\Delta H_{\text {dissolution }}=R\left(\frac{d(\ln P)}{d(1 / T)}\right)_{x 1}
$$

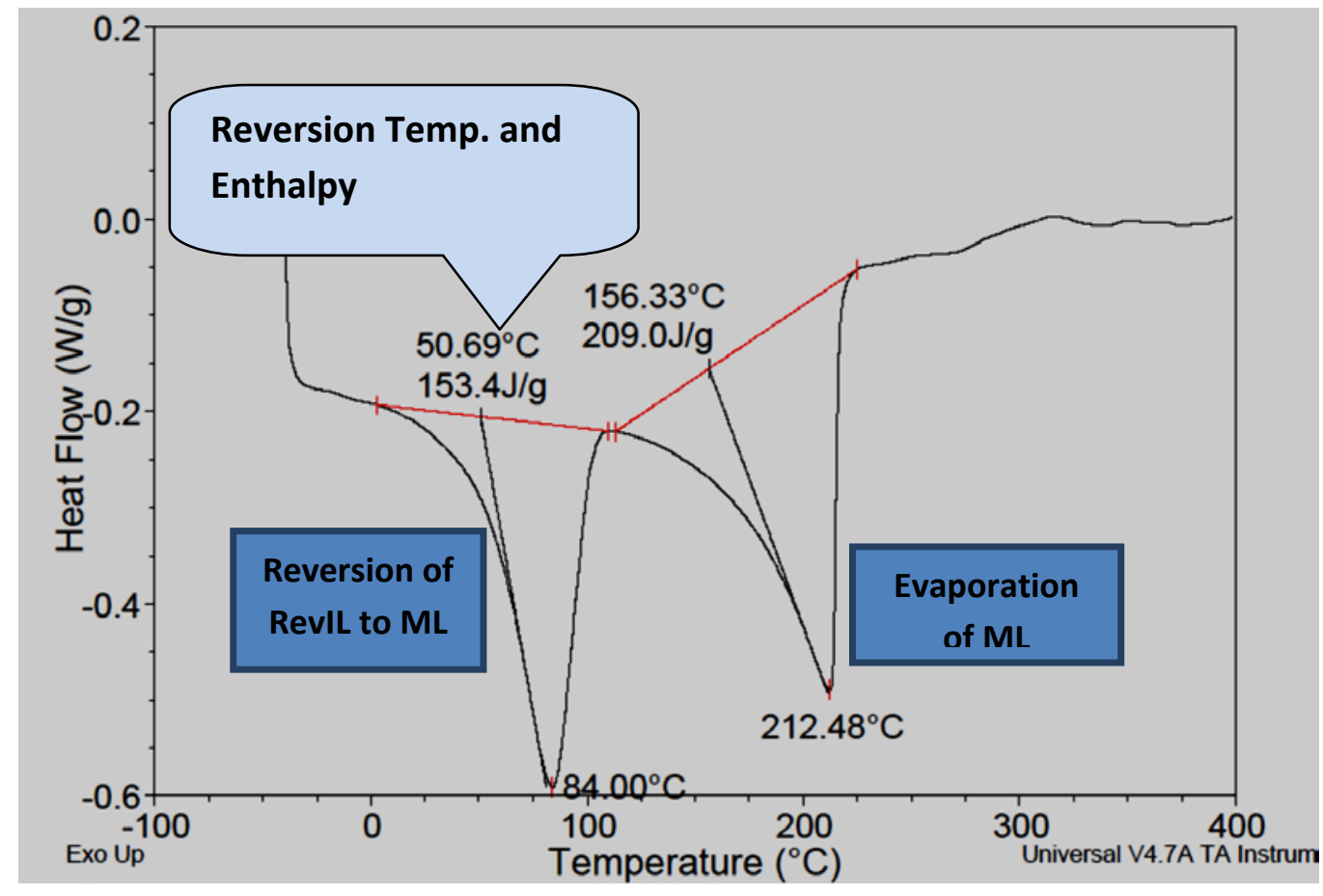

Figure 4: DSC of RevIL showing reversion temperature and regeneration enthalpy 


\section{c) Viscosity}

Viscosity of both the $\mathrm{CO}_{2}$-rich and the $\mathrm{CO}_{2}$-lean solvent are important processing parameters that determine the pumping costs associated with the process and the heat and mass transfer during absorption and desorption.

Viscosity of each compound, both in molecular and ionic form, was measured using a Rheosys Merlin II Viscometer located in our laboratory.

\section{d) Effect of Water}

One of the major challenges in the ethanolamine based $\mathrm{CO}_{2}$ capture solvent systems is the large quantities of water (70-80\% by weight) used to bring down the viscosity and minimize amine degradation ${ }^{5}$. This results in a large parasitic energy requirement $\left(165 \mathrm{KJ} / \mathrm{mol} \text { of } \mathrm{CO}_{2}\right)^{1}$ for heating water during regeneration as well as for separating $\mathrm{CO}_{2}$ and steam in the exit stream of the stripper. However, some water will always be present because of water in the flue gas. In fact, in small quantities of water prove beneficial in improving the $\mathrm{CO}_{2}$ capture capacity due to the formation of extra bicarbonate $\left(\mathrm{HCO}_{3}{ }^{-}\right)$and carbonate ions $\left(\mathrm{CO}_{3}{ }^{2-}\right)$. In addition, the presence of water also brings down the viscosity of the ionic liquid and hence the pumping costs. Upon reversal of the ionic liquid-water mixture, any excess water might phase-separate which can be decanted off and the water-saturated molecular liquid can be returned to the absorber for $\mathrm{CO}_{2}$ capture. Identifying this, equilibrium water concentration in the molecular liquid-water and ionic liquid-water mixtures will be useful for further studying and modeling the $\mathrm{CO}_{2}$ capture process.

Water content in the distilled molecular liquids and water solubility in the molecular liquids was analyzed using a Metrohm 852 Titrando Volumetric Karl Fischer Titration system. The Hydranal Composite 5 (Fluka) titer was determined using a 10.0 water standard (10.0 mg $\mathrm{H}_{2} \mathrm{O} / \mathrm{g}$ solution). The methanol working solution was buffered with salicylic acid for the presence of the amine-containing molecular liquids. Approximately $1 \mathrm{~g}$ of synthesized molecular liquid was injected into the volumetric cell for a single analysis. Results were replicated, with a

\footnotetext{
${ }^{5}$ J.T. Yeh, H.W. Pennline, K.P. Resnik, Study of CO2 Absorption and Desorption in a Packed Column, Energy \& Fuels, 15 (2001) 274-278.
} 
10.0 water standard being run between samples to verify the result and the stability of the buffered system. For the water solubility analyses, 0.2-0.3 g of water-saturated molecular liquid was injected into the volumetric cell for single analysis and replicated with 10.0 water standards being run between samples.

\section{e) Density and Refractive Index}

Density and refractive index are required for the Beer-Lambert law calculations for determining the capacities from infrared measurements. We have also used refractive index as a measure of conversion from molecular liquid to the ionic liquid.

The density measurements were performed using an Anton Paar DMA 38 densitometer capable of measurements from $15^{\circ} \mathrm{C}$ to $40^{\circ} \mathrm{C}$ with a precision of $\pm 0.001 \mathrm{~g} / \mathrm{mL}$. This is a vibrating tube densitometer containing a "U-shaped" tube that is vibrated at its natural frequency. The densitometer records measurements when a stable density is observed over a 15 second period.

The refractive indices of both the molecular and the ionic liquid forms were measured using a Reichert Arias 500 Abbe-style refractometer, connected to a circulated cooling bath with glycol as the heat transfer fluid, enabling measurements from $0^{\circ} \mathrm{C}$ to $75^{\circ} \mathrm{C}$. The refractometer is a semi-

automatic design which eliminates the need for users to interpret the shadowline intercept, resulting in an accuracy of \pm 0.0001 regardless of the user. This proves important for establishing refractive index as a measure of conversion.

\section{f) Kinetics and Mass Transfer}

For all our RevILs, the $\mathrm{CO}_{2}$ absorption times were found to be mass transfer limited. The actual reaction of the silyl-amine with $\mathrm{CO}_{2}$ is almost instantaneous. Detailed Analysis of this is given in the results section. 


\section{g) Process Modeling and Economic Analysis}

An ASPEN HYSYS simulation was performed to evaluate the energy required by our silylamines to meet the $90 \% \mathrm{CO}_{2}$ capture target. Experimental data for equilibrium constants, reaction enthalpy, reversal temperature, density, and boiling point of our solvents was integrated in the simulation. The results were compared to the literature values for aqueous monoethanolamine (MEA) based $\mathrm{CO}_{2}$ capture process.

Although HYSYS is also capable of doing an economic analysis, we did not proceed to implement this feature. The reason was that there were so many unknown properties of the new molecules that would have to be estimated, and the estimation techniques were all developed for molecules as opposed to ionic liquids, rendering an unacceptable degree of uncertainty in any economic estimate at this time.

\subsection{Results:}

\section{a) Guanidine based RevILs}

In the initial proposal, we had proposed the use of silylguanidine as the second category of RevILs for $\mathrm{CO}_{2}$ capture. However, we found that these compounds do not have desirable properties for carbon capture. First, the synthesis resulted in poor yield of the desired products. In addition, our collaborators (Jessop et al.) discovered and published other problems with using similar compounds alkanolguanidines (Scheme 3$)^{6}$

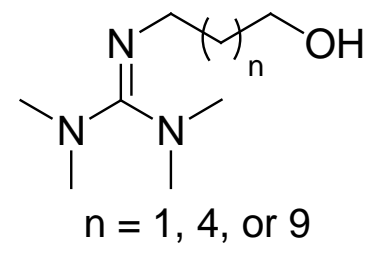

Scheme 3: Structure of alkanolguanidines reported by Jessop et al.

\footnotetext{
${ }^{6}$ David J. Heldebrant, Phillip K. Koech, M. Trisha C. Ang, Chen Liang, James E. Rainbolt, Clement R. Yonker, and Philip G. Jessop, "Reversible zwitterionic liquids, the reaction of alkanol guanidines, alkanol amidines, and diamines with $\mathrm{CO}_{2}$," Green Chemistry, 713-721 (2010).
} 


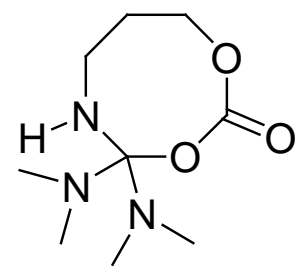

Scheme 4: Proposed structure of cyclic carbonate product of short-chain alkanolguanidine reacted with $\mathrm{CO}_{2}$

When a short alkane chain (3 carbons) was used to connect the alcohol and guanidine moieties, reaction with $\mathrm{CO}_{2}$ led to the formation of a non-reversible cyclic carbonate as shown in Scheme 4. The use of a longer alkane chain (11 carbons) resulted in a waxy solid upon the addition of $\mathrm{CO}_{2}$. Finally, when a medium alkane chain length (6 carbons) was used, reaction with $\mathrm{CO}_{2}$ provided a reversible ionic liquid. However, the $\mathrm{CO}_{2}$ absorption capacity was found to be low ( $\sim 10 \%$ by weight) due to entropic effects. Due to these limitations of working with guanidines, we chose to focus primarily on silylamines that showed greater potential for the $\mathrm{CO}_{2}$ capture application.

\section{b) Silylamine based RevILs}

Our focus in this project has been towards silylamines that remain in the liquid state post $\mathrm{CO}_{2}$ capture, i.e. in the ionic form.

Table 2 lists the compounds with their physical state (at $25^{\circ} \mathrm{C}$ ) after $\mathrm{CO}_{2}$ was sparged through them. 
Table 2: Physical form of silylamine after bubbling $\mathrm{CO}_{2}$

\begin{tabular}{|l|c|c|}
\hline & Acronym & $\begin{array}{c}\text { Physical State after COO } \\
\text { reaction at 1bar and room } \\
\text { temperature }\end{array}$ \\
\hline & Liquid \\
\hline
\end{tabular}


Trialkoxy, trialkyl, and fluorinated silylamines were liquids or viscous gels after sparging while the last two compounds in the table with a bulky side group attached to the Si turned into solids. Additionally, trialkoxy compounds were found to be unsuitable for $\mathrm{CO}_{2}$ capture as they were unstable under air and moisture. Therefore, the results discussed in this report primarily focus on four compounds: TEtSA, TPSA, THSA, and FSA.

\section{c) Capacity: Chemisorption, Physisorption, and Overall}

Chemisorption: The extent of the reaction between the silylamine and $\mathrm{CO}_{2}$ at a specific temperature is given by the equilibrium constant $(\mathrm{K})$. In this report, we present the details involved in the calculation of $\mathrm{K}$ for (3-aminopropyl) tripropylsilane (TPSA) at various temperatures. As mentioned in the approach section, this requires determination of equilibrium mole fractions of molecular and ionic liquid $\left(\mathrm{K}_{\mathrm{c}}\right)$ and corrections for non-ideality of the system $\left(\mathrm{K}_{\gamma}\right)$. Values for $\mathrm{K}_{\mathrm{c}}$ at $60,65,70$ and $80^{\circ} \mathrm{C}$, are shown below in Table 3.

Table 3: Experimental values of Kc for TPSA

\begin{tabular}{|c|c|c|}
\hline Temperature $\left({ }^{\circ} \mathbf{C}\right)$ & $\mathbf{X}_{\mathbf{I L}}$ & $\mathbf{K}_{\mathbf{c}}$ \\
\hline 60 & 0.80 & 28.6 \\
\hline 65 & 0.66 & 7.4 \\
\hline 70 & 0.53 & 2.9 \\
\hline 80 & 0.20 & 0.3 \\
\hline
\end{tabular}

A linear plot between reciprocal temperature and $\log \mathrm{K}$ (van't Hoff equation) generated using data at the known temperatures is used to determine the equilibrium constants and hence equilibrium conversions at the other unknown temperatures. The slope of the graph gives the reaction enthalpy. If $\mathrm{K}_{\mathrm{c}}$ is plotted against the reciprocal temperature, though the graph is linear, the slope gives enthalpy of $-213 \mathrm{~kJ} / \mathrm{mol}$ of $\mathrm{CO}_{2}$. As will be shown in the next section, reaction enthalpy from DSC measurements is equal to $-114 \mathrm{~kJ} / \mathrm{mol}$ of $\mathrm{CO}_{2}$. To avoid this discrepancy, we 
need to account for the non-ideal behavior of the system through $\mathrm{K}_{\gamma}$ as described in the approach section. $\mathrm{K}_{\gamma}$ were estimated using COSMO-RS through collaboration ${ }^{7}$ beyond this DOE project. Table 4 lists the values of $K_{\gamma}$ corresponding to the four $K_{c}$ values reported in Table 3.

Table 4: Values of $\boldsymbol{K} \boldsymbol{\gamma}$ for TPSA estimated Using COSMO-RS

\begin{tabular}{|c|c|c|}
\hline Temperature $\left({ }^{\circ} \mathbf{C}\right)$ & $\boldsymbol{x}_{\boldsymbol{I L}}$ & $\boldsymbol{K} \boldsymbol{\gamma}$ \\
\hline 60 & 0.8 & 0.1 \\
\hline 65 & 0.66 & 0.21 \\
\hline 70 & 0.53 & 0.35 \\
\hline 80 & 0.2 & 0.98 \\
\hline
\end{tabular}

When equilibrium constants $\mathrm{K}$ calculated as the product of $\mathrm{Kc}$ and $\mathrm{K} \gamma$ were plotted against reciprocal temperature (as shown below in Figure 5), reaction enthalpy was found to be $-104 \mathrm{~kJ} / \mathrm{mol}$ of $\mathrm{CO}_{2}$. This value falls within the experimental error of the DSC value of $-109 \pm 6$ $\mathrm{kJ} / \mathrm{mol}$ of $\mathrm{CO}_{2}$. The data validates this approach for calculating the equilibrium constants at various temperatures.

\footnotetext{
${ }^{7}$ Calculations were jointly performed by researchers from the Eckert-Liotta group at Georgia Institute of technology and Palomar and Rodriguez group from Universidad Complutense de Madrid and Universidad Autónoma de Madrid.
} 


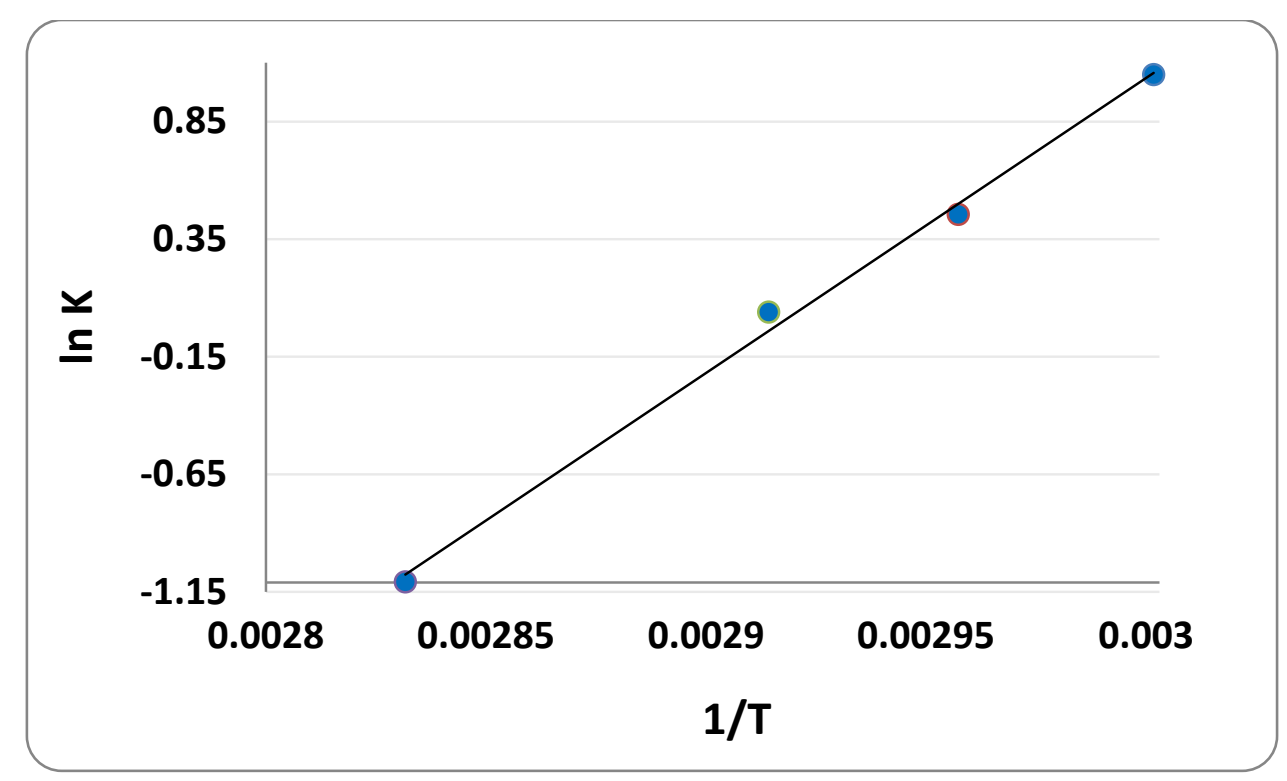

Figure 5: van't Hoff Plot of TPSA

Physisorption: Figure 6 shows the mole fraction of physisorbed $\mathrm{CO}_{2}$ in TPSA RevIL as a function of pressure calculated using asymmetric $\mathrm{CO}_{2}$ stretch in FT-IR. Henry's law is applicable at low concentrations of solute where solute-solute interactions are negligible. The straight line in the figure shows the applicability of Henry’s Law up to $\mathrm{x}_{\mathrm{CO} 2} \sim 0.4$ (25 bar $\mathrm{CO}_{2}$ ). Henry's law constants are calculated as the reciprocal of the slope in the graph. Results for the four reversible ionic liquids at $35^{\circ} \mathrm{C}$ are presented in Table 5 . 


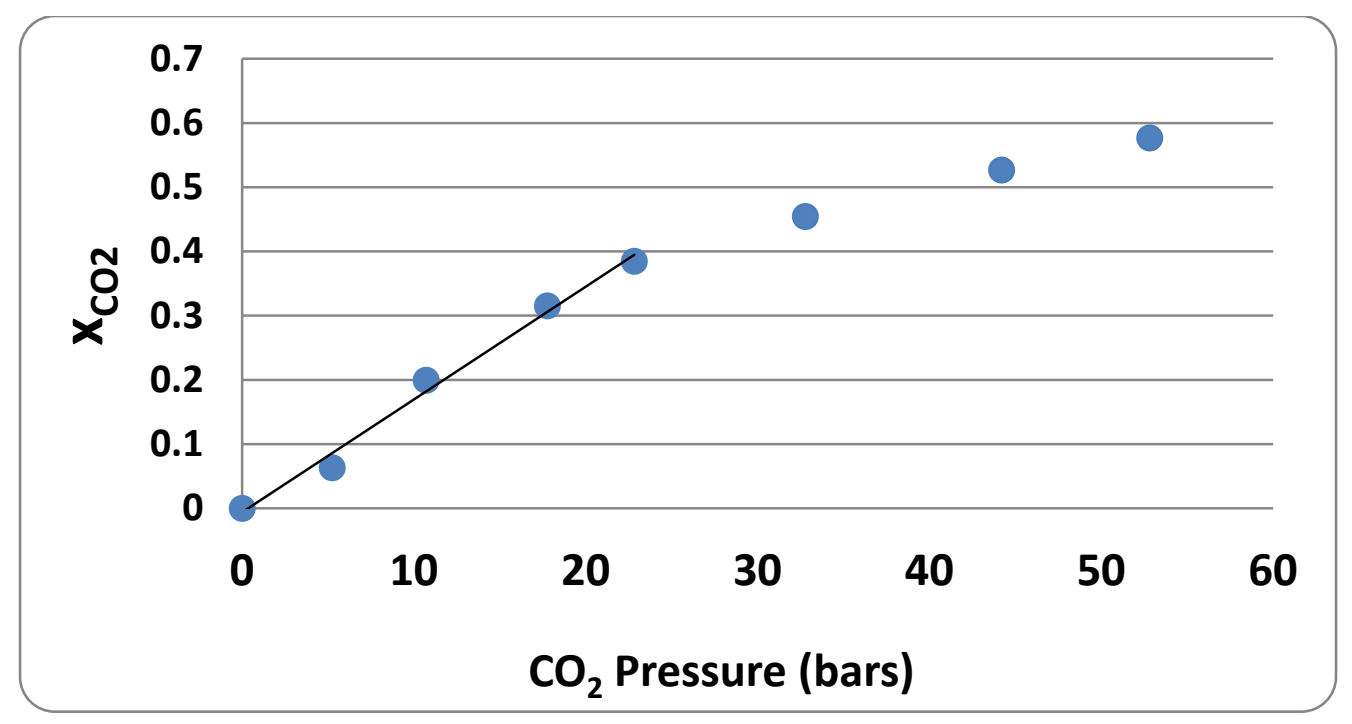

Figure 6: Mole fraction of $\mathrm{CO}_{2}$ in TPSA ionic liquid as a function of pressure at $35^{\circ} \mathrm{C}$

Table 5. Henry's Law constants for ionic liquids at $35^{\circ} \mathrm{C}$

\begin{tabular}{|c|c|}
\hline Ionic Liquid & Henry's Constant (bar) \\
\hline TEtSA & $73 \pm 9$ \\
\hline TPSA & $60 \pm 7$ \\
\hline THSA & $43 \pm 4$ \\
\hline FSA & $44 \pm 6$ \\
\hline
\end{tabular}

Physisorption of $\mathrm{CO}_{2}$ in the ionic liquids increases with decreasing temperature. At $25^{\circ} \mathrm{C}$ the Henry’s Law constant for TPSA ionic liquid decreased to 49 bar. 
Our technique was validated by comparing the literature value of Henry’s Law constant of $\mathrm{CO}_{2}$ in the conventional ionic liquid, $[\mathrm{Bmim}]\left[\mathrm{PF}_{6}\right]$, against the one found from our FT-IR technique. At $25^{\circ} \mathrm{C}$, our experiments show Henry's Law constant of 58 bar, which is consistent with the reported value of 53.4 bar $^{8}$.

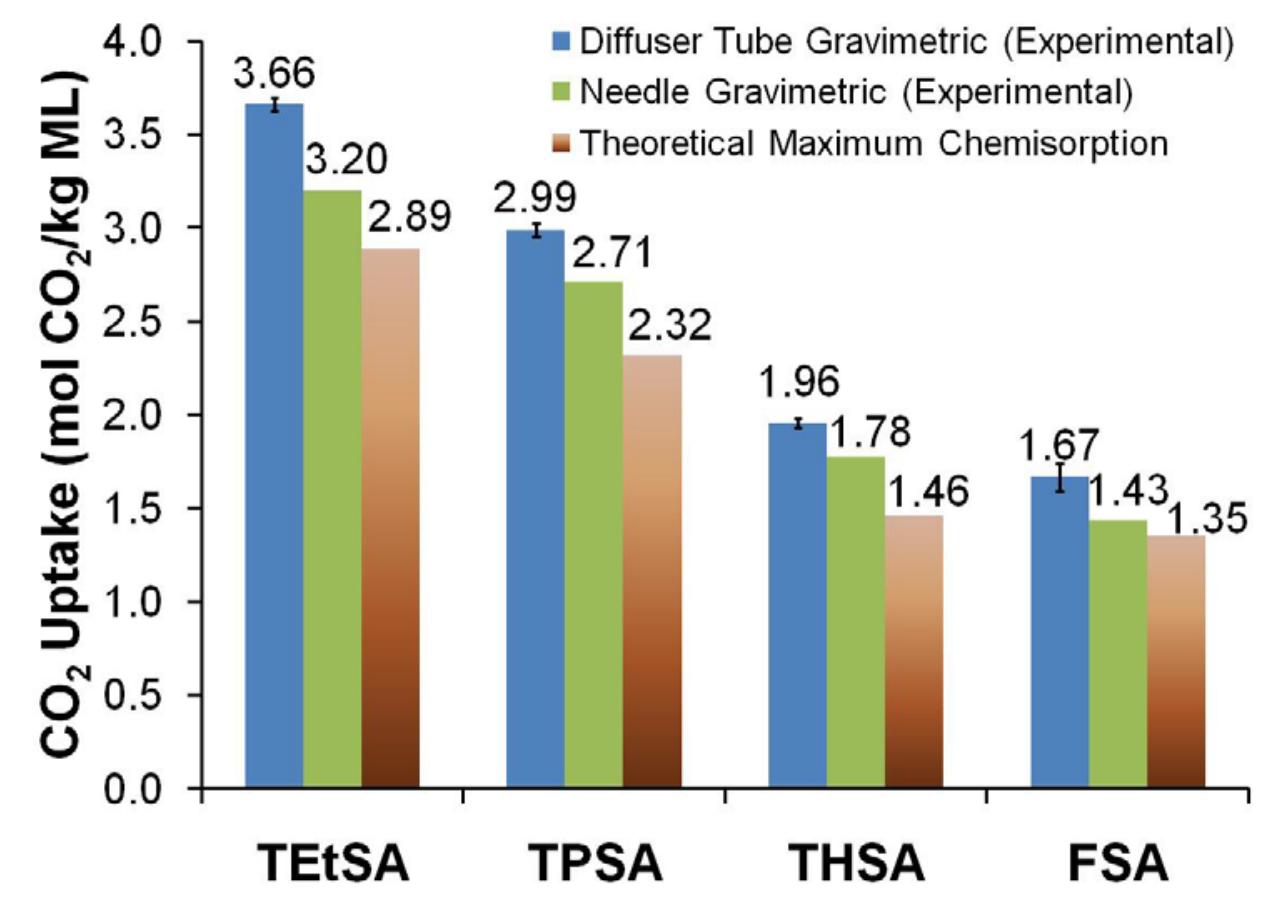

Figure 7: $\mathrm{CO}_{2}$ uptake comparison for select RevILs using both diffuser tube and needle $\mathrm{CO}_{2}$ introduction methods. $25^{\circ} \mathrm{C}, 200 \mathrm{ml} / \mathrm{min}$ pure $\mathrm{CO}_{2}$.

Overall Capacity: The overall capacity was calculated as the net weight gained by sparging (bubbling) $\mathrm{CO}_{2}$ at 1 bar through the molecular precursor at room temperature. Two modes of bubbling were used: (a)18 gauge needle and (b) diffuser tube. All four compounds can chemically absorb only 0.5 moles of $\mathrm{CO}_{2}$ per mole. However, as we go from TEtSA to FSA the molecular weight increases from 173 to 369. Therefore the theoretical chemisorption capacity (in moles of $\mathrm{CO}_{2}$ per kg of solvent) decreases from 2.89 for TEtSA to 1.35 for FSA. Comparison of

\footnotetext{
${ }^{8}$ Jessica L. Anderson, Janeille K. Dixon, and Joan F. Brennecke, Acc. Chem. Res. 2007, 40, 1208-1216
} 
theoretical chemisorption, $\mathrm{CO}_{2}$ uptake through diffuser tube, and through an 18 gauge needle are given in Figure 7. Both the needle and diffuser tube gravimetric results significantly exceed the complete conversion to RevIL value. For TPSA, if we include $0.047 \mathrm{~mol} \mathrm{CO}_{2} / \mathrm{kg} \mathrm{ML}$ of physisorption at $25^{\circ} \mathrm{C}$ as measured by FT-IR, the combined physisorption and chemisorption should equal $2.37 \mathrm{~mol} \mathrm{CO} / \mathrm{kg}$ ML. However, from gravimetric analyses, $\mathrm{CO}_{2}$ uptake is much higher: $2.99 \mathrm{~mol} \mathrm{CO}_{2} / \mathrm{kg} \mathrm{ML}$ through the tube and $2.71 \mathrm{~mol} \mathrm{CO}_{2} / \mathrm{kg} \mathrm{ML}$ for the needle. Although this is highly advantageous for $\mathrm{CO}_{2}$ capture from flue gas, fundamental understanding of the causal mechnism is required to fully utilize this. Three proposed possibilities that can explain this are currently being investigated in research subsequent to this DOE-funded project.

1) Entrainment of $\mathrm{CO}_{2}$ bubbles in the viscous ionic liquid.

2) Additional chemical reaction of $\mathrm{CO}_{2}$ to form a specie other than carbamate ion.

3) Introduction of moisture into the experimental system, increasing the $\mathrm{CO}_{2}$ uptake by additional reaction with water to form carbonates and bicarbonates.

\section{d) Thermodynamics}

We have studied the thermodynamic properties of four alkyl substituted silylamines: TEtSA, TPSA, THSA, FSA to determine the effects of fluorination and the chain length of the substituent groups. Differential Scanning Calorimetry (DSC) was used on preformed ionic liquids to determine the reaction enthalpy $\left(\Delta \mathrm{H}_{\mathrm{rxn}}\right)$ required for regenerating the molecular liquid back from the ionic liquid and the temperature at which the reversion is initiated $\left(\mathrm{T}_{\text {rev }}\right)$. These two quantities are extremely useful in designing the scrubber for the $\mathrm{CO}_{2}$ capture process.

For all the compounds that we have analyzed, the reaction mechanism remains the same: an amine reacting with $\mathrm{CO}_{2}$ to form ammonium and carbamate ion pair. Hence the enthalpies calculated in $\mathrm{KJ}$ per mole of $\mathrm{CO}_{2}$ captured, should be similar to one another. This is shown in Figure 8 where the values of average $\Delta \mathrm{H}_{\mathrm{rxn}}$ (in $\mathrm{KJ} / \mathrm{mol}$ of $\mathrm{CO}_{2}$ ) are similar for the four compounds (the differences in values lie within the range of experimental variability/error bars). 


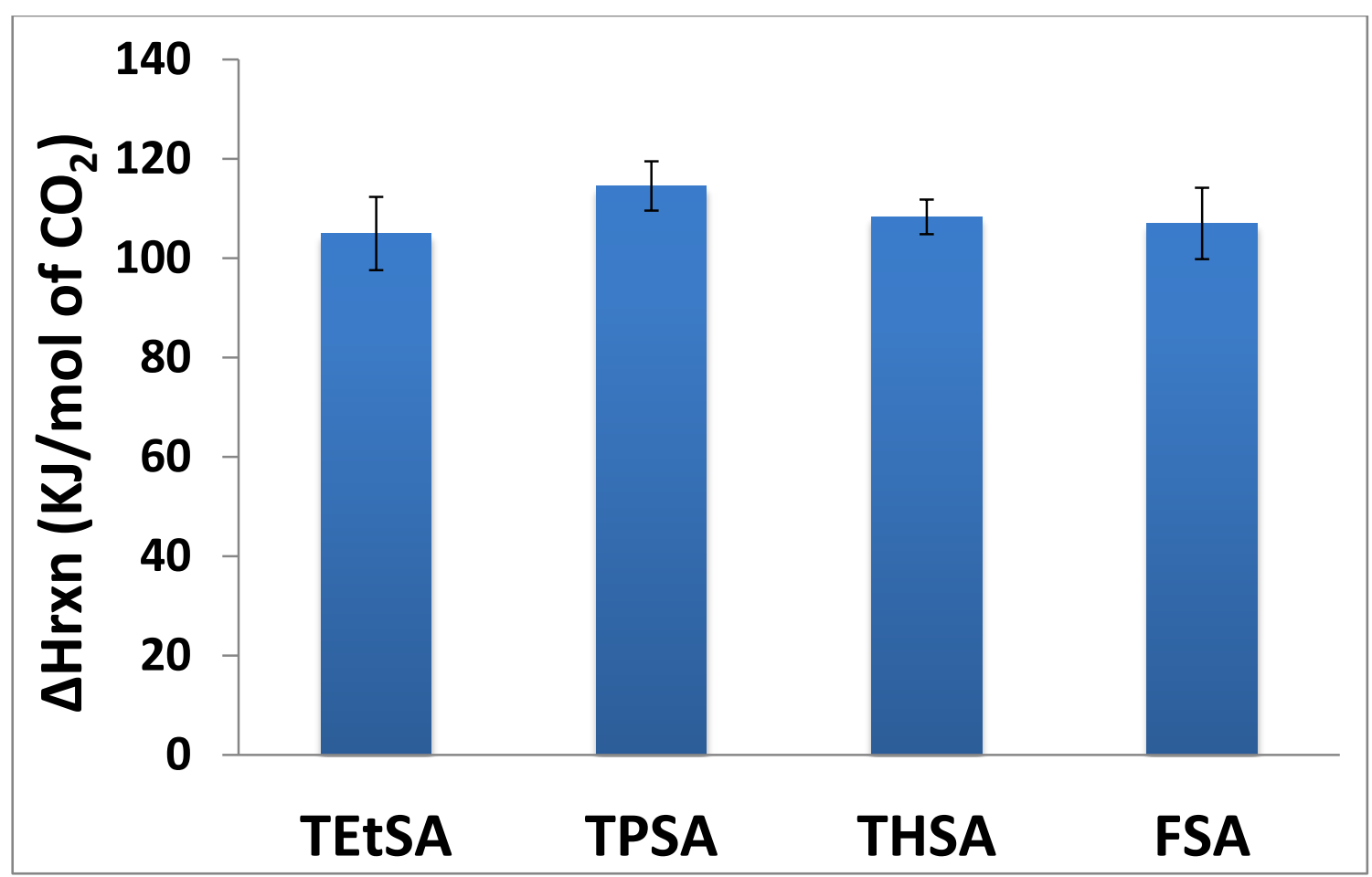

Figure 8 : Enthalpy of reaction $\Delta \mathbf{H}_{\mathrm{rxn}}$ in $\mathrm{KJ} / \mathrm{mol}$ of $\mathrm{CO}_{2}$ for alkyl-substituted silylamines

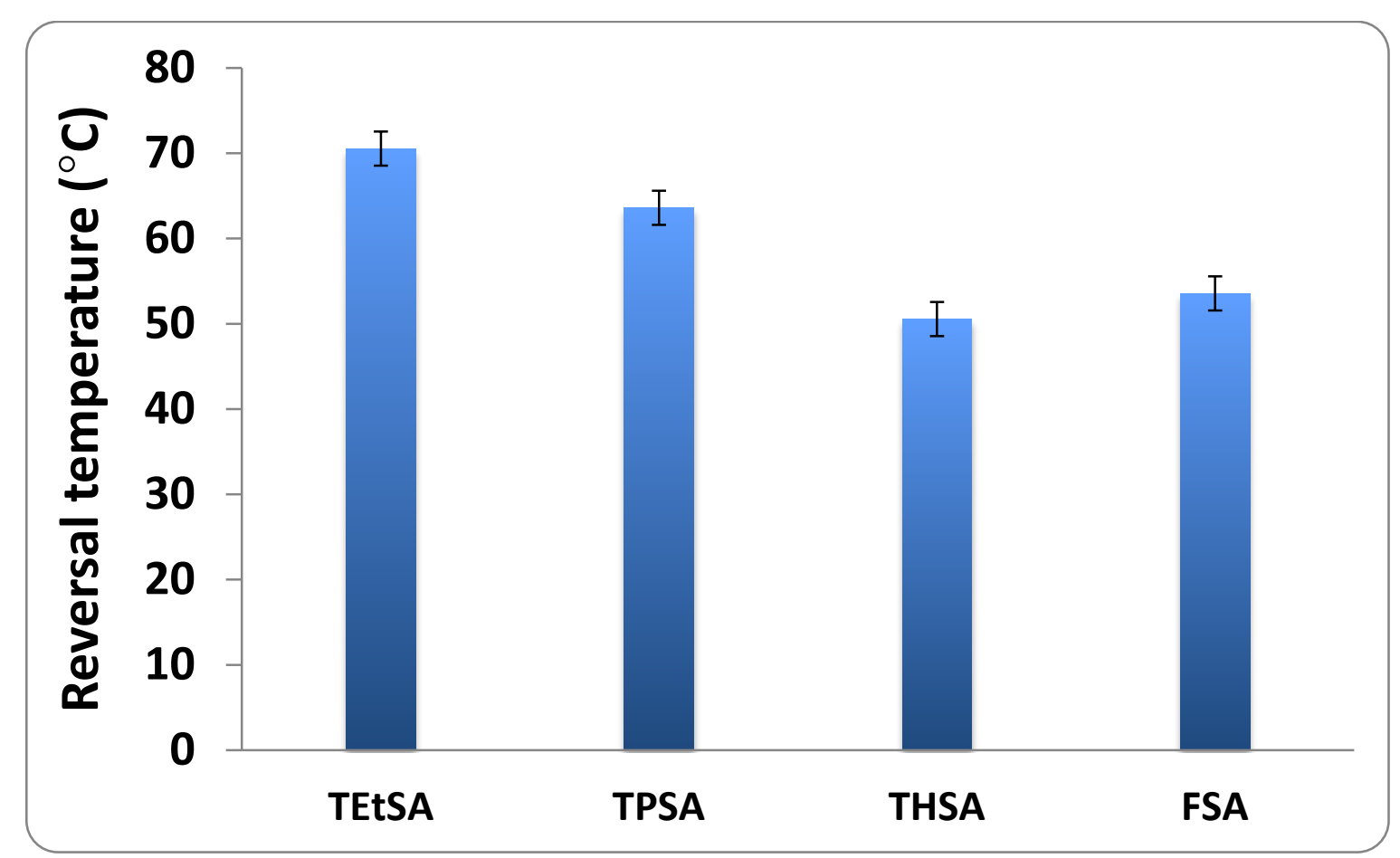

Figure 9: Reversal temperature of ionic liquids of alkyl-substituted silylamines 
We have compiled the data for reversion temperature $\mathrm{T}_{\text {rev }}$ for our silylamines in Figure 9. The average reversion temperature decreases as we increase the size (chain length) of our substituent groups, from $70.6^{\circ} \mathrm{C}$ for TEtSA to $50.6^{\circ} \mathrm{C}$ for THSA. The reason for this is the increasing entropic effects due increasing size of the substituent groups. FSA also has a low $\mathrm{T}_{\text {rev }}$ of $53.6^{\circ} \mathrm{C}$ due to the lengthy fluorinated chain attached to the $\mathrm{Si}$.

The third quantity of interest is the enthalpy related to the physisorption of $\mathrm{CO}_{2}$ in RevIL. This is calculated by using Clausius-Clapeyron relationship on the solubility data of $\mathrm{CO}_{2}$ in RevIL at different temperatures. An example of such data for TEtSA RevIL is shown in Figure 10. The value of $\Delta \mathrm{H}_{\text {dissolution }}$ for TEtSA was found to be $15 \mathrm{KJ} / \mathrm{mol}$ of $\mathrm{CO}_{2}$. This is only a seventh of the reaction enthalpy thus indicating that physisorption involves a much lower energy penalty as compared to chemisorption.

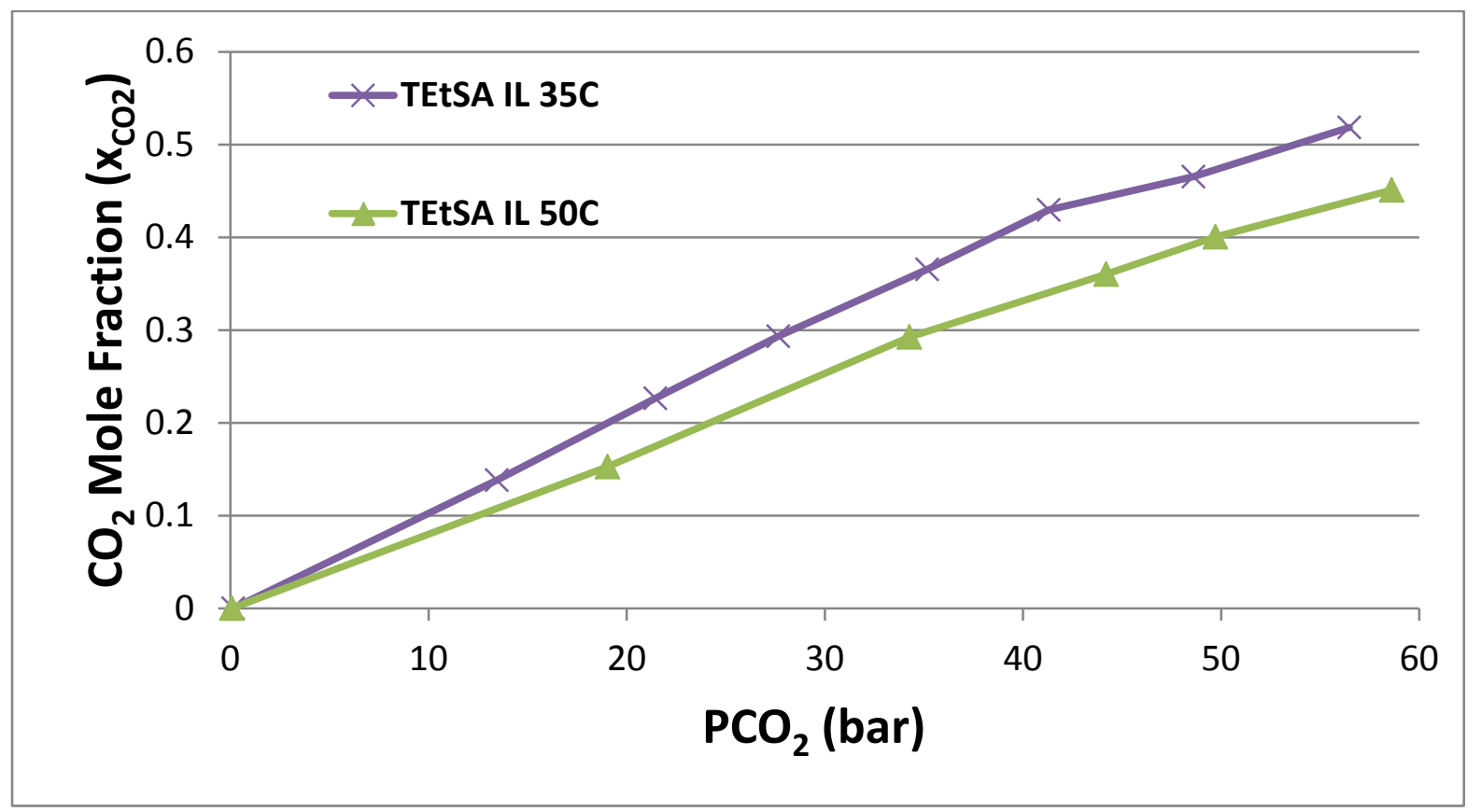

Figure 10: Plot of $\mathrm{CO}_{2}$ solubilities $\left(\mathrm{x}_{\mathrm{CO} 2}\right)$ as a function of $\mathrm{CO}_{2}$ pressure $\left(\mathrm{P}_{\mathrm{CO} 2}\right)$ for TEtSA at $35^{\circ} \mathrm{C}$ and $50^{\circ} \mathrm{C}$ 


\section{e) Viscosity}

Viscosity of the $\mathrm{CO}_{2}$ capture solvents both pre- and post-capture is one of the important parameters determining the processing costs. Viscosity of all our silylamines in molecular form (pre-capture) was less than $30 \mathrm{cP}$ at $40^{\circ} \mathrm{C}$. For the ionic form (post-capture), we have established that the viscosity can be decreased significantly by introducing systematic structural changes to our molecules. For example, molecular packing of the ionic liquid can be disrupted by increasing the size of the substituent chain, thus decreasing the viscosity from 7600cP for TEtSA RevIL to 1650 for THSA RevIL at $25^{\circ} \mathrm{C}$. In FSA RevIL on the other hand, there is a strong affinity between the molecules due to the presence of $F$ atom, thus resulting in significantly high viscosity. The ionic liquid viscosity also decreases with temperature as shown in Table 6.

Table 6: Comparison of viscosity of silylamine ionic liquids

\begin{tabular}{|c|c|c|}
\hline Compound & Viscosity @ 25 ${ }^{\circ} \mathbf{C ~ ( c P ) ~}$ & Viscosity @ 40 ${ }^{\circ} \mathbf{C ~ ( c P ) ~}$ \\
\hline TEtSA & 7600 & 2000 \\
\hline TPSA & 4000 & 1050 \\
\hline THSA & 1650 & 500 \\
\hline FSA & 12300 & 2900 \\
\hline
\end{tabular}

Viscosity and extent of conversion: Our RevILs show a very unique viscosity behavior with increasing conversion. From Figure 11, it can be seen that there is only a small increase in viscosity up to $80 \%$ conversion $\left(\mathrm{CO}_{2}\right.$ capture), however, beyond that small increments in conversion result in large increase in viscosity. This gives a very important processing advantage as we can get significant reduction in pumping costs as well as minimize the water requirement with only a very small compromise in capacity, which would not have been the case had the correlation between viscosity and conversion been linear. 


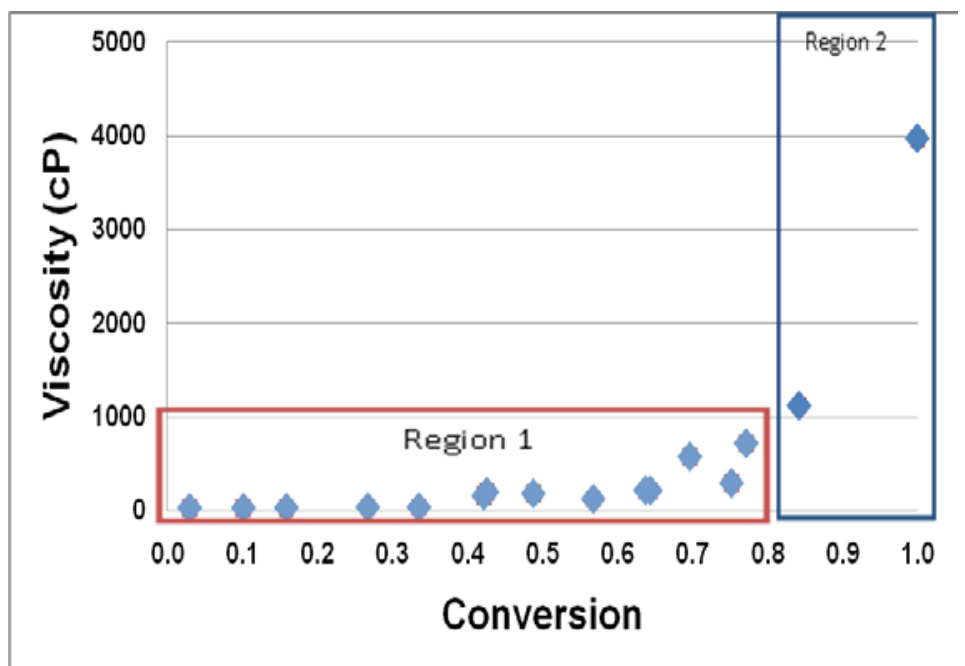

Figure 11: Relationship between viscosity \& conversion of molecular liquid to ionic liquid

Although these experiments were run at room temperature, the above behavior will be similar even at higher temperatures such as $40{ }^{\circ} \mathrm{C}$. In fact, at higher temperature the viscosity values at maximum conversion would be lower to begin with.

\section{f) Effect of Water}

The solubility of water in the molecular liquids is important for multiple reasons as discussed in the approach section. To study the water solubility in the MLs, excess water beyond phase separation at $25^{\circ} \mathrm{C}$ was added to the ML and the solution was rapidly agitated, resulting in an emulsion. This emulsion was broken by centrifuging the ML-water system, again forming two separate phases. The top phase was identified as the water-saturated ML, based upon the density of the MLs. Analysis of this top phase with Karl Fischer titrations showed that water was more soluble in TEtSA than TPSA. The solubility of water in TPSA was found to be $9.8 \pm 0.2 \mathrm{wt} \%$ and in TEtSA to be $17.2 \pm 0.6 \mathrm{wt} \%$. The longer hydrocarbon chains in TPSA make the molecule more hydrocarbon-like in behavior, thus reducing the solubility of water. 
We also analyzed water content in the distilled silyl-amine samples and found that to be less than $0.2 \%$ by weight.
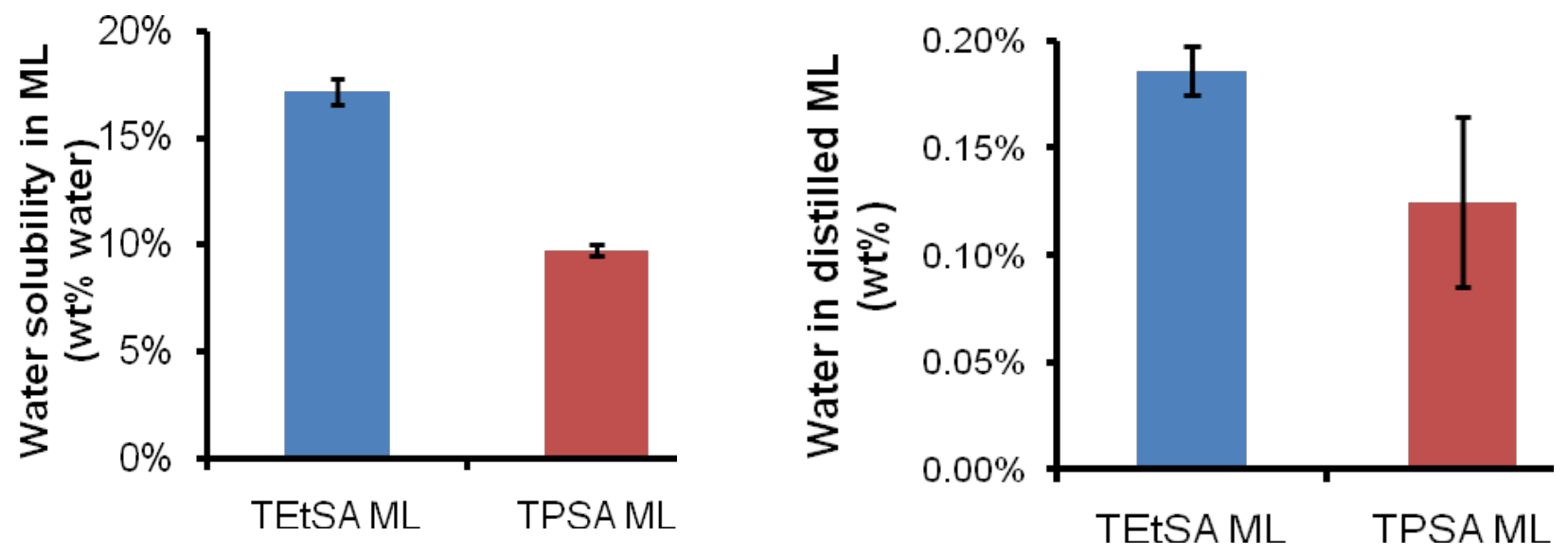

Figure 12: Water content (a) in saturated molecular liquid (solubility of water in molecular liquid) (b) in distilled molecular liquid (for determination of purity)

g) Kinetics and Mass Transfer

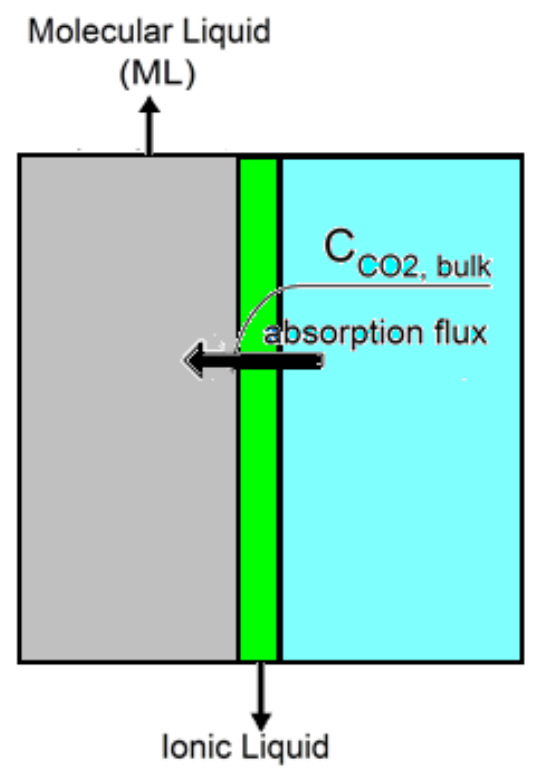

(IL)

Figure 13: Competing processes affecting the overall absorption times 
During our experiments we found that the reaction of our amines with $\mathrm{CO}_{2}$ was instantaneous. The reaction half lives are therefore less than a second $\left(\boldsymbol{t}_{r \times n} \sim 1 \mathrm{~s}\right)$. However, the total absorption time depends on three processes in series: (a) gas phase mass transfer from gas bulk to the solvent interface, (b) reaction kinetics and (c) $\mathrm{CO}_{2}$ mass transfer through the ionic liquid skin into the bulk molecular liquid. The slowest of these dictates the absorption time. The three competing processes affecting the absorption times are depicted in Figure 13.

Here we will present a simple order of magnitude estimate of the dependence of absorption times on the three processes. For $\mathrm{CO}_{2}$, the gas-phase diffusivity $\boldsymbol{D}_{\text {gas }}$ is $\sim 16 \mathrm{~mm}^{2} / \mathrm{s}$ at $\mathrm{STP}^{9}$ while the diffusivity in the ionic liquid $\boldsymbol{D}_{I L}$ (estimated from Stokes-Einstein equation) is $\sim 3.1 \times 10^{-6} \mathrm{~mm}^{2} / \mathrm{s}$. The diffusion time scales can be related to diffusivity by $\left(\boldsymbol{t} \sim \boldsymbol{\delta}^{2} / \boldsymbol{D}\right)$, where $\boldsymbol{\delta}$ is the characteristic diffusion path length. Typical diffusion length in gas phase is $\boldsymbol{\delta}_{\text {gas }} \sim 20 \mu \mathrm{m}{ }^{10}$, which gives $\boldsymbol{t}_{\text {diff,gas }}$ $\sim 25 \mu$ s (which is less than $\boldsymbol{t}_{r x n} \sim 1 \mathrm{~s}$.) On the other hand, even if we consider a limiting case where the thickness of the ionic liquid layer is as small as $\boldsymbol{\delta}_{I L}=1.8 \mu \mathrm{m}$, the diffusion time scale for $\mathrm{CO}_{2}$ across ionic liquid layer will be $\boldsymbol{t}_{\text {diff, } I L}>1 \mathrm{~s}$. Typically $\boldsymbol{\delta}_{I L}$ is orders of magnitude larger than $1.8 \mu \mathrm{m}$, making the mass transfer of $\mathrm{CO}_{2}$ in the IL the rate-limiting step.

Supporting experimental evidence of the dependence of absorption times on the mass transfer between the gas and liquid phase is found in the following two experimental results:

a) $\underline{\mathrm{CO}}_{2}$ Flowrate: $\mathrm{CO}_{2}$ was sparged through TPSA molecular liquid for 60 seconds at $25^{\circ} \mathrm{C}$ through an 18 gauge needle at flowrates from 200 to $1340 \mathrm{ml} / \mathrm{min}$, and $\mathrm{CO}_{2}$ uptake was measured gravimetrically. Figure 14 shows that the $\mathrm{CO}_{2}$ uptake increases from $0.86 \mathrm{~mol} \mathrm{CO}_{2} / \mathrm{kg}$ $\mathrm{ML}$ at $200 \mathrm{ml} / \mathrm{min} \mathrm{CO}_{2}$, to $2.15 \mathrm{~mol} \mathrm{CO}_{2} / \mathrm{kg} \mathrm{ML}$ at $1340 \mathrm{ml} / \mathrm{min} \mathrm{CO}_{2}$. The maximum chemisorption limit for TPSA is $2.32 \mathrm{~mol} \mathrm{CO}_{2} / \mathrm{kg} \mathrm{ML}$. The stoichiometric quantity of $\mathrm{CO}_{2}$ required for complete chemical conversion for the quantity of molecular liquid used was only 74 $\mathrm{ml}$ of $\mathrm{CO}_{2}$ at STP, significant excess of $\mathrm{CO}_{2}$ were used to assure reaching the saturation limit. This suggests that the increased aggitation due to increased flowrate increased the rate of $\mathrm{CO}_{2}$ uptake. Hence the process is mass transfer limited.

\footnotetext{
${ }^{9}$ NIST Thermodynamics and Transport Database 23

${ }^{10}$ E.R.G. Eckert, R.M. Drake, Analysis of Heat and Mass Transfer, McGraw Hill, New York.
} 


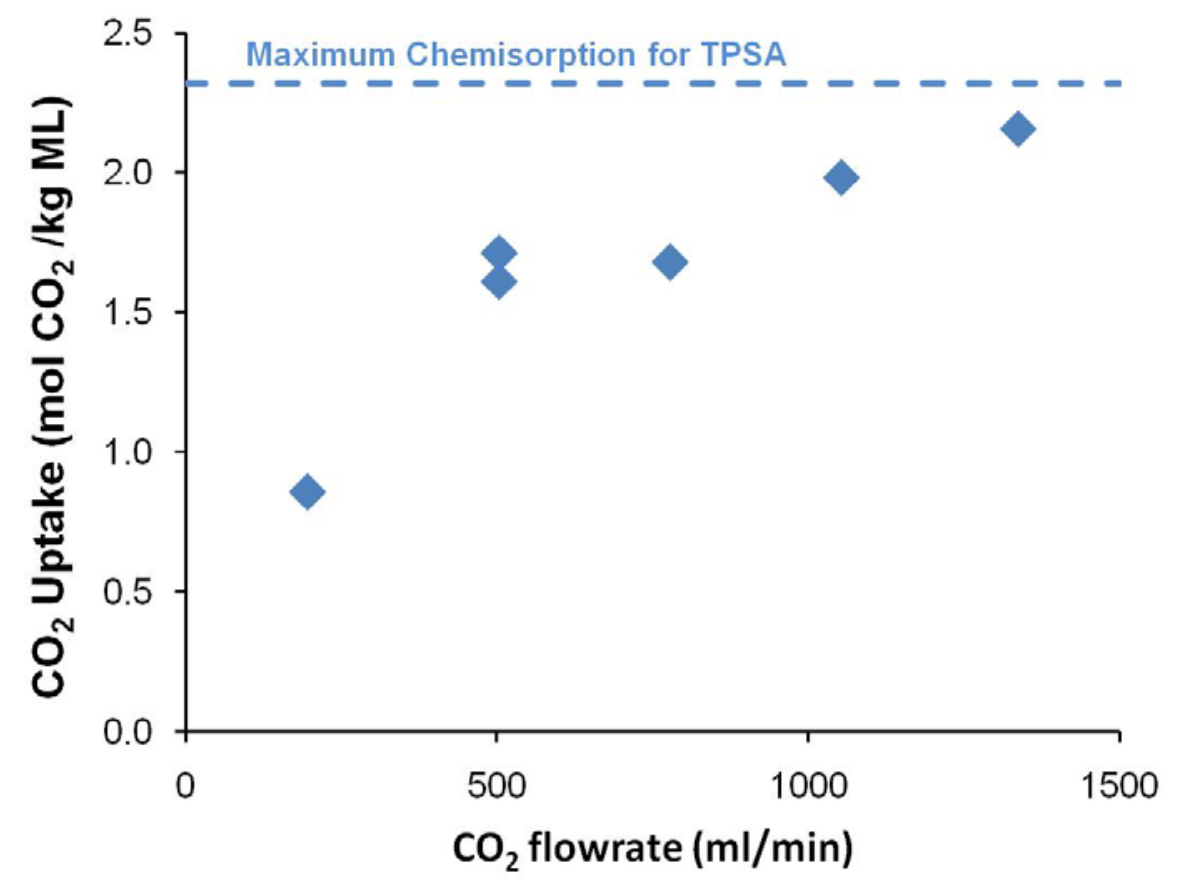

Figure 14: $\mathrm{CO}_{2}$ uptake in TPSA in $60 \mathrm{sec}$ as a function of $\mathrm{CO}_{2}$ flowrate. Conditions: $25^{\circ} \mathrm{C}$, pure $\mathrm{CO}_{2}$, needle. Theoretical maximum chemisorption at $2.32 \mathrm{~mol} \mathrm{CO}_{2} / \mathrm{kg} \mathrm{ML}$ indicated by dashed line.

b) Diffuser Tube Studies: $\mathrm{CO}_{2}$ was sparged through TPSA molecular liquid at a constant $\mathrm{CO}_{2}$ flowrate of $200 \mathrm{ml} / \mathrm{min}$ using both 18 gauge needle and a diffuser tube as shown in Figure 15. Diffuser tube allows better $\mathrm{CO}_{2}$ dispersion, and hence enhanced mass transfer. Complete theoretical chemical conversion was achieved in less than 90 seconds when the diffuser tube was used compared to 300 seconds with the needle. Even beyond this, the $\mathrm{CO}_{2}$ uptake through diffuser tube continued to exceed that through a needle and at 75 minutes maximum $\mathrm{CO}_{2}$ uptake for the samples were $2.99 \mathrm{~mol} \mathrm{CO} / \mathrm{kg}$ ML through the tube and $2.71 \mathrm{~mol} \mathrm{CO}_{2} / \mathrm{kg} \mathrm{ML}$ for the needle. 

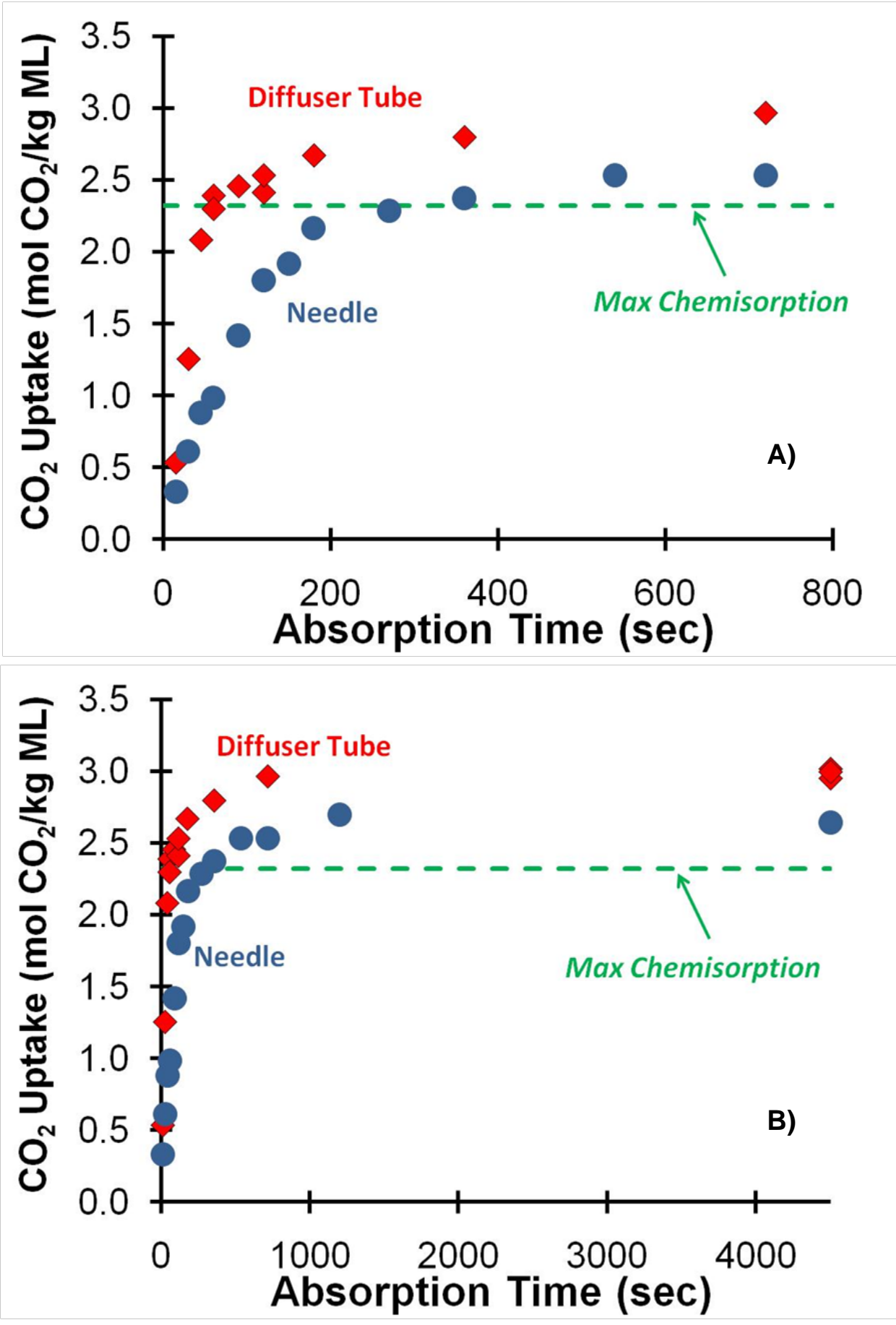

Figure 15: Comparison of diffuser tube (red diamonds) and needle (blue circles) $\mathrm{CO}_{2}$ introduction methods as a function of time in TPSA. $200 \mathrm{ml} / \mathrm{min}$ pure $\mathrm{CO}_{2}, 25^{\circ} \mathrm{C}$. Green dashed line indicates theoretical maximum chemisorption for TPSA. A) 15 -seconds -12 minutes. B) 15 seconds -75 minutes 


\section{h) Density and Refractive Index}

The densities of the molecular liquids were measured from $25^{\circ} \mathrm{C}$ to $40^{\circ} \mathrm{C}$, and are shown in Figure 16. The densities of TEtSA, TPSA, and THSA are all very close in value, with substantially higher densities observed for FSA molecular liquid. The molecular liquid densities as a function of temperature appear to follow a linear decreasing trend.

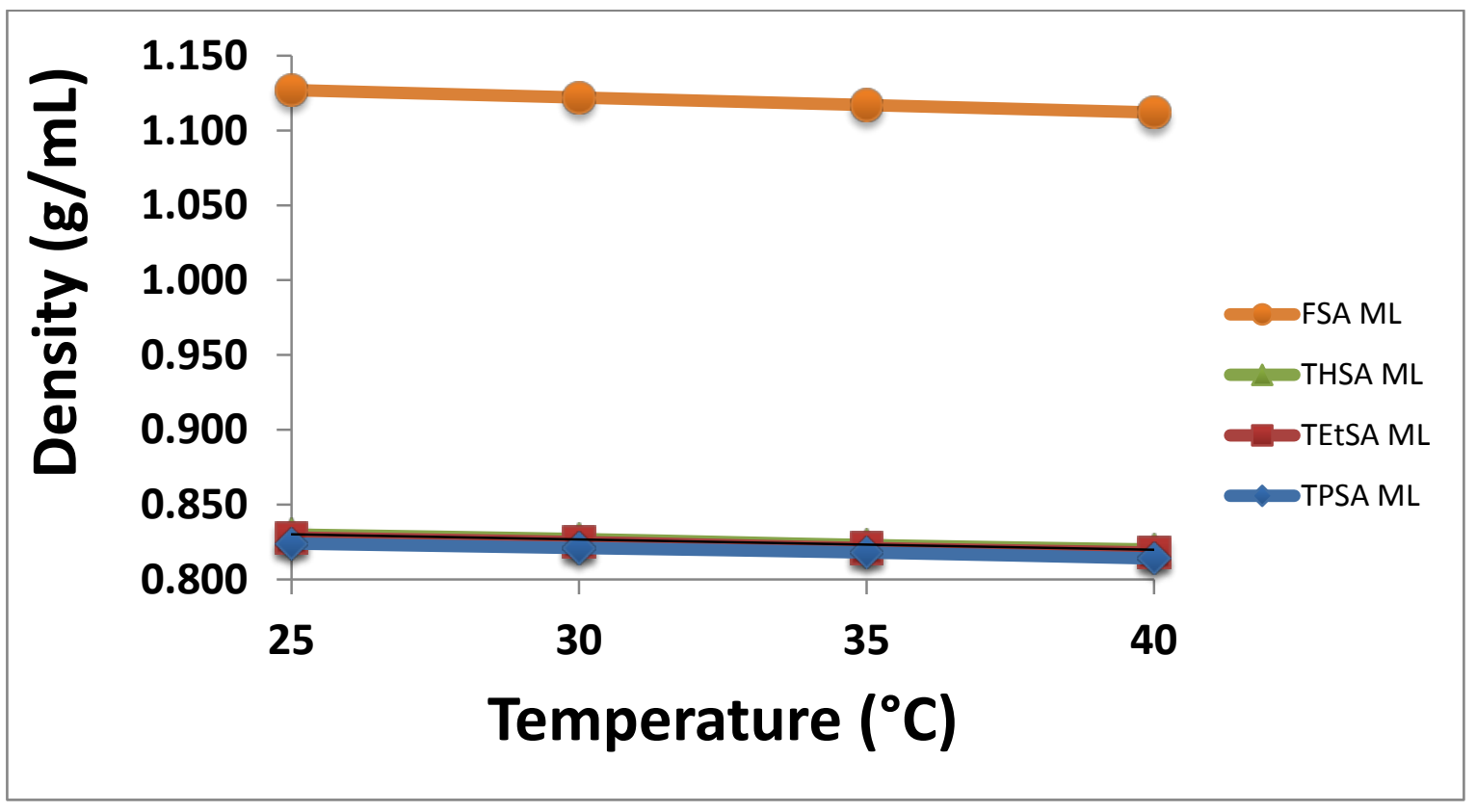

Figure 16:. The silylamine molecular liquid densities as a function of temperature

The densities of the corresponding ionic liquids are given in Figure . The TEtSA ionic liquid sample was the only material that was successfully measured over the entire temperature range. Due to the operation of the densitometer, the vibrations caused pockets of $\mathrm{CO} 2$ to be formed that in turn caused the interface of the liquid to rise in the vibrating tube, resulting in large fluctuations in density. As a result the densitometer was not able to converge on a stable density reading. 


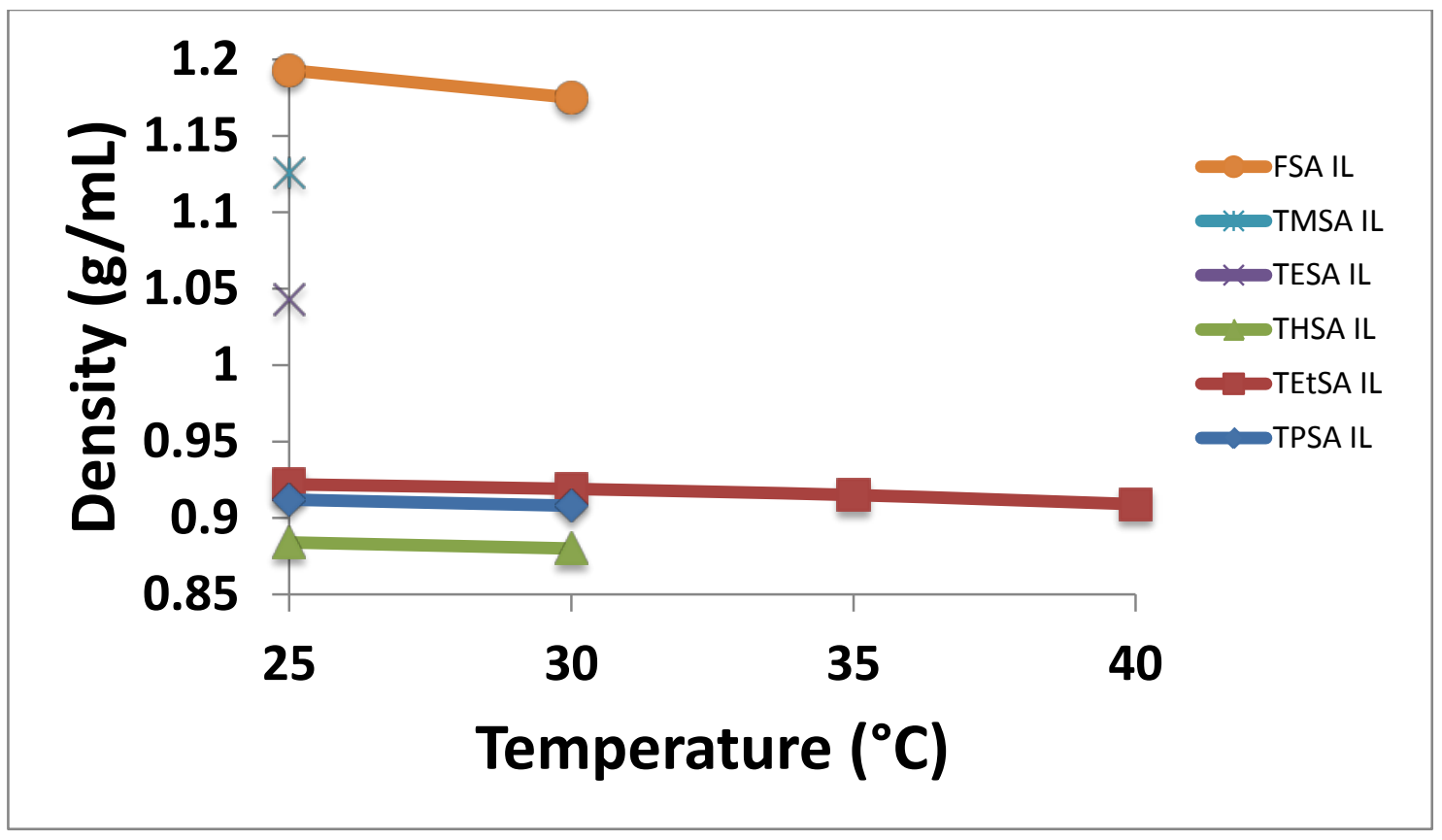

Figure 17: The silylamine ionic liquid densities as a function of temperature

The density of the TEtSA ionic liquid appears to decrease linearly with respect to temperature. This trend has been observed to be true even for conventional room temperature ionic liquids (non-reversible) over broad temperature ranges.

Density measurements are shown in Figure 17.

Refractive index is one of the important quantities required in the Beer-Lambert Law calculation. We have also shown experimentally (Figure 18) that the relationship between the RI and conversion (measured using gravimetric technique) is linear. For these experiments, $\mathrm{CO}_{2}$ was bubbled through the molecular liquid for short durations of times to allow incomplete conversion and the RI of corresponding samples was recorded. This is a very useful result as it shows that we can easily establish the extent of reaction of a sample by its RI. 


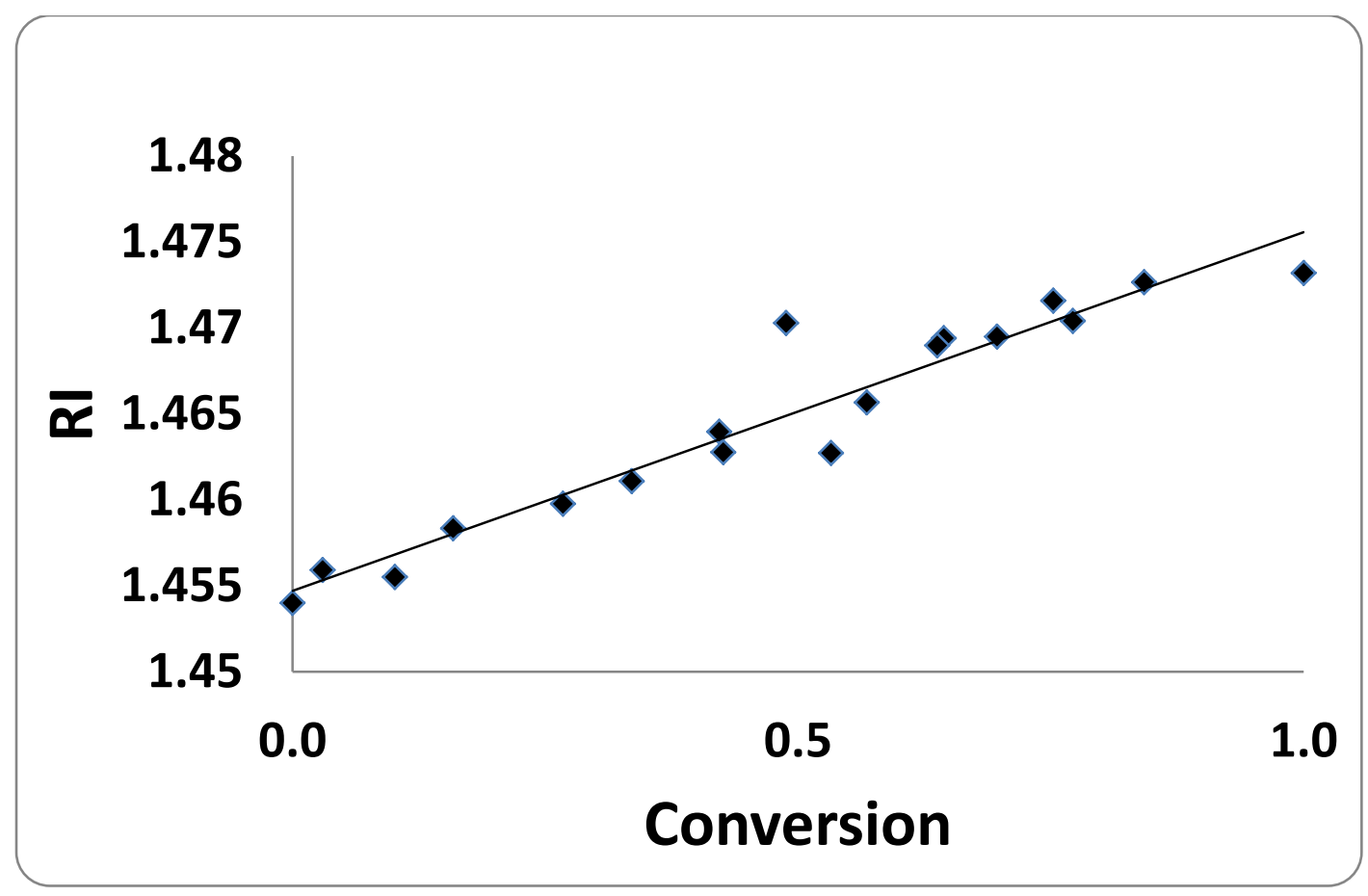

Figure 18: Relationship between refractive index and extent of conversion from molecular liquid to ionic liquid for TPSA.

\section{i) Recyclability}

Recyclability of TPSA and THSA for capture and release of $\mathrm{CO}_{2}$ over five cycles is shown in Figure 19 and Figure 20. $\mathrm{CO}_{2}$ was bubbled through the molecular liquid and the ionic liquid thus formed was reversed by heating at $100^{\circ} \mathrm{C}$ for $1-1.5$ hours. Refractive index, which is considered the indicator of the extent of the reaction, was measured after every absorption and reversion step. We expect the refractive index of the pure TPSA molecular liquid to be 1.454 while that of the ionic liquid to be 1.474. Similarly for THSA, we expect the refractive index of the pure molecular liquid to be 1.459 while that of the ionic liquid to be 1.472 . The molecular liquids at the end of the fifth cycle were analyzed using ${ }^{1} \mathrm{H}$ NMR and were found to be same as that at the beginning of the experiment. With almost negligible loss of activity over five cycles we expect that our silylamines (especially THSA and TPSA) can be effectively recycled over several more cycles. 


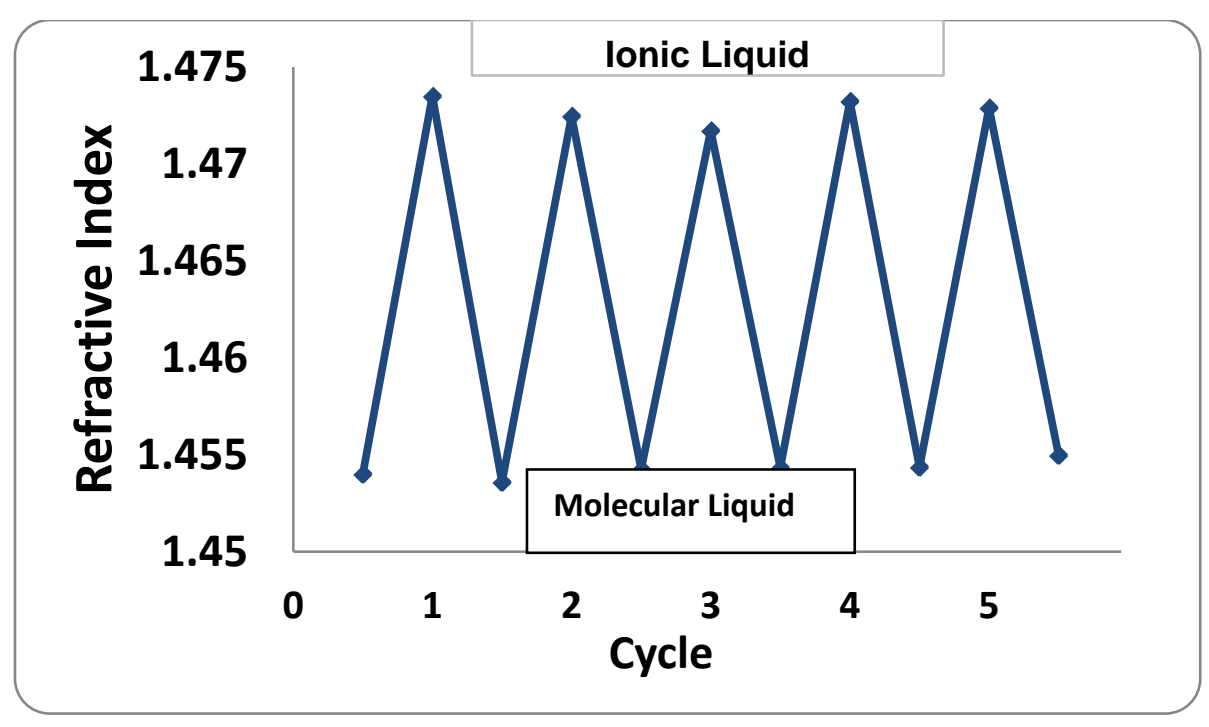

Figure 19: Recyclability of TPSA explored using Refractive Index

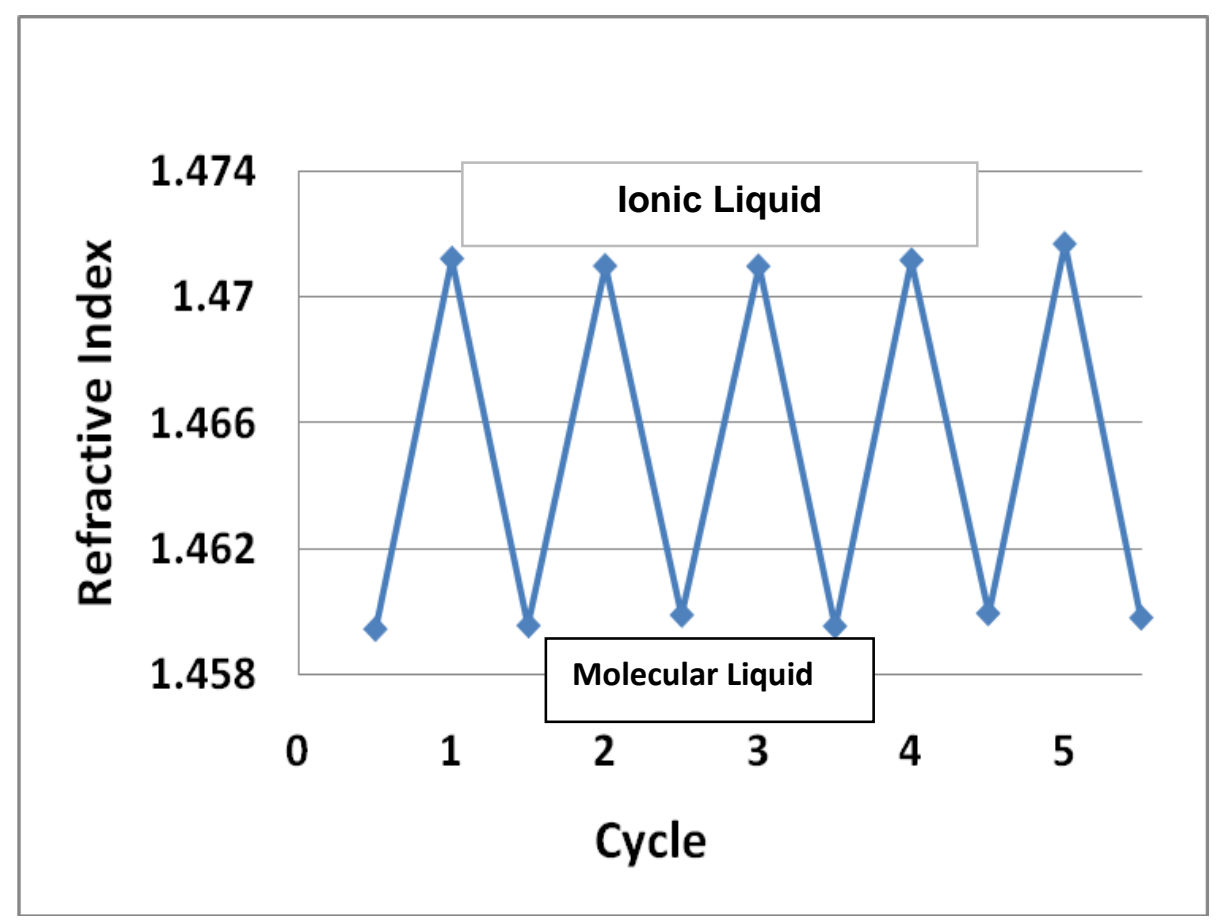

Figure 20: Recyclability of THSA explored using Refractive Index 


\section{j) Optimum Single Component RevIL for $\mathrm{CO}_{2}$ capture}

In this section we will analyze the results in terms of structure-property relationships to determine the RevIL with optimum properties of $\mathrm{CO}_{2}$ capture. Among the compounds listed in Table 7, the trialkoxy silylamines (TESA and TMSA) were unstable under air and moisture, while the last two compounds with a bulky side group attached to Si (CHDMSA \& PDMSA) turned into solids upon reaction with $\mathrm{CO}_{2}$. Among the rest of the compounds, the fluorinated compound (FSA) gave very low chemisorption and very high viscosity, making it unsuitable for commercial use.

For the trialkyl silylamines (TEtSA, TPSA, THSA) we sought a good balance of properties (See Table 7). Increasing the chain length from TEtSA to THSA increases the molecular weight as well as disruption in packing of the chains. While the former decreases the capacity, the latter helps in bringing down the reversal temperature and viscosity, thus decreasing the processing costs. TPSA, whose properties lie between TETSA and THSA, qives the right balance making it the optimum $\mathrm{CO}_{2}$ capture solvent among the silylamines studied in this project. 
Table 7: Comparison of properties of trialkylsilylamines

\begin{tabular}{|l|l|l|l|}
\hline RevIL & TEtSA & TPSA & THSA \\
\hline $\begin{array}{l}\text { Gravimetric capacity } \\
\text { (mol CO } / \text { kg amine) }\end{array}$ & 3.52 & 2.56 & 1.79 \\
\hline $\begin{array}{l}\text { Theoretical capacity } \\
\left(\text { mol CO}_{2} / \text { kg amine) }\right.\end{array}$ & 2.89 & 2.32 & 1.46 \\
\hline $\begin{array}{l}\mathbf{\Delta H}_{\text {regeneration }} \\
\left(\mathrm{kJ} / \mathrm{CO}_{2}\right)\end{array}$ & 104 & 114 & 108 \\
\hline $\mathbf{T}_{\text {reversal }}\left({ }^{\circ} \mathrm{C}\right)$ & 71 & 64 & 51 \\
\hline $\begin{array}{l}\text { Ionic liquid Viscosity } \\
(\mathrm{cP}) 25^{\circ} \mathrm{C}\end{array}$ & 7600 & 3600 & 1650 \\
\hline $\begin{array}{l}\text { Ionic liquid Viscosity } \\
(\mathrm{cP}) 40^{\circ} \mathrm{C}\end{array}$ & 1300 & 985 & 711 \\
\hline
\end{tabular}

k) Scale up of Synthesis Process

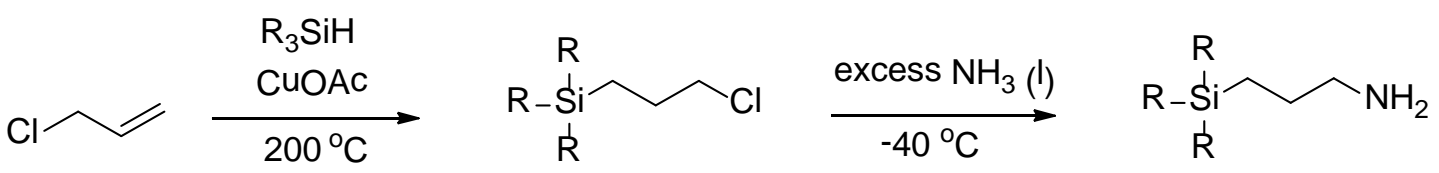

Scheme 5: Proposed Synthesis Route for Bulk Manufacture of Silylamines

Although allyl amine and trialkylsilanes are available in bulk and can be considered raw materials, the use of expensive platinum catalyst and toluene, along with un-optimized reactions, render the lab scale method unfavorable for bulk production. Therefore, we have outlined a revised procedure which may be better adapted for scale up and mass production of trialkylsilylamines. The proposed synthesis (Scheme 5) utilizes allyl chloride and trialkylsilanes, 
as bulk raw materials reacting without solvent at high temperatures and pressures in the presence of a relatively cheaper copper acetate catalyst. This procedure is adapted from a previously outlined procedure in the literature ${ }^{11}$. The trialkylsilylchloride would then be reacted with liquid ammonia as both solvent and reagent to aminate the chloride ${ }^{12}$. Neutralization of the hydrochloride salt of the amine formed would then provide the pure trialkylsilylated amines. This method would use relatively cheap raw materials along with greener methods for the production of the desired silylamines.

\section{l) Process Modeling and Economic Analysis}

We have used Aspen-HYSYS for modeling the $\mathrm{CO}_{2}$ capture process using our optimum silylamine, TPSA. TPSA molecular and ionic liquids were modeled as hypotheticals and ENRTL package was used. Estimates of the critical properties calculated using the methods described in 'The properties of gases and liquids ${ }^{13}$, and the density and the boiling point data for TPSA were used for modeling these compounds. The flow diagram of the process is shown in Figure 21.

\footnotetext{
${ }^{11}$ Nguyen, B. T.: US, 2004; Vol. US 6713644 B1.

${ }^{12}$ Shreve, R. N. R., L. W. Journal of Industrial and Engineering Chemistry 1937, 29, 1361-1364.

${ }^{13}$ B.E. Poling, The properties of gases and liquids, 5th ed. ed., McGraw-Hill, New York :, 2001
} 


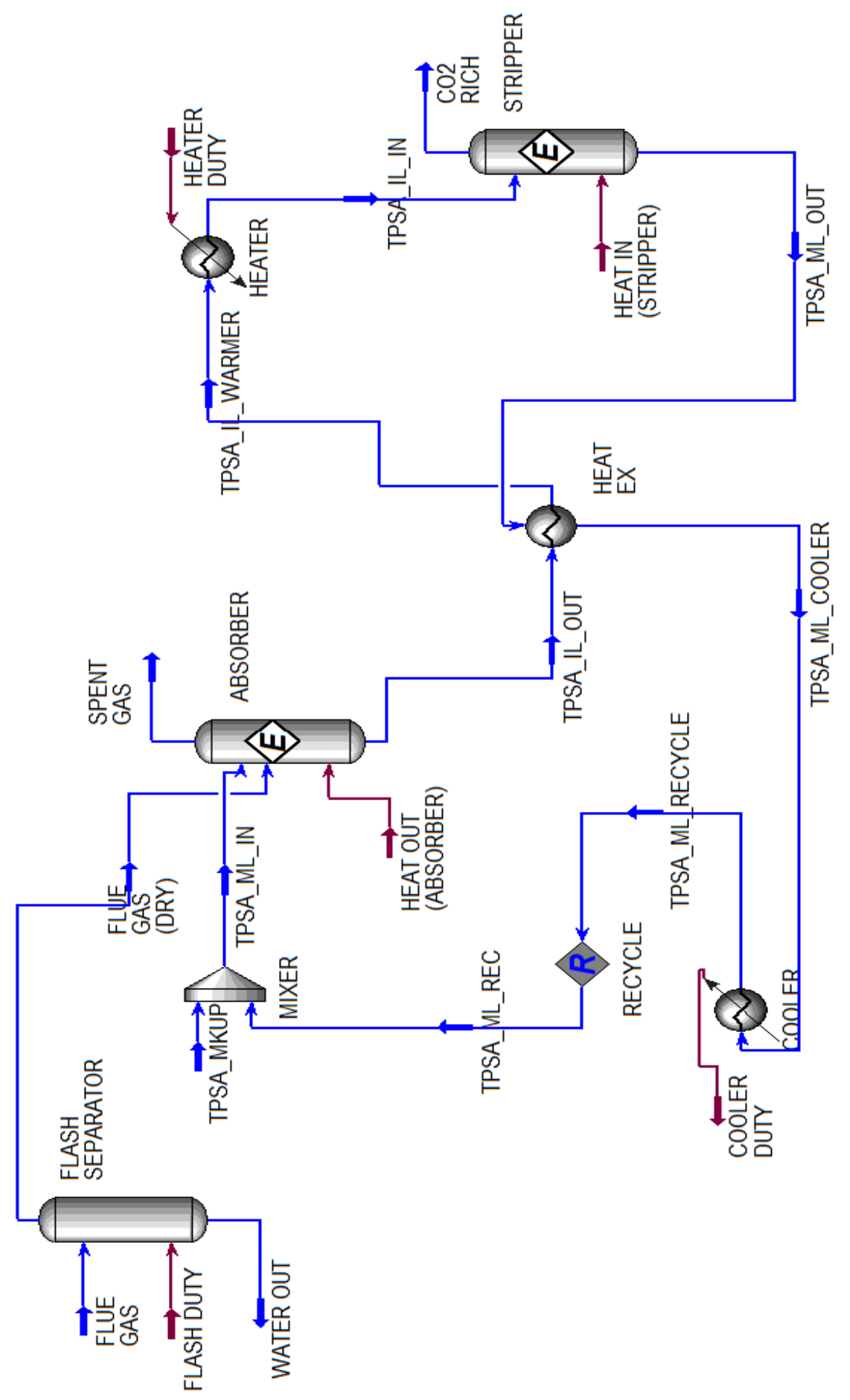

Figure 21: Process Flow Diagram of $\mathrm{CO}_{2}$ capture using neat TPSA 
Our objective in this project has been to use silylamines without water hence water was removed from the flue gas using a flash separator. Composition and physical conditions of the flue gas are given below

1) Composition of flue gas leaving FGD (wet basis):

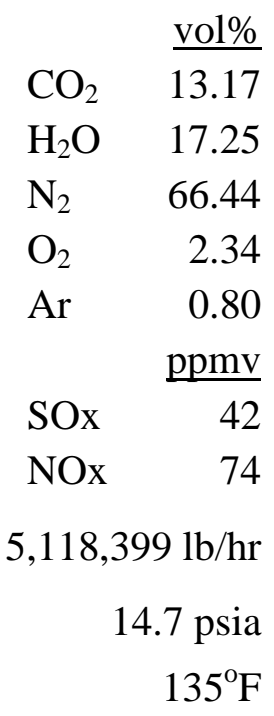

2) Flowrate of flue gas leaving FGD (based on $550 \mathrm{MW}$ net PC plant):

3) Pressure and temperature of flue gas leaving FGD: $135^{\circ} \mathrm{F}$

The process starts with the dry flue gas entering the bottom of the absorber. An equilibrium reactor is used for modeling the absorber. This allows us to use the equilibrium constant data found using FT-IR measurements and COSMO-RS calculations. The unit is operated at $40^{\circ} \mathrm{C}$. The $\mathrm{CO}_{2}$ lean solvent (TPSA molecular liquid) enters the top of the absorber and reacts with the $\mathrm{CO}_{2}$ available in the dry flue gas. In the absence of water there is no formation of bicarbonates. Enthalpies of formation of the TPSA molecular and ionic liquids are adjusted to match the reaction enthalpy of the silylamine- $\mathrm{CO}_{2}$ reaction. The spent gas primarily containing nitrogen leaves from the top of the absorber while the $\mathrm{CO}_{2}$ rich solvent exits from the bottom. The composition and the physical conditions of these streams are given in the calculation table below.

\begin{tabular}{|l|r|r|r|}
\hline \multicolumn{4}{|c|}{ Table 8: $\mathrm{CO}_{2}$ Capture Calculations CAPTURE CONDITIONS } \\
\hline & Flowrate $(\mathrm{kg} / \mathrm{h})$ & \multicolumn{1}{|c|}{ Temperature C } & Pressure (kPa) \\
\hline TPSA Makeup & $1.07 \mathrm{E}+04$ & 40 & 101.3 \\
\hline Absorber & $4.43 \mathrm{E}+06$ & 40 & 101.3 \\
\hline Absorber / IL out (TPSA_IL_OUT) & $4.73 \mathrm{E}+06$ & 40 & 101.3 \\
\hline
\end{tabular}




\begin{tabular}{|c|c|c|c|}
\hline \multicolumn{4}{|c|}{ Heat exchanger (TPSA_IL_WARMER) } \\
\hline \multicolumn{4}{|c|}{$\begin{array}{l}\text { Heater output (TPSA_IL_IN) = stripper op. } \\
\mathrm{T}\end{array}$} \\
\hline \multicolumn{4}{|c|}{ Stripper $\mathrm{CO}_{2}$ rich gas } \\
\hline \multicolumn{3}{|c|}{ Cooler } & \\
\hline \multicolumn{4}{|c|}{ INLET FLUE GAS } \\
\hline & Mass Flows (kg/h) & Mole Fra & tion \\
\hline $\mathrm{CO}_{2}$ & 305807.4 & & 0.08 \\
\hline $\mathrm{H}_{2} \mathrm{O}$ & 400545 & & 0.26 \\
\hline Oxygen & 54334.8 & & 0.02 \\
\hline Nitrogen & 154273.7 & & 0.64 \\
\hline TPSA_ML & 0 & & 0 \\
\hline TPSA IL & 0 & & 0 \\
\hline Argon & 18576 & & .005 \\
\hline
\end{tabular}

\begin{tabular}{|c|c|c|c|}
\hline $4.73 \mathrm{E}+04$ & 50 & & 120 \\
\hline $4.73 E+06$ & 85 & & 126 \\
\hline $3.47 \mathrm{E}+05$ & 85 & & 126 \\
\hline $4.38 \mathrm{E}+06$ & 74.42 & & 120 \\
\hline $\mathrm{CO}_{2}$ Removed & \multicolumn{2}{|r|}{0.899} & \\
\hline $\mathrm{CO}_{2}$ Recovered & \multicolumn{2}{|r|}{0.899} & \\
\hline
\end{tabular}

$$
\begin{gathered}
\text { CO2 removed }=\frac{C_{\mathrm{CO} 2}^{\text {Flue }}-C_{\mathrm{CO} 2}^{\text {Spent }}}{C_{\mathrm{CO} 2}^{\text {Flue }}} \\
\text { CO2 recovered }=\frac{C_{\mathrm{CO} 2}^{\text {Rich }}}{C_{\mathrm{CO} 2}^{\mathrm{Flue}}}
\end{gathered}
$$

Total Energy Required $=3.824 \mathrm{E}+08 \mathrm{~kJ} / \mathrm{h}$

Energy Per $\mathrm{kg}$ of $\mathrm{CO}_{2}$ captured $=1.39 \mathrm{MJ} / \mathrm{kg}$

\begin{tabular}{|c|c|c|}
\hline \multicolumn{3}{|c|}{$\mathrm{CO}_{2}$ SPENT GAS } \\
\hline & $\begin{array}{l}\text { Mass Flows } \\
(\mathrm{kg} / \mathrm{h})\end{array}$ & $\begin{array}{l}\text { Mole } \\
\text { Fraction }\end{array}$ \\
\hline $\mathrm{CO}_{2}$ & 30621.3 & 0.01 \\
\hline $\mathrm{H}_{2} \mathrm{O}$ & 54312.6 & 0.05 \\
\hline Oxygen & 54313.5 & 0.03 \\
\hline Nitrogen & 1541889 & 0.90 \\
\hline TPSA_ML & 11646 & 0.0009 \\
\hline TPSA IL & .02 & 0 \\
\hline Argon & 18567.95 & 0.008 \\
\hline
\end{tabular}

\begin{tabular}{|l|r|r|}
\hline \multicolumn{3}{|c|}{$\mathrm{CO}_{2}$ RICH GAS } \\
\hline & Mass Flows $(\mathrm{kg} / \mathrm{h})$ & Mole Fraction \\
\hline $\mathrm{CO}_{2}$ & 275200.02 & 0.72 \\
\hline $\mathrm{H}_{2} \mathrm{O}$ & 39921.98 & 0.26 \\
\hline Oxygen & 21 & 0.0001 \\
\hline Nitrogen & 845.64 & 0.004 \\
\hline TPSA_ML & 31039.92 & 0.02 \\
\hline TPSA IL & 0 & 0 \\
\hline Argon & 7.94 & 0 \\
\hline
\end{tabular}


The $\mathrm{CO}_{2}$ rich solvent is fed to the stripper via a heat exchanger. As with the absorber, an equilibrium reactor is used for modeling the stripper. Stoichiometry and equilibrium constants of the reverse reaction are entered in the design specifications of the stripper. The stripper is operated at $85^{\circ} \mathrm{C}$, which is a temperature above the onset reversal temperature $\left(64^{\circ} \mathrm{C}\right)$ found from DSC. The reason for this is that the reaction would go to completion at this temperature and would potentially require shorter residence times in the absorber. Vapor stream rich in $\mathrm{CO}_{2}$ exits from the top of the stripper while the $\mathrm{CO}_{2}$-lean solvent from the bottom. The $\mathrm{CO}_{2}$-lean solvent stream is passed through the heat exchanger that simultaneously cools the $\mathrm{CO}_{2}$-lean stream and heats up the $\mathrm{CO}_{2}$-rich stream. After cooling down, a make-up steam of TPSA molecular liquid is added to the $\mathrm{CO}_{2}$-lean stream, and re-fed to the absorber to complete the loop.

Details of the operating conditions and the calculation for the amount of energy required for the DOE target of $90 \% \mathrm{CO}_{2}$ captured are shown in the Table 8, above. Our neat TPSA solvent (without water) required $1.39 \mathrm{MJ} / \mathrm{kg}$ of $\mathrm{CO}_{2}$ captured. This nearly a third of the $4 \mathrm{MJ} / \mathrm{kg}$ of $\mathrm{CO}_{2}$ reported using aq. MEA process ${ }^{14}$.

${ }^{14}$ Lars E Oi, Telemark Univ., Norway, SIMS2007 Conference, Goteborg, 2007 


\section{Milestones Appraisal}

The milestones listed in the Project Management Plan are as follows:

\begin{tabular}{|c|c|c|c|}
\hline ID & Milestone Description & $\begin{array}{c}\text { Planned } \\
\text { Completion }\end{array}$ & Verification Method \\
\hline A & Complete Project Management Plan & $10 / 01 / 08$ & PMP approved by DOE COR \\
\hline B & $\begin{array}{l}\text { Complete laboratory synthesis and } \\
\text { characterization of one new single- } \\
\text { component silyl amine-based reversible ionic } \\
\text { liquid. }\end{array}$ & $6 / 30 / 09$ & $\begin{array}{l}\text { laboratory synthesis and } \\
\text { characterization of single- } \\
\text { component silyl amine-based } \\
\text { reversible ionic liquid. }\end{array}$ \\
\hline $\mathrm{C}$ & $\begin{array}{l}\text { Complete laboratory synthesis and } \\
\text { characterization of one new single- } \\
\text { component silyl guanidine-based reversible } \\
\text { ionic liquid. }\end{array}$ & 9/30/09 & $\begin{array}{l}\text { Progress Report describing } \\
\text { laboratory synthesis and } \\
\text { characterization of one new single- } \\
\text { component silyl guanidine-based } \\
\text { reversible ionic liquid }\end{array}$ \\
\hline $\mathrm{D}$ & $\begin{array}{l}\text { Complete laboratory synthesis and } \\
\text { characterization of 2nd new single- } \\
\text { component silyl amine-based reversible ionic } \\
\text { liquid and 2nd new single-component silyl } \\
\text { guanidine-based reversible ionic liquid. }\end{array}$ & $3 / 30 / 10$ & $\begin{array}{l}\text { Progress Report describing } \\
\text { synthesis and characterization of 2nd } \\
\text { new silyl amine-based and } \\
\text { guanidine-based reversible ionic } \\
\text { liquids }\end{array}$ \\
\hline $\mathrm{E}$ & $\begin{array}{l}\text { Complete synthesis and characterization of } \\
\text { single-component Silyl Amine-Based ILs }\end{array}$ & $06 / 30 / 10$ & $\begin{array}{l}\text { Synthesis and Characterization } \\
\text { results for Silyl Amine-Based ILs } \\
\text { documented in Progress Report }\end{array}$ \\
\hline $\mathrm{F}$ & $\begin{array}{l}\text { Complete laboratory measurement of the } \\
\text { thermodynamics of formation of one new } \\
\text { single-component silyl amine-based } \\
\text { reversible ionic liquid and one new single- } \\
\text { component silyl guanidine-based reversible } \\
\text { ionic liquid. }\end{array}$ & 9/30/10 & $\begin{array}{l}\text { Progress Report describing } \\
\text { thermodynamics of formation of } \\
\text { new single-component silyl amine- } \\
\text { based and single-component silyl } \\
\text { guanidine-based reversible ionic } \\
\text { liquids }\end{array}$ \\
\hline G & 1-Component Silyl Guanidine-Based ILs & $02 / 28 / 11$ & $\begin{array}{l}\text { Synthesis and Characterization } \\
\text { results documented in Progress } \\
\text { Report }\end{array}$ \\
\hline $\mathrm{H}$ & $\begin{array}{l}\text { Complete laboratory measurements of the } \\
\text { rates of formation of one new single- } \\
\text { component silyl amine-based reversible ionic } \\
\text { liquid and one new single-component silyl }\end{array}$ & $3 / 30 / 11$ & $\begin{array}{l}\text { Progress Report describing rates of } \\
\text { formation of new single-component } \\
\text { silyl amine-based and single- } \\
\text { component silyl guanidine-based }\end{array}$ \\
\hline
\end{tabular}




\begin{tabular}{|l|l|c|l|}
\hline & guanidine-based reversible ionic liquid. & & reversible ionic liquids \\
\hline I & Thermo \& Rates of IL Formation & $6 / 30 / 11$ & $\begin{array}{l}\text { Test results documented in Progress } \\
\text { Report }\end{array}$ \\
\hline J & $\begin{array}{l}\text { Complete synthesis and characterization of } \\
\text { optimized single-component silyl reversible } \\
\text { ionic liquid. }\end{array}$ & $9 / 30 / 11$ & $\begin{array}{l}\text { Progress Report describing synthesis } \\
\text { and characterization of optimized } \\
\text { single-component silyl reversible } \\
\text { ionic liquid }\end{array}$ \\
\hline K & Optimize CO ${ }_{2}$ Capture Solvent Structure & $9 / 30 / 11$ & $\begin{array}{l}\text { Optimal Solvent Identified and } \\
\text { described in Progress Report }\end{array}$ \\
\hline L & Process Design and Economic Analysis & $9 / 30 / 11$ & $\begin{array}{l}\text { Design and Scaleup process and } \\
\text { results documented in Progress } \\
\text { Report }\end{array}$ \\
\hline M & Final Report & $9 / 30 / 11$ & Draft Final Report Submitted \\
\hline
\end{tabular}

In year one, Milestone A was completed on schedule with the approval of the Project Management Plan. Milestone B was completed ahead of schedule, with the complete laboratory synthesis and characterization of four new single-component silylamine-based reversible ionic liquids. For Milestone $\mathrm{C}$ we proposed to synthesize and characterize a silylguanidine based reversible ionic liquid. However, before we achieved this goal, reports from the Jessop group at Queen's University in Canada showed that the guanidine based RevILs are unsuitable for $\mathrm{CO}_{2}$ capture because only very high molecular weight compounds are in fact liquids - thereby offering extremely low capacities. We discussed this in our Quarter 6 Report, and shifted our focus solely to the silylamine-based reversible ionic liquids.

In year two, for milestone $\mathrm{D}$, we reported the complete laboratory synthesis and characterization of two more (6 total) silylamine-based reversible ionic liquids in the Progress Reports for Quarter 6 \& 7. Subsequently, we realized that TEtSA, which is the compound with highest $\mathrm{CO}_{2}$ capture capacity (moles of $\mathrm{CO}_{2} / \mathrm{kg}$ solvent), is solid just below room temperature. In order to reduce the melting point of TEtSA, we introduced further changes to the structure and synthesized two new compounds in Quarter 8 and Quarter 9, taking the tally to eight silylamine solvents for milestone E. In Quarter 7, we had also reported the viscosities and refractive indices of six compounds both in molecular and ionic forms. In Quarter 8, we went ahead of our 
schedule (Milestone F) by measuring the physical absorption capacities of six silyl-amine compounds and other important thermodynamic properties (regeneration enthalpies and reversal temperature) for three alkyl substituted silylamines.

In Quarter 9 (year three), we presented the thermodynamics and capture capacities of Fluorinated silylamine (FSA) solvent along with further insights into the reversion temperature and recyclability of the solvent in $\mathrm{CO}_{2}$ capture process (Milestone F). In Quarter 10, we completed Milestone $\mathrm{H}$ in time by showing the rate of formation of TPSA ionic liquid is dominated by the mass transfer between $\mathrm{CO}_{2}$ and the ionic liquid/molecular liquid mixture. In quarter eleven, we successfully calculated the equilibrium constant of reaction of $\mathrm{CO}_{2}$ with TPSA molecular liquid to give ionic liquid. Results for enhanced $\mathrm{CO}_{2}$ absorption using diffuser tube were reported as well. With these results, we completed the study of the thermodynamics, kinetics and mass transfer of $\mathrm{CO}_{2}$ absorption (Milestone I).

Finally with this report, we have completed Milestones J to M. TPSA was found to be the optimum silylamine with the right balance of physical and thermodynamic properties. This is discussed in detail in section 3.2(k) of this report. The process design using HYSYS is presented in section 3.2(l) showing that our solvents will only use a third of the energy required by the aq. MEA based process. 


\section{Conclusions}

We have successfully developed a very promising class of $\mathrm{CO}_{2}$ capture solvents, RevILs, that would potentially require only a third of the energy for $\mathrm{CO}_{2}$ capture as compared to the conventional aq. MEA process. These RevILs are silylamines that can capture $\mathrm{CO}_{2}$ through dual mode: chemisorption and physisorption, thus giving enhanced capacity. Presence of Si in the molecules reduces the viscosity and hence the pumping costs and the mass and heat transfer limitations. The low viscosity also minimizes the water requirement, thus reducing the parasitic sensible heat required for heating water. RevILs desorb at much lower temperatures $\left(\sim 70-80^{\circ} \mathrm{C}\right)$ as compared to $\mathrm{MEA}\left(120^{\circ} \mathrm{C}\right)$ further reducing the sensible heat requirement.

We have adopted a structure-property relationships based approach for improving the properties of our RevILs. Through systematic changes to the structure we have developed (3aminopropyl) tripropylsilane as an optimum solvent for $\mathrm{CO}_{2}$ capture. This molecule has relatively low viscosity of $1000 \mathrm{cP}$ post capture at $40^{\circ} \mathrm{C}$, low reversal temperature of $64^{\circ} \mathrm{C}$ and $\mathrm{CO}_{2}$ uptake of $3 \mathrm{~mol} \mathrm{CO} / \mathrm{kg}$ of silylamine. In future, we will build on these structure-property paradigms to further improve the properties.

To conclude, our silylamine based RevILs, due to their lower energy requirement have tremendous potential for meeting DOE's goal of $90 \% \mathrm{CO}_{2}$ capture with less than $35 \%$ cost increase. 


\section{Appendices}

\section{a) Design of Custom-built ATR cell}

\section{High Pressure ATR IR Experimental Apparatus}

A Shimadzu IRPrestige-21 FT-IR spectrophotometer (with a DLaTGS detector) was used for collection of the IR spectroscopic data. For all measurements, a total of 32 scans with a resolution of $1.0 \mathrm{~cm}^{-1}$ were used. The ATR IR accessory used in this study was the Heated Golden ATR offered by Specac, Ltd. The Heated Golden Gate has a Type IIa diamond optical crystal, ZnSe focusing lenses, and is capable of measurements at temperatures up to $200^{\circ} \mathrm{C}$ ( $\pm 0.5^{\circ} \mathrm{C}$ ) using the supplied external temperature controller. The Heated Golden Gate apparatus was not modified to accommodate the high pressure measurements. Rather, a custom built stainless steel reactor was designed to replace the supplied sapphire anvil (Figure 22).

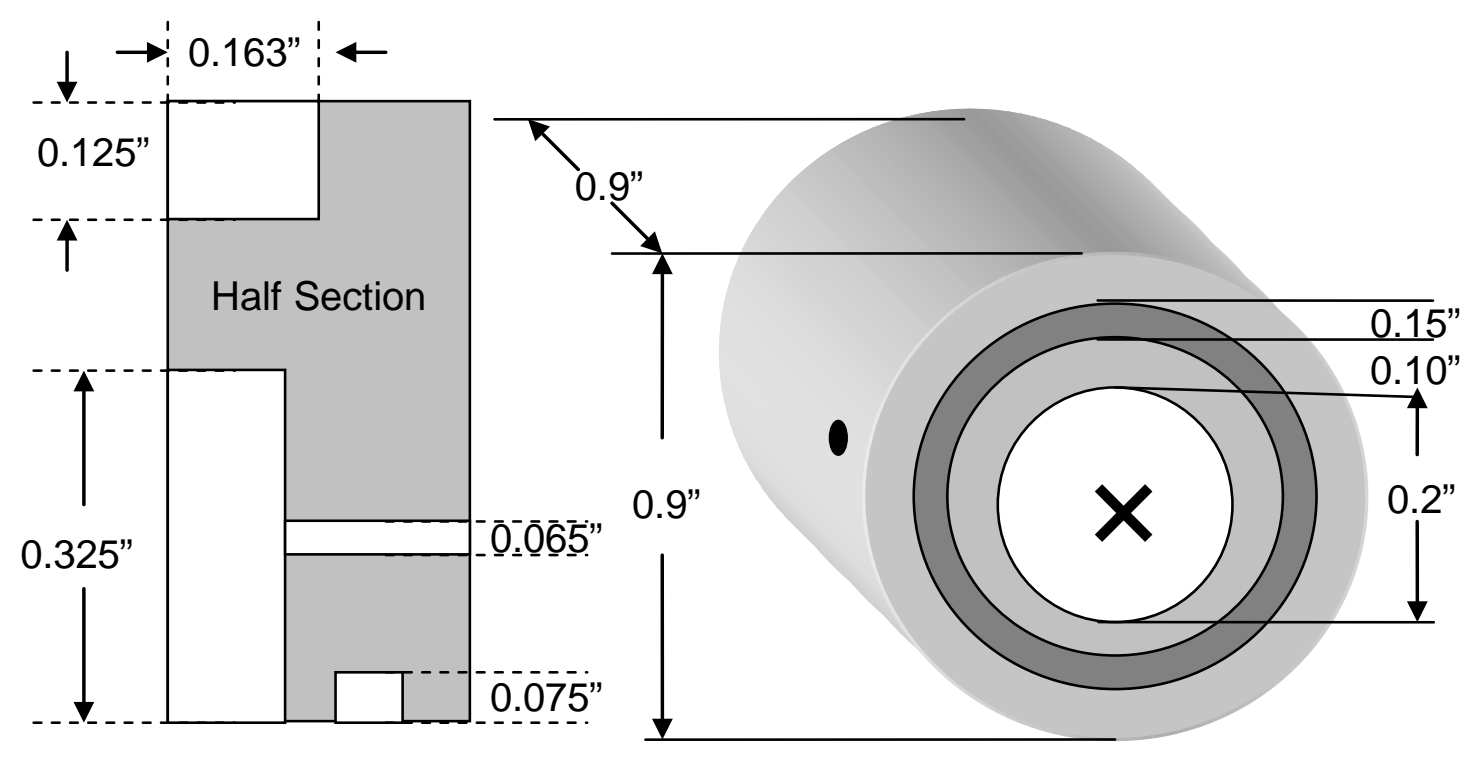

The reactor was designed in collaboration with Prof. Sergei Kazarian of Imperial College London, and it was machined from 316 stainless steel with tight tolerances ( \pm 0.001 ”). Approximately 12” of HiP 1/16” 316 stainless steel tubing was fixed in the 0.065 ” inlet port with 
the use of silver solder, to withstand high temperatures. As there is only one inlet in the reactor, the design was not intended for analyzing constant flow processes. However, the design allows for modification to accommodate such experiments. The 0.075 ” recess was used to maintain alignment of the Kalrez O-ring that sealed the base of the reactor to the diamond-embedded tungsten carbide puck on the Heated Golden Gate. The bridge on the Heated Golden Gate was secured and the retaining nut (normally used to press the anvil against the sample) was tightened according to the manufacturer's specification to seal completely the reactor against the puck. The apparatus was successfully tested at a temperature of $150^{\circ} \mathrm{C}$ and pressure of $1500 \mathrm{psi}$. 
b) Characterization of Molecular and Ionic Liquids

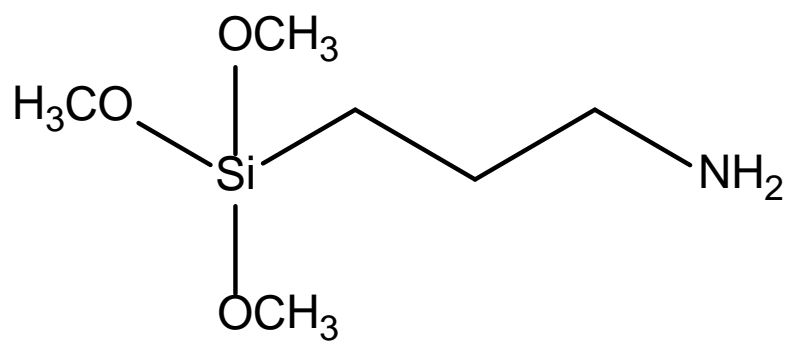

Compound 1. Structure of (3-aminopropyl)trimethoxysilane (TMSA).

\section{NMR Data:}

TMSA Molecular Liquid ${ }^{1} \mathrm{H}: 3.9(\mathrm{~s}, 9) ; 2.9(\mathrm{t}, 2) ; 1.8(\mathrm{~m}, 2) ; 0.9(\mathrm{t}, 2)$

TMSA Molecular Liquid ${ }^{13} \mathrm{C}:$ 49.7, 45.0, 27.1, 6.1

TMSA Ionic Liquid ${ }^{1} \mathrm{H}: 6.0(\mathrm{br}, 3) ; 4.5(\mathrm{br}, 1) ; 3.5(\mathrm{br}, 18) ; 3.0(\mathrm{br}, 2) ; 1.6(\mathrm{br}, 2) ; 0.2(\mathrm{br}, 4)$

TMSA Ionic Liquid ${ }^{13} \mathrm{C}: 162.6,50.0,43.9,42.8,23.8,23.2,5.8$

\section{Elemental Analysis:}

TMSA Molecular Liquid: $\quad$ Expected: $\mathrm{C}(40.19), \mathrm{H}(9.56), \mathrm{N}(7.81)$

Actual: C(40.19), $\mathrm{H}(9.56), \mathrm{N}(7.81)$

TMSA Ionic Liquid: $\quad$ Expected: $\mathrm{C}(38.78), \mathrm{H}(8.51), \mathrm{N}(6.96)$

Actual: $\mathrm{C}(38.34), \mathrm{H}(8.57), \mathrm{N}(6.95)$

Distillation Temperature: Used as received

Infrared Spectra: 


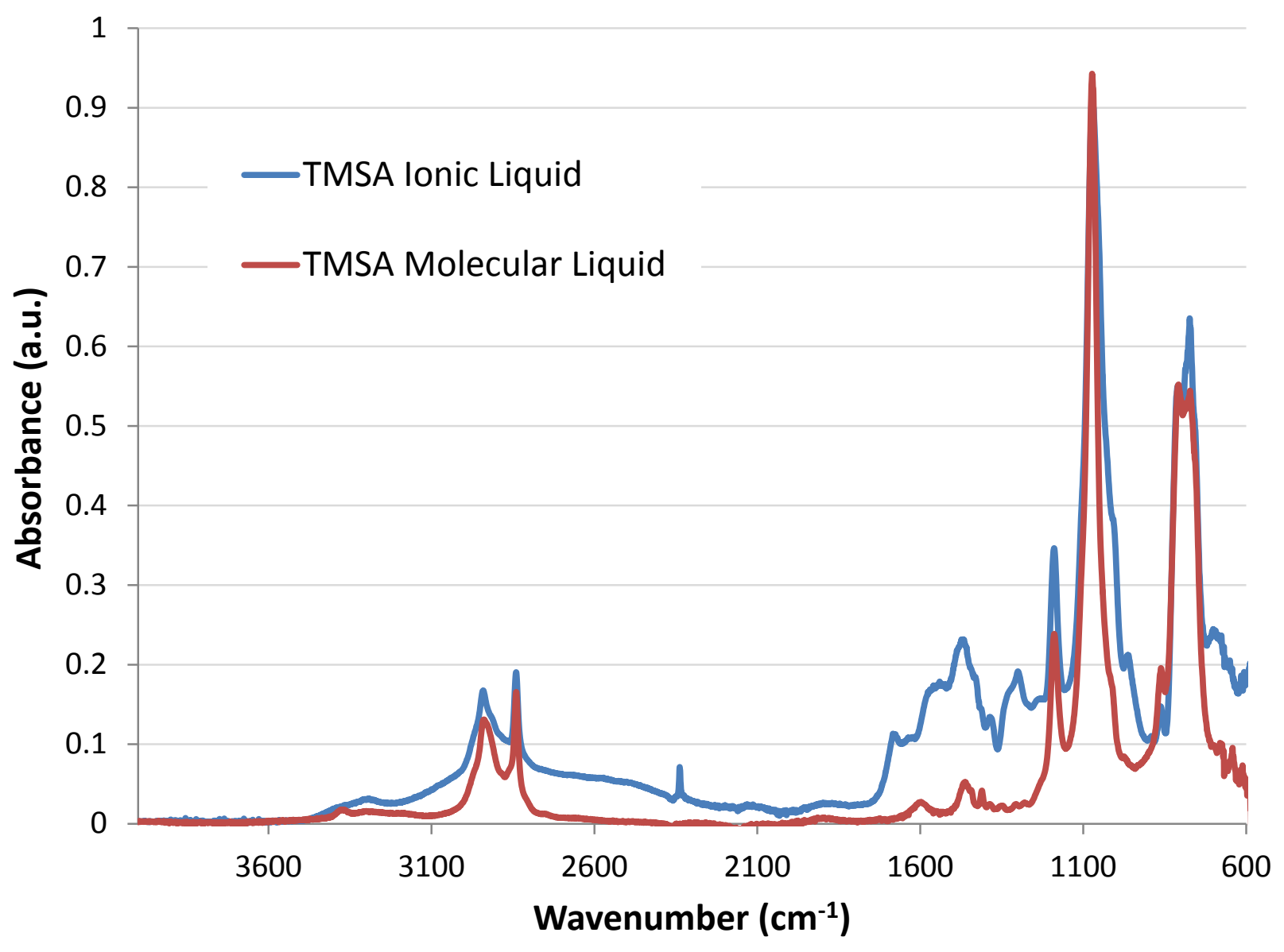

DSC Thermogram:

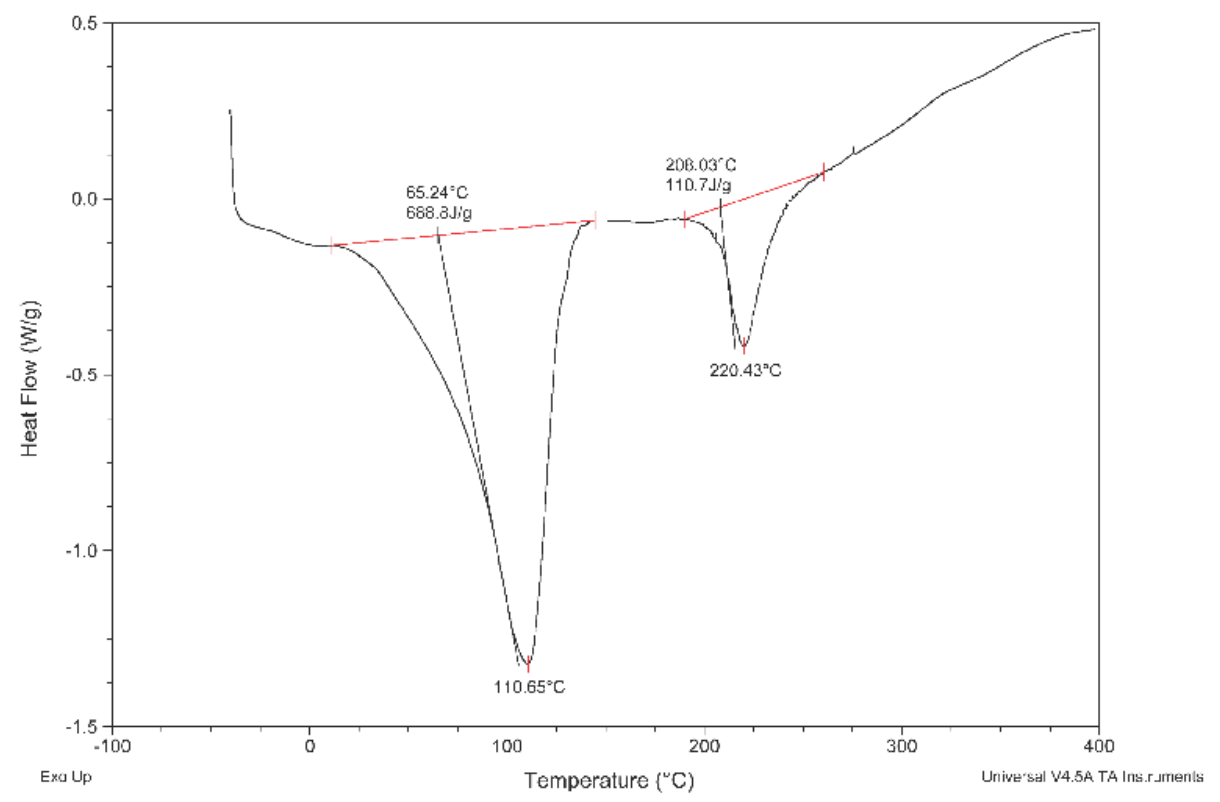




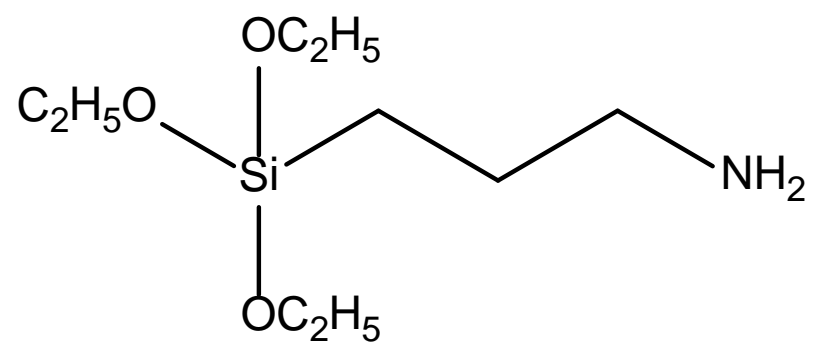

Compound 2. Structure of (3-aminopropyl)triethoxysilane (TESA).

\section{NMR Data:}

TESA Molecular Liquid ${ }^{1} \mathrm{H}: 4.1(\mathrm{~m}, 6) ; 2.9(\mathrm{t}, 2) ; 1.8(\mathrm{~m}, 2) ; 1.5(\mathrm{t}, 9) ; 0.9(\mathrm{t}, 2)$

TESA Molecular Liquid ${ }^{13} \mathrm{C}: 51.2,45.5,18.9,17.9,8.8$

TESA Ionic Liquid ${ }^{1} \mathrm{H}: 9.6(\mathrm{br}, 3) ; 6.0(\mathrm{br}, 1) ; 4.0(\mathrm{br}, 12) ; 3.2(\mathrm{br}, 2) ; 3.0(\mathrm{br}, 2) ; 1.9(\mathrm{br}, 2) ; 1.7(\mathrm{br}, 2) ; 1.4(\mathrm{br}, 18)$;

$0.8(\mathrm{br}, 4)$

TESA Ionic Liquid ${ }^{13} \mathrm{C}: 162.5,57.7,44.1,41.5,23.7,21.3,17.9,7.6,7.4$

\section{Elemental Analysis:}

TESA Molecular Liquid: $\quad$ Expected: $\mathrm{C}(48.83), \mathrm{H}(10.47), \mathrm{N}(6.33)$

Actual: $\mathrm{C}(48.29), \mathrm{H}(10.56), \mathrm{N}(6.05)$

TESA Ionic Liquid:

Expected: $\mathrm{C}(46.88), \mathrm{H}(9.53), \mathrm{N}(5.76)$

Actual: C(46.66), $\mathrm{H}(9.49), \mathrm{N}(5.77)$

Distillation Temperature: Used as received 
Infrared Spectra:

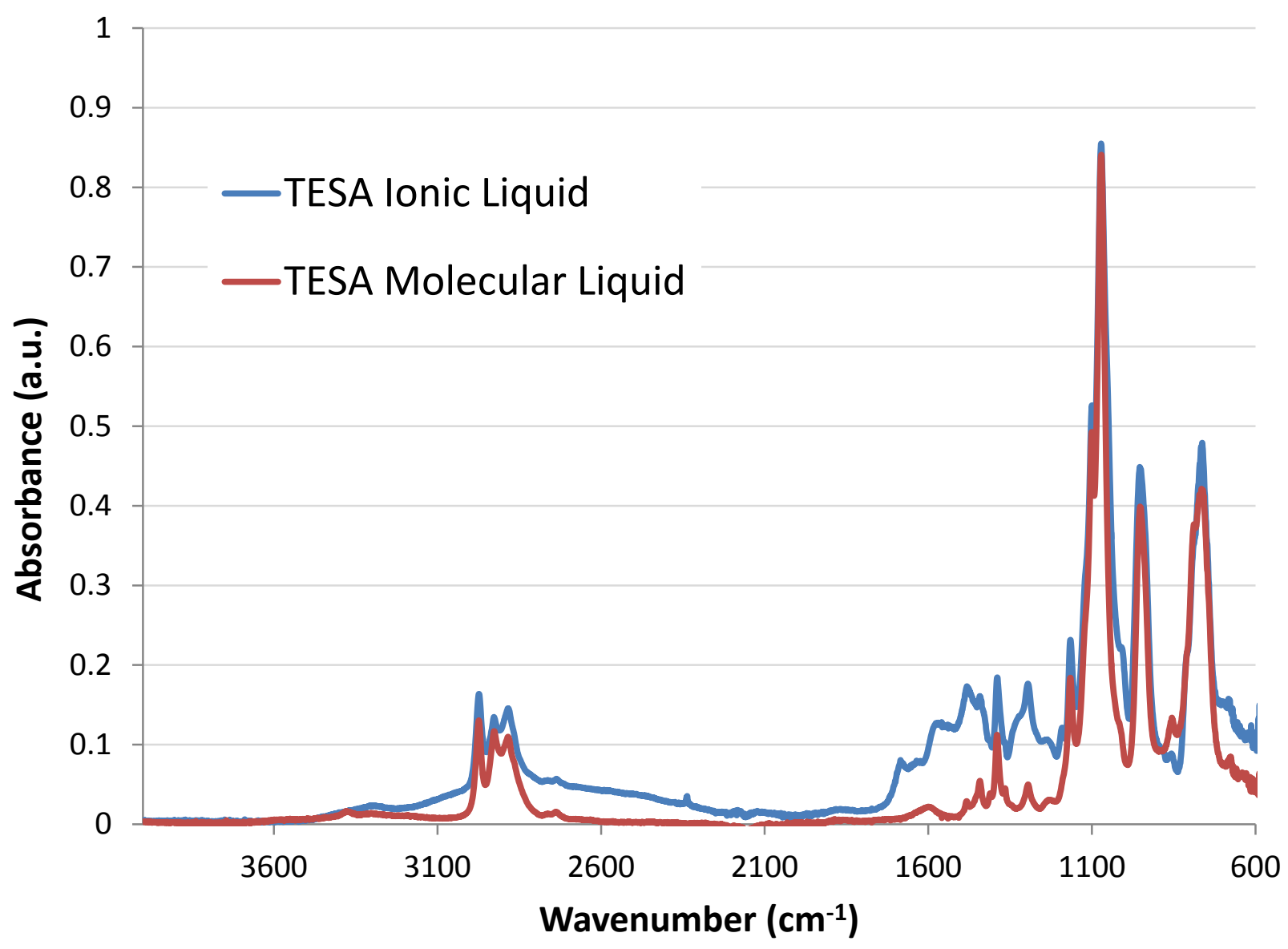

DSC Thermogram:

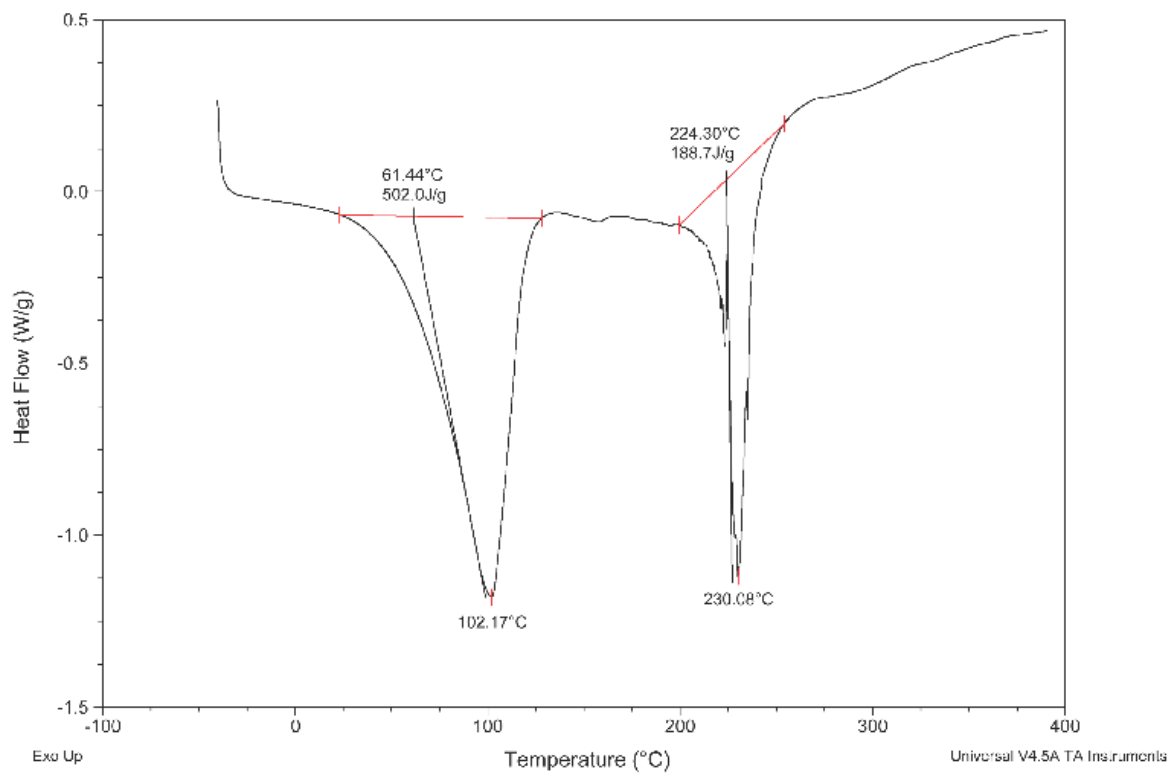




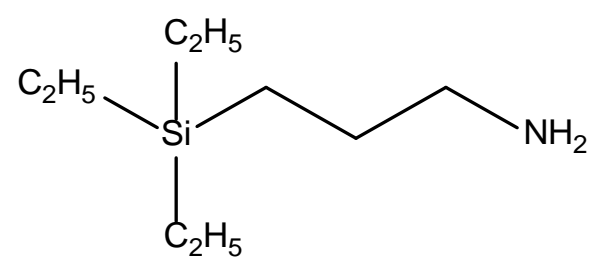

Compound 3. Structure of (3-aminopropyl)triethylsilane (TEtSA).

NMR Data:

TEtSA Molecular Liquid ${ }^{1} \mathrm{H}: 2.59(\mathrm{t}, 2) ; 1.38(\mathrm{p}, 2) ; 1.02(\mathrm{~s}, 2) ; 0.86(\mathrm{t}, 9) ; 0.45(\mathrm{q}, 8)$

TEtSA Molecular Liquid ${ }^{13} \mathrm{C}:$ 45.68, 28.08, 8.10, 7.15, 3.07

TEtSA Ionic Liquid ${ }^{1} \mathrm{H}: 9.22(\mathrm{br}, 3) ; 5.84(\mathrm{br}, 1) ; 3.09(\mathrm{br}, 4) ; 1.58,1.05,0.64(3 \mathrm{br}, 38)$

TEtSA Ionic Liquid ${ }^{13} \mathrm{C}: 163.01,45.52,43.06,25.23,22.56,9.07,7.65,7.61,3.71$

\section{Elemental Analysis:}

TEtSA Molecular Liquid: $\quad$ Expected: $\mathrm{C}(62.35), \mathrm{H}(13.37), \mathrm{N}(8.08)$

Actual: $\mathrm{C}(62.41), \mathrm{H}(13.42), \mathrm{N}(7.94)$

TEtSA Ionic Liquid: $\quad$ Expected: $\mathrm{C}(58.40), \mathrm{H}(11.87), \mathrm{N}(7.17)$

Actual: $\mathrm{C}(57.93), \mathrm{H}(11.79), \mathrm{N}(6.91)$

Distillation Temperature: $75^{\circ} \mathrm{C}$ under vacuum 
Infrared Spectra:

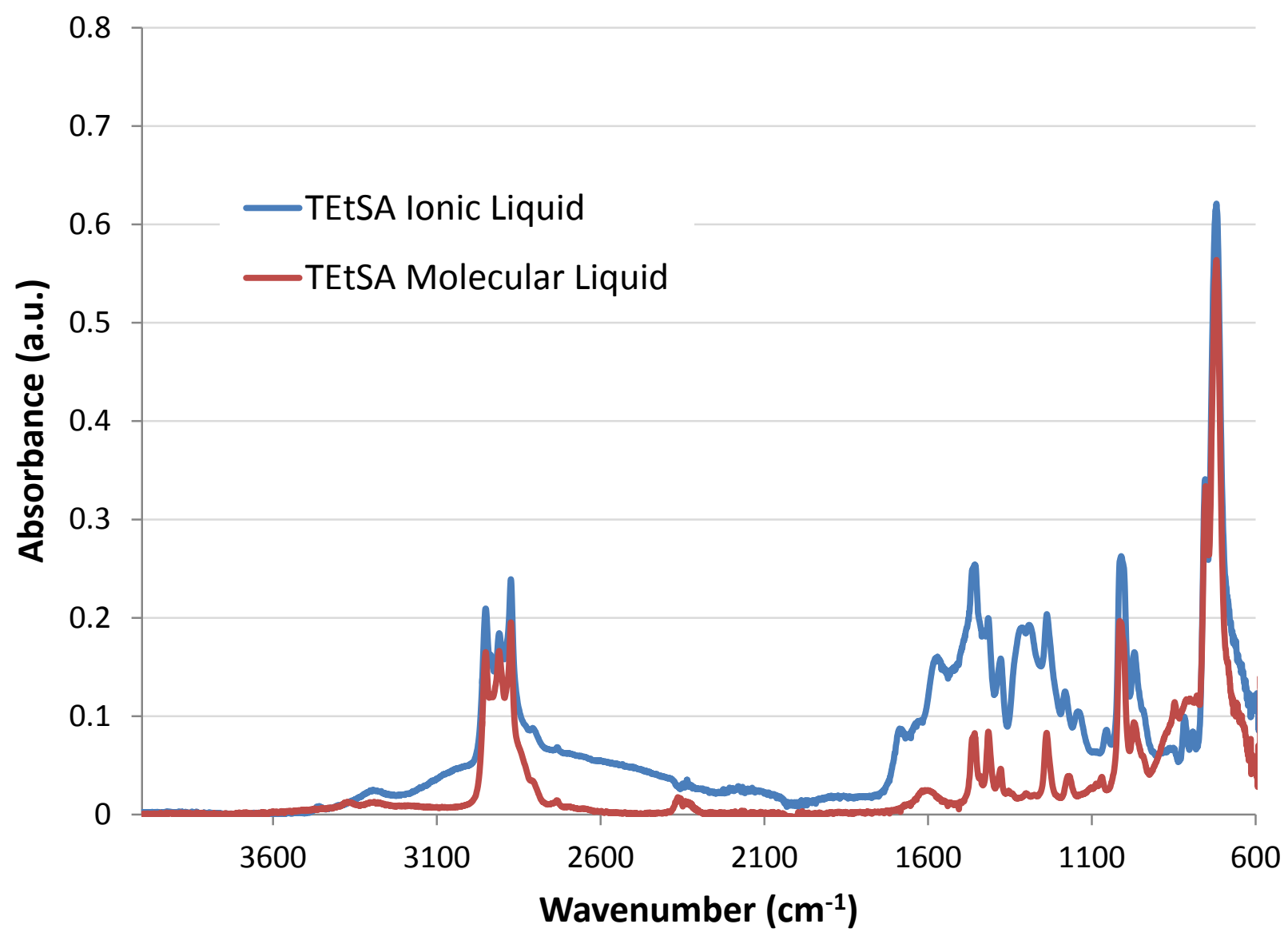

DSC Thermogram:

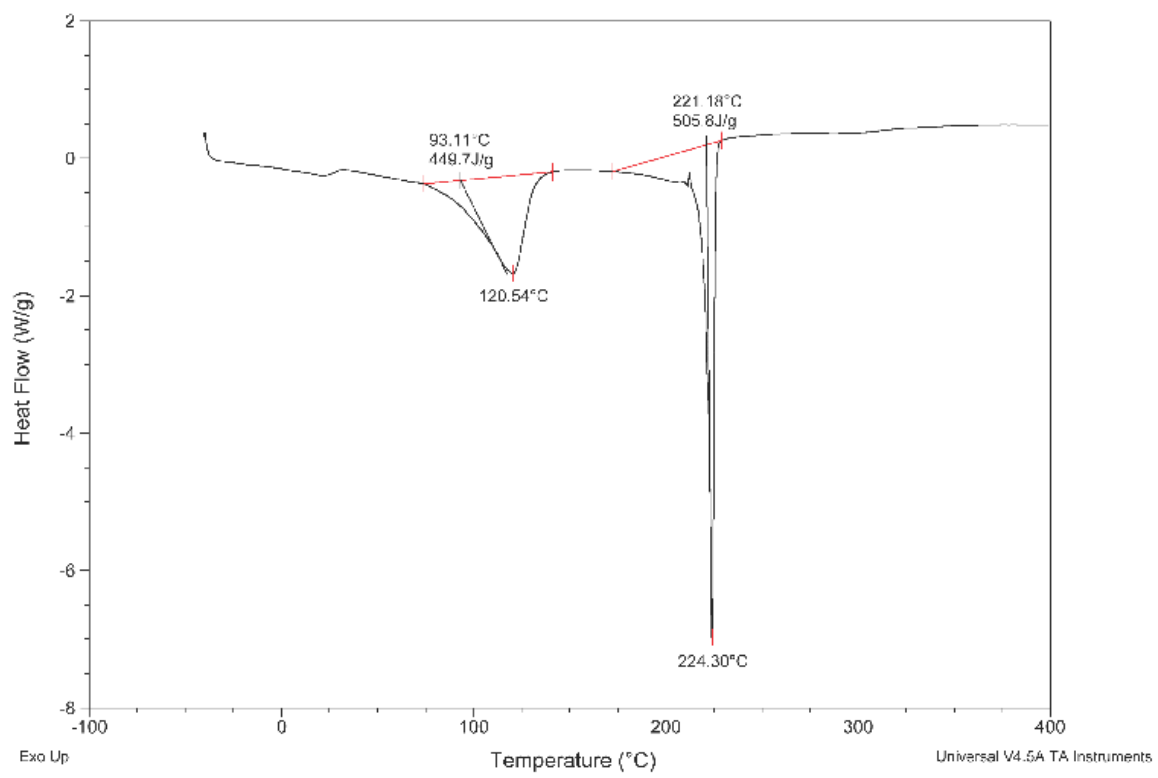




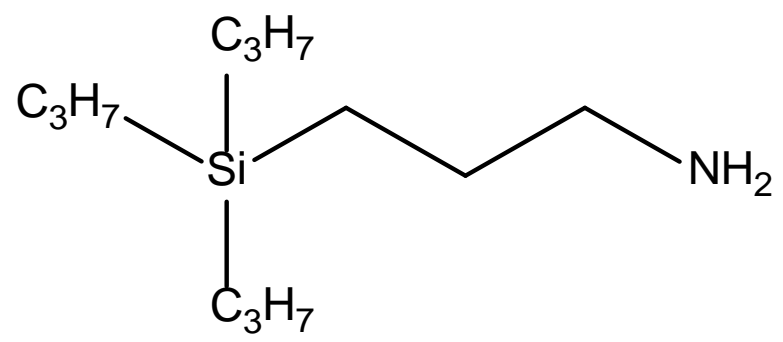

Compound 4. Structure of (3-aminopropyl)tripropylsilane (TPSA).

\section{NMR Data:}

TPSA Molecular Liquid ${ }^{1} \mathrm{H}: 2.59(\mathrm{t}, 2) ; 1.38(\mathrm{p}, 2) ; 1.27(\mathrm{~m}, 6) ; 1.17(\mathrm{~s}, 2) ; 0.89(\mathrm{t}, 9) ; 0.43(\mathrm{q}, 8)$

TPSA Molecular Liquid ${ }^{13} \mathrm{C}: \quad 45.78,28.27,18.48,17.35,15.20,9.47$

TPSA Ionic Liquid ${ }^{1} \mathrm{H}:$ 9.54(br,3); 5.76(br,1); 3.14(br,4); 1.46, 1.07, 0.65(3br,74)

TPSA Ionic Liquid ${ }^{13} \mathrm{C}: 162.45,44.9,25.0,21.5,18.63,17.59,15.41,15.26,10.0$

\section{Elemental Analysis:}

TPSA Molecular Liquid:

Expected: C(66.90), H(13.57), N(6.50)

Actual: $\mathrm{C}(66.74), \mathrm{H}(13.64), \mathrm{N}(6.35)$

TPSA Ionic Liquid:

Expected: $C(63.23), H(12.31), N(5.90)$

Actual: $\mathrm{C}(62.78), \mathrm{H}(12.31), \mathrm{N}(5.72)$

Distillation Temperature: $90^{\circ} \mathrm{C}$ under vacuum 
Infrared Spectra:

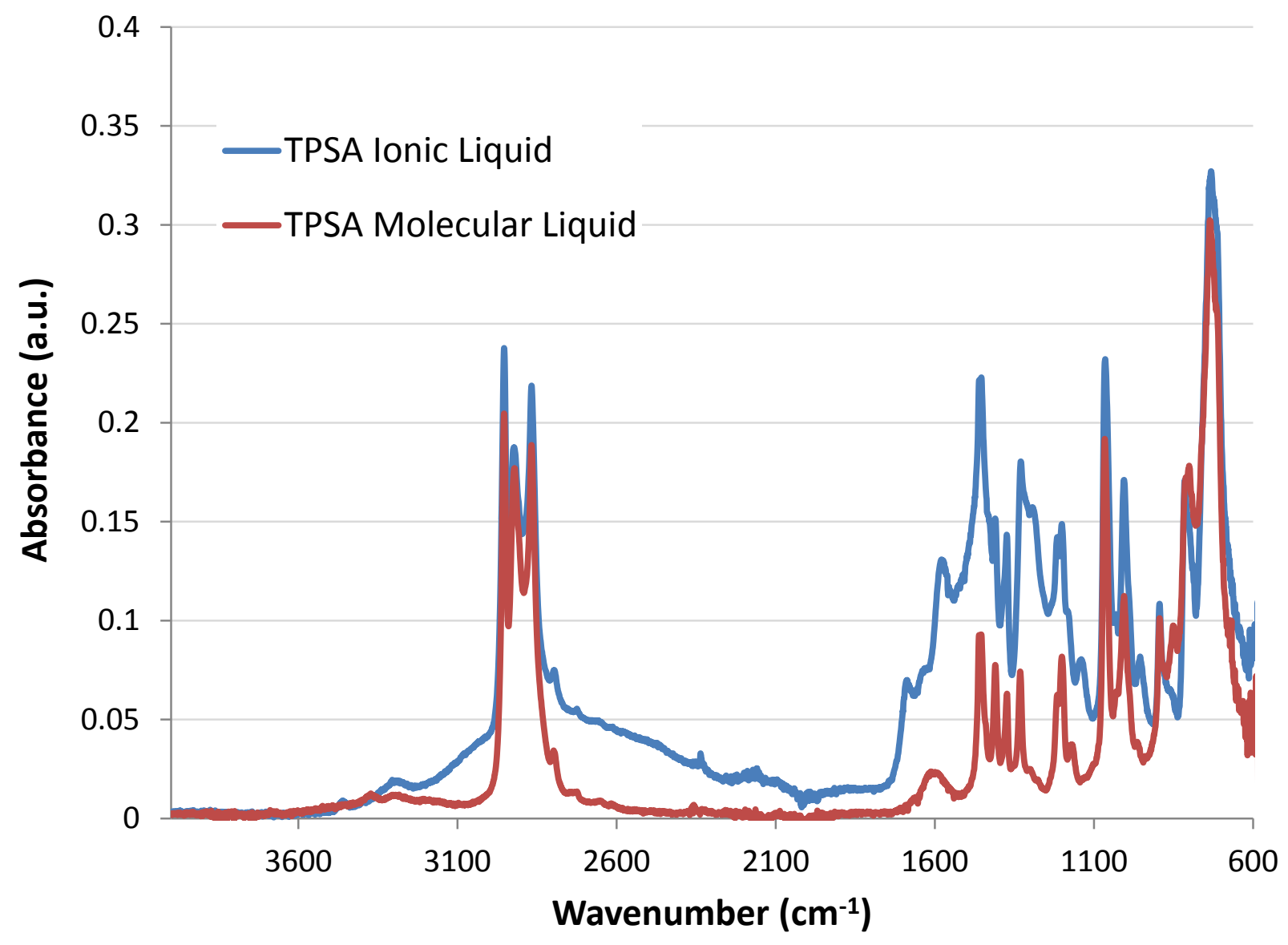

\section{DSC Thermogram:}

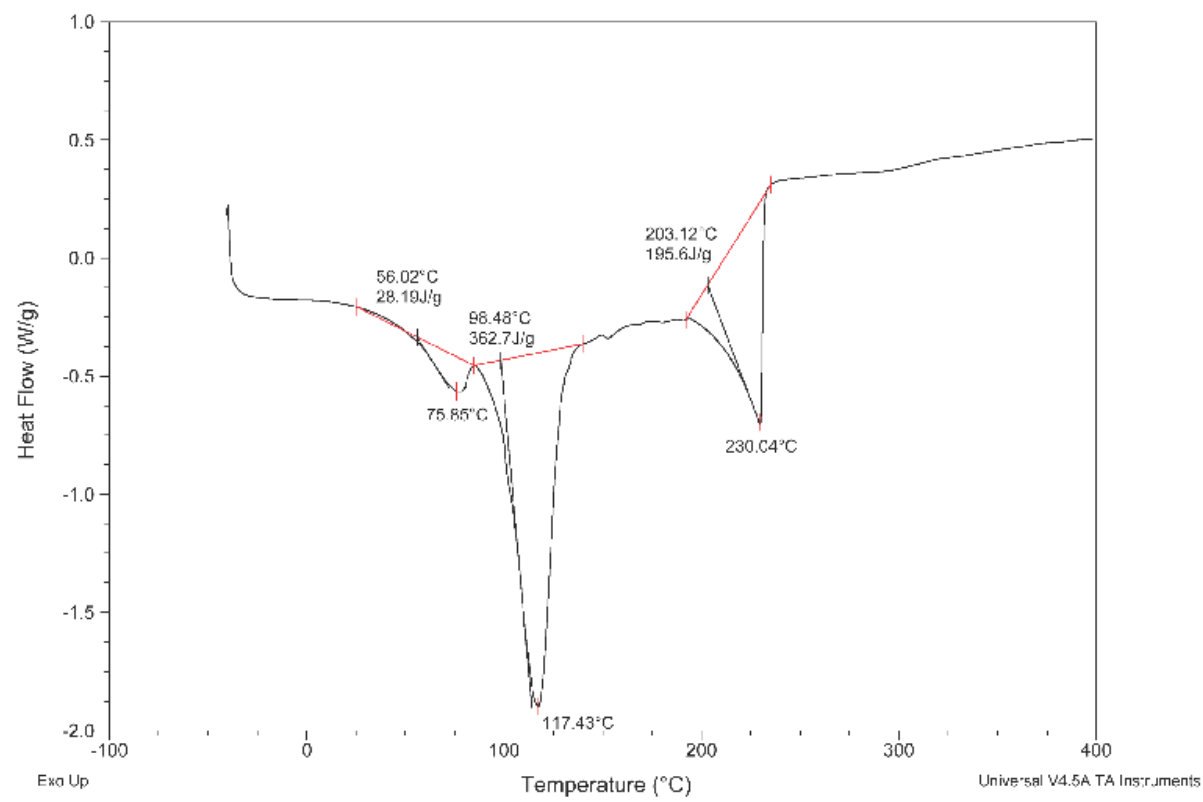




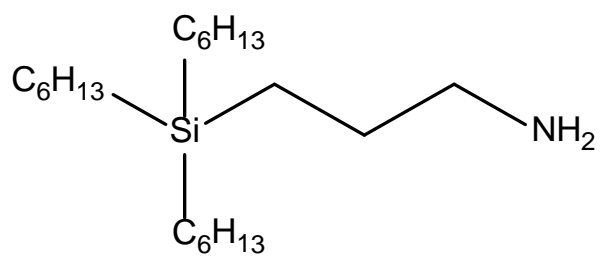

Compound 5. Structure of (3-aminopropyl)trihexylsilane (THSA).

NMR Data:

THSA Molecular Liquid ${ }^{1} \mathrm{H}: 2.63(\mathrm{t}, 2) ; 1.39(\mathrm{p}, 2) ; 1.25(\mathrm{~s}(\mathrm{br}), 26) ; 0.87(\mathrm{t}, 9) ; 0.47(\mathrm{~m}, 8)$

THSA Molecular Liquid ${ }^{13} \mathrm{C}:$ 45.73, 33.45, 31.40, 28.22, 23.71, 22.50, 13.95, 12.26, 9.30

THSA Ionic Liquid ${ }^{1} \mathrm{H}: 1.45(\mathrm{br}), 1.05(\mathrm{br}), 0.86(\mathrm{br})$

THSA Ionic Liquid ${ }^{13} \mathrm{C}: 162.34,45.286,33.76,31.72,25.03,24.00,22.80,14.11,12.52,10.05$

\section{Elemental Analysis:}

THSA Molecular Liquid: $\quad$ Expected: $\mathrm{C}(73.82), \mathrm{H}(13.86), \mathrm{N}(4.10)$

Actual: $\mathrm{C}(72.87), \mathrm{H}(13.59), \mathrm{N}(4.07)$

THSA Ionic Liquid: $\quad$ Expected: $C(71.00), H(13.03), N(3.85)$

Actual: $\mathrm{C}(70.92), \mathrm{H}(13.12), \mathrm{N}(3.74)$

Distillation Temperature: $150^{\circ} \mathrm{C}$ under vacuum 
Infrared Spectra:

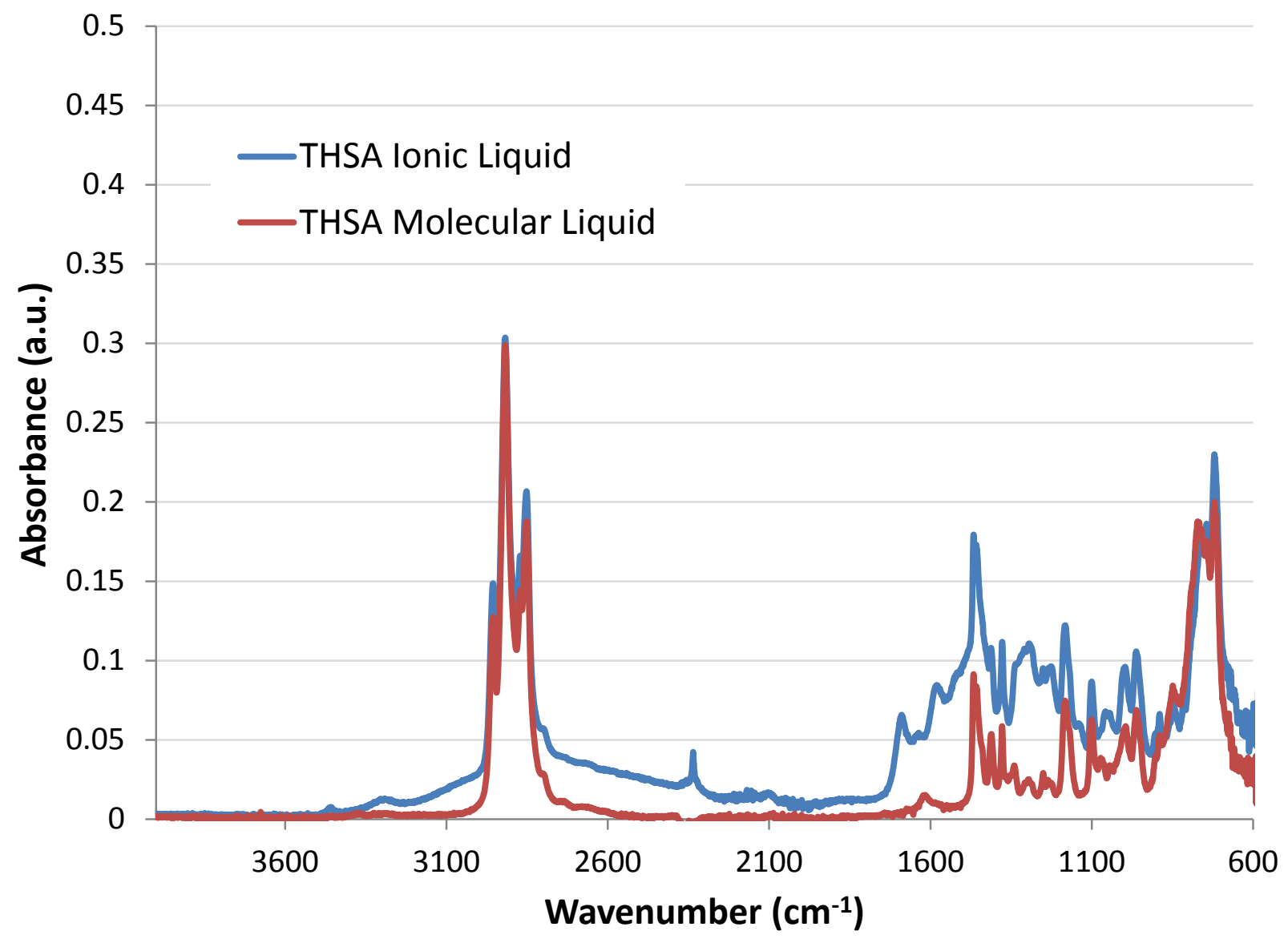

DSC Thermogram:

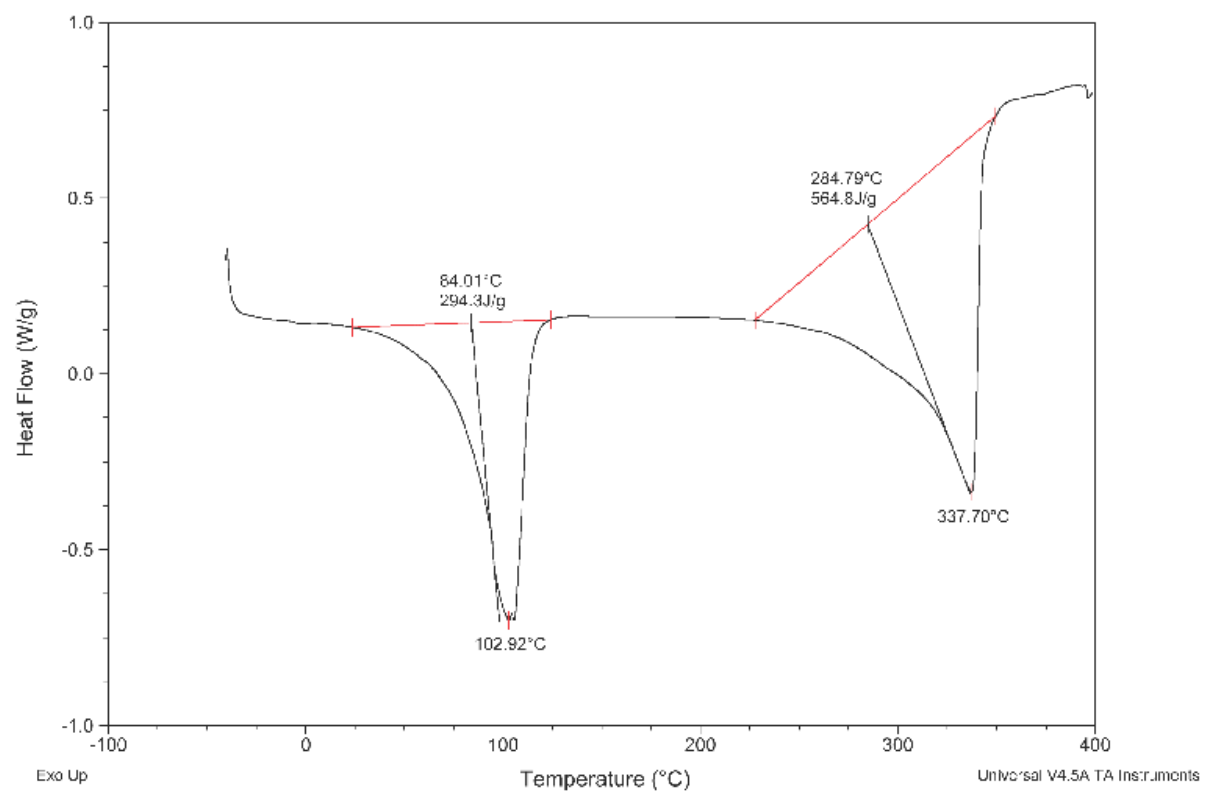




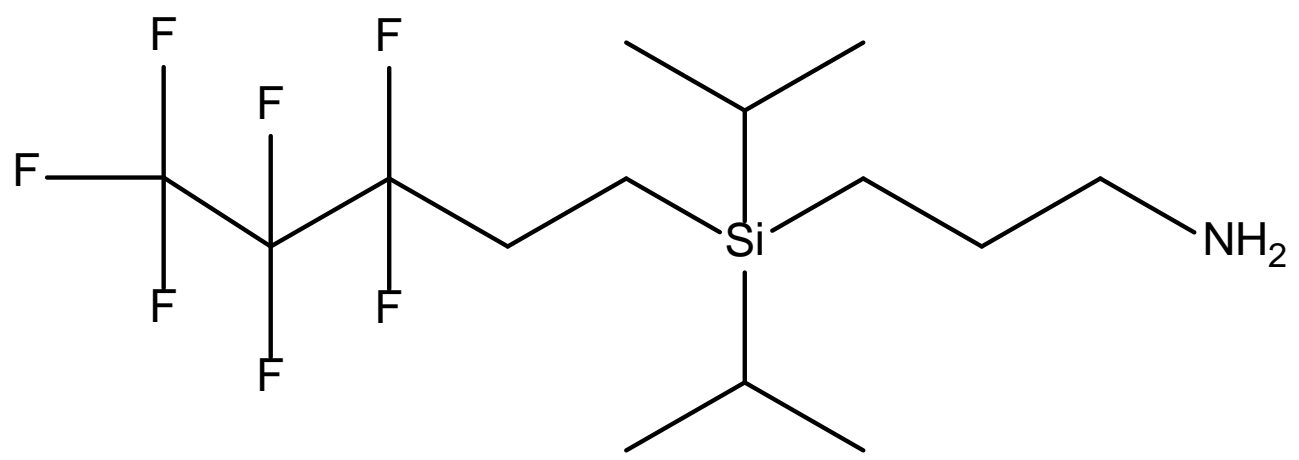

Compound 6. Structure of (3-aminopropyl)diisopropyl $(1 \mathrm{H}, 1 \mathrm{H}, 2 \mathrm{H}, 2 \mathrm{H}$-perfluoropentyl)silane (FSA).

NMR Data:

FSA Molecular Liquid ${ }^{1} \mathrm{H}: 2.68(\mathrm{t}, 2) ; 2.03$ (m(pent),2); 1.44(p,2); 1.013(s,16); 0.79(m,2); 0.58(m,2)

FSA Molecular Liquid ${ }^{13} \mathrm{C}:$ 45.9, 28.0, 25.9(trip), 18.1, 11.0, 6.4, -1.0

FSA Ionic Liquid ${ }^{1} \mathrm{H}:(2-0, \mathrm{br})$

FSA Ionic Liquid ${ }^{13} \mathrm{C}: 162.34(\mathrm{br}), 120-100$ (8 broad peaks), 25.64(br), 17.42(br), 10.86(br), 6.59(br), $1.18(\mathrm{br})$

Elemental Analysis:

FSA Molecular Liquid: $\quad$ Expected: $\mathrm{C}(45.52), \mathrm{H}(7.09), \mathrm{N}(3.79)$

Actual: $\mathrm{C}(45.29), \mathrm{H}(7.12), \mathrm{N}(3.84)$

FSA Ionic Liquid: $\quad$ Expected: $\mathrm{C}(44.49), \mathrm{H}(6.69), \mathrm{N}(3.58)$

Actual: $\mathrm{C}(44.42), \mathrm{H}(6.69), \mathrm{N}(3.58)$

Distillation Temperature: $120^{\circ} \mathrm{C}$ under vacuum

Infrared Spectra: 


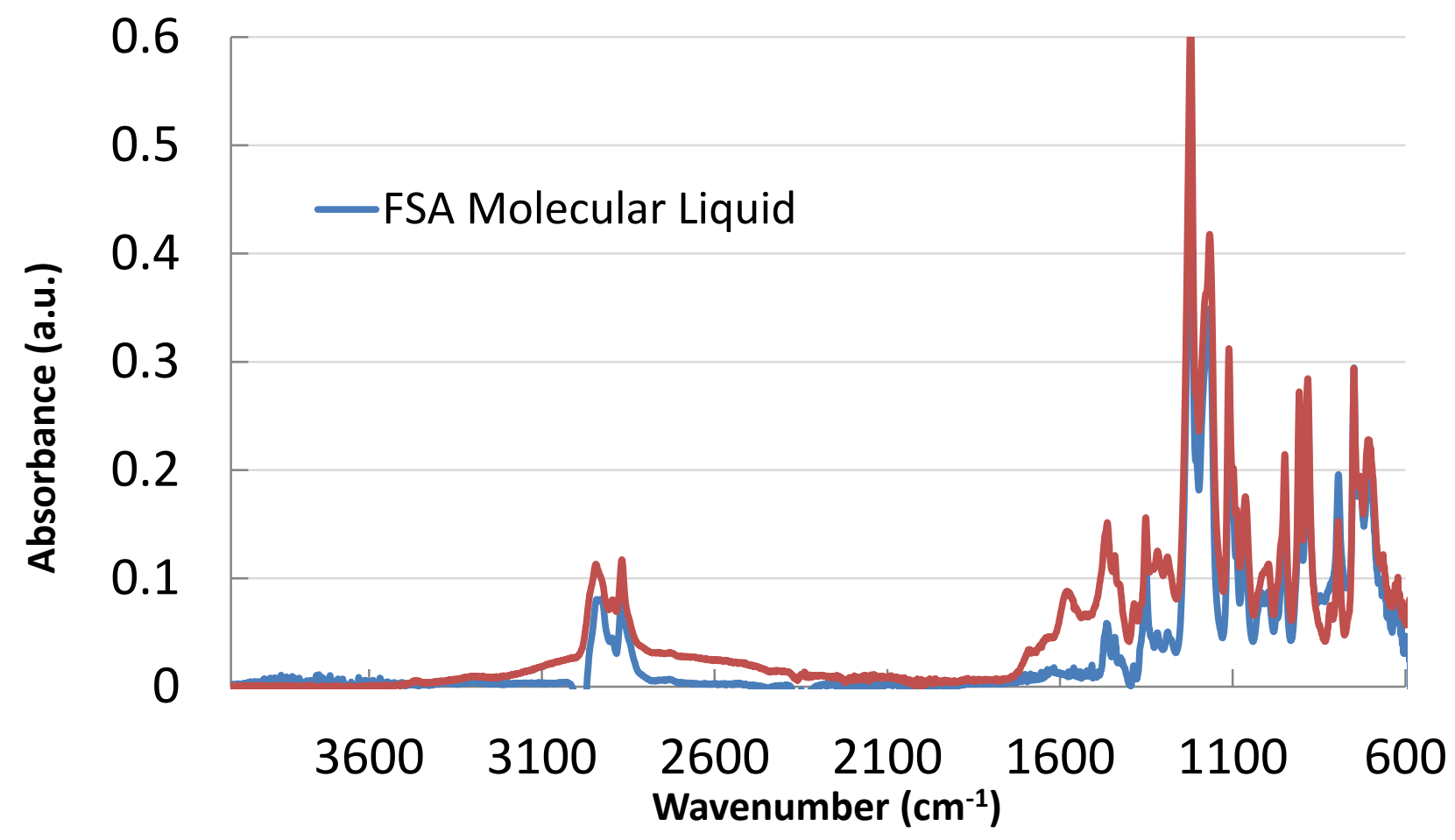

DSC Thermogram:

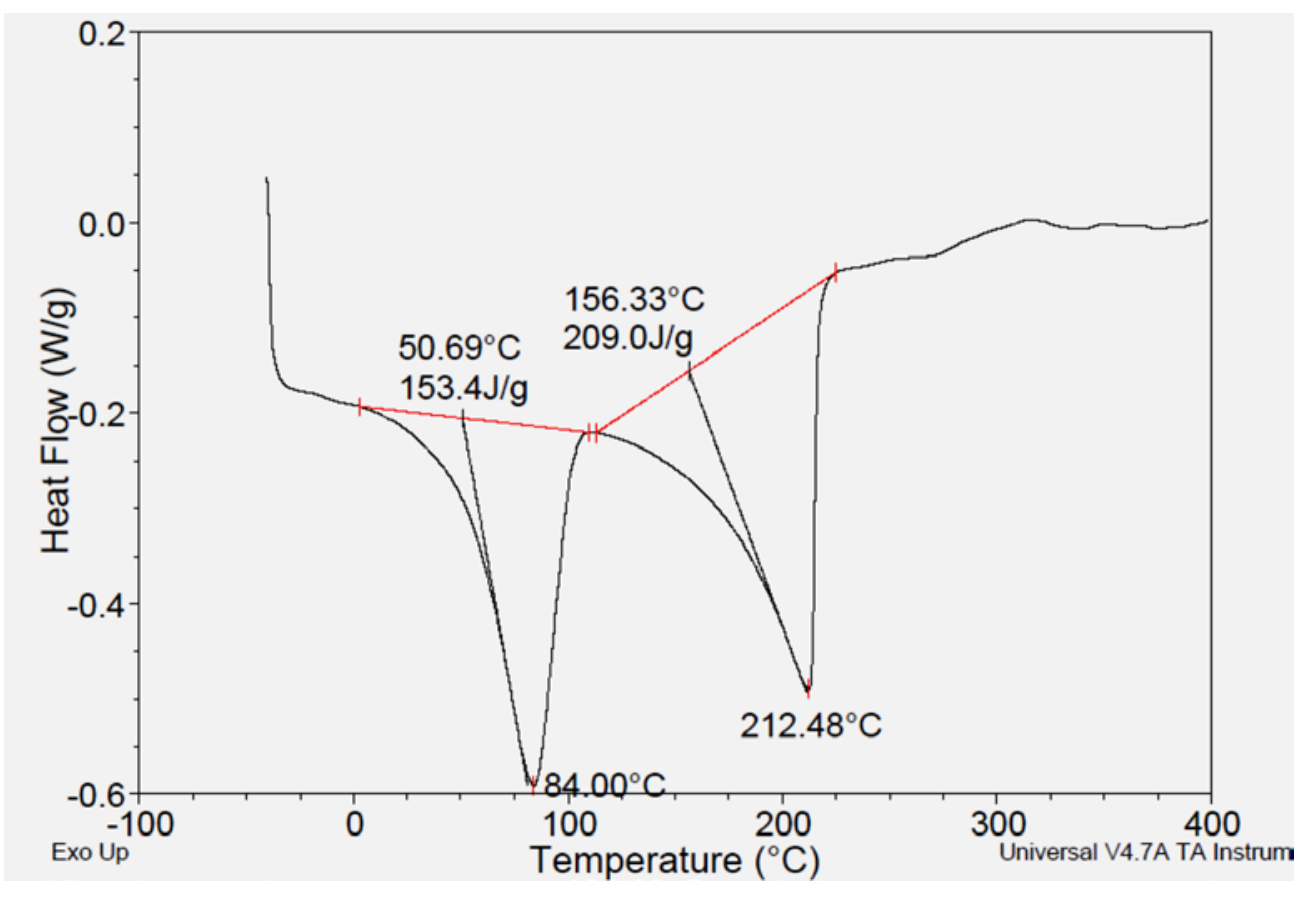




\section{List of Publications and Presentations}

\section{a. Publications}

> Vittoria Blasucci, Cerag Dilek, Hillary Huttenhower, Ejae John, Veronica Llopis-Mestre, Pamela Pollet, Charles A. Eckert, and Charles L. Liotta, “One Component, Switchable, Neutral to Ionic Liquid Solvents Derived from Siloxylated Amines,” Chem Comm, 116119, 2009.

> Vittoria Blasucci, Ryan Hart, Veronica Llopis-Mestre, D. Julia Hahne, Melissa Burlager, Hillary Huttenhower, Reginald Thio, Charles L. Liotta, and Charles A. Eckert, "Single Component, Reversible Ionic Liquids for Energy Applications,” Fuel, 89, 1315-1319, 2010.

> Vittoria M. Blasucci, Ryan Hart, Pamela Pollet, Charles L. Liotta, and Charles A. Eckert, “Reversible Ionic Liquids Designed for Facile Separations,” Fluid Phase Equilibria, 294, 1-6, 2010.

> Ryan Hart, Pamela Pollet, Dominique J. Hahne, Ejae John, Veronica Llopis-Mestre, Vittoria Blasucci, Hillary Huttenhower, Walter Leitner, Charles A. Eckert, and Charles L. Liotta, "Benign Coupling of Reactions and Separations with Reversible Ionic Liquids," Tetrahedron, 66, 1082-1090, 2010.

\section{b. Presentations}

1- Invited papers:

$>$ Charles A. Eckert and Charles L. Liotta, "Reversible Ionic Liquids as Double-Action Solvents for $\mathrm{CO}_{2}$ Capture,” Annual NETL $\mathrm{CO}_{2}$ Capture Technology for Existing Plants R\&D Meeting, Pittsburgh, PA, August 23, 2011.

$>$ Charles A. Eckert and Charles L. Liotta, "Reversible Ionic Liquids as Double-Action Solvents for $\mathrm{CO}_{2}$ Capture,” Annual NETL $\mathrm{CO}_{2}$ Capture Technology for Existing Plants R\&D Meeting, Pittsburgh, PA, September 13, 2010. 
Charles A. Eckert and Charles L. Liotta, "Reversible Ionic Liquids as Double-Action Solvents for CO2 Capture,” Annual NETL $\mathrm{CO}_{2}$ Capture Technology for Existing Plants R\&D Meeting, Pittsburgh, PA, March 24, 2009.

> Ryan Hart, Charles L. Liotta and Charles A. Eckert, "Molecular Design of Liquid Sorbents for $\mathrm{CO}_{2}$ Capture,” Georgia Tech $\mathrm{CO}_{2}$ Forum, September 2009

> Charles A. Eckert, Ryan Hart, Vittoria Blasucci, Pamela Pollet, and Charles L. Liotta, "Smart" Solvents for Extractions and Purifications, Annual AIChE Meeting, Nashville, TN, November, 2009.

> Charles A. Eckert and Charles L. Liotta, "Novel Solvents for Sustainable Technology," Basore Distinguished Lecture, Auburn University, January 2010

$>$ Charles L. Liotta and Charles A. Eckert, "Solvent Systems for Green and Sustainable Chemical Processes," BASF, Wyandotte, MI, March 18, 2010

> Charles L. Liotta and Charles A. Eckert, "Solvent Systems for Green and Sustainable Chemical Processes," Virginia Commonwealth University, Richmond, VA, March 31, 2010

> Charles L. Liotta and Charles A. Eckert, "Solvent Systems for Green and Sustainable Chemical Processes," Chemistry Department, U. Texas, Dallas, Wyandotte, TX, April 8, 2010.

> Charles A. Eckert, Charles L. Liotta, Pamela Pollet, Ryan Hart, "Provoking Phase Changes for Extractive Separations," AIChE Annual Meeting, Salt Lake City, UT, November, 2010.

\section{2- Contributed Papers:}

> Vittoria Blasucci, Cerag Dilek, Hillary Huttenhower, Ejae John, Veronica Llopis-Mestre, Pamela Pollet, Charles L. Liotta, and Charles A. Eckert "One-Component, Switchable, Neutral to Ionic Liquid Solvents Derived from Siloxylated Amines," 237th National Meeting, ACS, Salt Lake City, UT, March, 2009.

> Vittoria Blasucci, Ryan Hart, Cerag Dilek, Hillary Huttenhower, Veronica Llopis-Mestre, Pamela Pollet, Eduardo Vyhmeister, Charles L. Liotta, and Charles A. Eckert, 
"Reversible Ionic Liquids as Double-Action Solvents for Efficient $\mathrm{CO}_{2}$ Capture," AIChE Spring National Meeting, Tampa, FL, April 2009

> Philip G. Jessop, Michael Cunningham, Charles A. Eckert, and Charles L. Liotta " $\mathrm{CO}_{2}$ as a Trigger for Switchable Chemistry,” International Conference on Carbon Dioxide Utilization, China, May 2009.

> Ali Fadhel, Vittoria Blasucci, Cerag Dilek, Ryan Hart, Hillary Huttenhower, Veronica Llopis-Mestre, Pamela Pollet, Eduardo Vyhmeister, Charles A. Eckert, and Charles L. Liotta “Designer Reversible Ionic Liquids for $\mathrm{CO}_{2}$ Capture," 13th Annual Green Chemistry \& Engineering Conference, Washington, DC, June 2009.

$>$ Ryan Hart, Vittoria Blasucci, Charles A. Eckert, and Charles L. Liotta, "Development of One-Component Reversible Ionic Liquids for Energy Applications," 2009 Annual AIChE Meeting,Poster, Nashville, TN, November 2009.

> Ryan Hart, Pamela Pollet, Dominique J. Hahne, Ejae John, Veronica Llopis-Mestre, Vittoria Blasucci, Hillary Huttenhower, Walter Leitner, Charles A. Eckert, Charles L. Liotta, “A Unique Class of Sustainable Solvents: Reversible Ionic Liquids,” ACS Spring Meeting, March 21 - 25, 2010, San Francisco.

> Cerag Dilek, Vittoria Blasucci, Ali Fadhel, Kyle Flack, Ryan Hart, Hillary Huttenhower, Kristen Kitagawa, Veronica Llopis-Mestre, Pamela Pollet, Manjusha Verma, Eduardo Vyhmeister, Charles L. Liotta, and Charles A. Eckert, "Reversible Ionic Liquids as Dual Functional Solvents for Post Combustion $\mathrm{CO}_{2}$ Capture " 6th Chemical Engineering Conference for Collaborative Research in Eastern Mediterranean Countries (EMCC6), March 2010, Antalya-Turkey.

> Rani Jha, Ali Fadhel, Vittoria Blasucci, Ryan Hart, Veronica Llopis-Mestre, Pamela Pollet, Charles L. Liotta, Charles A. Eckert, "Designer Reversible Ionic Liquids for $\mathrm{CO}_{2}$ Capture," Fall National Meeting, ACS, Boston MA, August 2010.

> Ryan Hart, Kyle Flack, Jackson Switzer, Amy Rohan, Manjusha Verma, Charles L. Liotta, and Charles A. Eckert, "The Design of Reversible Ionic Liquids for PostCombustion $\mathrm{CO}_{2}$ Recovery,” AIChE Annual Meeting, Salt Lake City, November 2010.

> Amy Rohan, Swetha Sivaswamy, Ryan Hart, Pamela Pollet, Manish Talreja, Elizabeth Biddinger, Jackson Switzer, Kyle Flack, Manjusha Verma, Charles Liotta, and Charles Eckert, "Novel $\mathrm{CO}_{2}$ Captue Solvent System,” 2010 Strategic Energy Institute Energy 
Symposium, Atlanta, GA, December 6, 2010.

> R. Hart' A. Fadhel' V. Blasucci, P. Pollet, C. A. Eckert, C. L. Liotta, "Design and development of one-component reversible ionic liquids for post-combustion $\mathrm{CO}_{2}$ capture.” ACS PacifiChem, Honolulu, December, 2010.

> Jackson R. Switzer, Amy L. Rohan, Ryan J. Hart, Pamela Pollet, Charles L. Liotta, Charles A. Eckert, "A Spectroscopic Technique for the Decoupled Measurement of Physical and Chemical Absorption in Reactive Solvent Systems,” Pittcon, Atlanta, GA, March 13-18, 2011.

> Swetha Sivaswamy, Ryan Hart, Kyle Flack, Amy Rohan, Jackson Switzer, Manjusha Verma, Elizabeth Biddinger, Manish Talreja, Pamela Pollet, Charles Liotta and Charles Eckert, "Reversible Ionic Liquids for Carbon Dioxide Capture," ACS Meeting, Anaheim, CA, March 2011

> Jackson Switzer, Kyle Flack, Ryan Hart, Amy Rohan, Swetha Sivaswamy, Elizabeth Biddinger, Manish Talreja, Manjusha Verma, Pamela Pollet, Charles Liotta, Charles Eckert, " Design of Dual-Capture $\mathrm{CO}_{2}$ Solvents using Structure-Property Relationships," 2011 Georgia Tech Research and Innovation Conference (Poster).

> Amy Rohan, Ryan Hart, Kyle Flack, Swetha Sivaswamy, Jackson Switzer, Elizabeth Biddinger, Manish Talreja, Pamela Pollet, Charles Liotta and Charles Eckert, " Advance of Reversible Silylamine-Based Ionic Liquids for Post-Combustion $\mathrm{CO}_{2}$ Capture from Coal-Fired Power Plants," 2011 Georgia Tech Research and Innovation Conference (Poster).

> Amy Rohan, Ryan Hart, Kyle Flack, Swetha Sivaswamy, Jackson Switzer, Elizabeth Biddinger, Manish Talreja, Pamela Pollet, Charles Liotta and Charles Eckert, " Use of Reversible Ionic Liquids as Solvents for Post-Combustion Recovery of $\mathrm{CO}_{2}$ from CoalFired Power Plants," AIChE National Meeting, Chicago, IL, March 2011.

\section{c. Website}

Webpages have been prepared and posted within the Eckert/Liotta group website http://eckert.chbe.gatech.edu/projects.html 


\section{d. Intellectual Property}

Two invention disclosures based on the work of this project have been filed:

GTID 4641: Eckert, C.A., Liotta, C.L., Huttenhower, H.; Mestre-Llopes, V.; Blasucci, V.; Pollet, P.; "Reversible Ionic Liquids as Double Action Solvents for Efficient $\mathrm{CO}_{2}$ Capture", Invention disclosure 9/29/2008.

GTID 5629: Hart, R.; Flack, K.; Switzer, J.; Pollet, P.; Eckert, C.; Liotta, C. "Substituted (Trialkylsilyl)-alkylpropylamine Reversible Ionic Liquids Systems." Invention Disclosure $4 / 14 / 2011$

\section{e. Education}

A major thrust of this project is the education of our future scientists and engineers who will be working in the environmental area developing sustainable processes. We are pleased to report our contributions in this area:

\section{Personnel/Students Present and Graduated}

Ryan Adams, (Chemical Engineering, Postdoctoral - Now at Algenol)

Vittoria Blasucci (PhD in Chemical Engineering, 2009 - Now at ExxonMobil)

Olga Dzenis (MS in Chemical Engineering, 2011 - Now at Wink Engineering)

Ali Fahdel (PhD in Chemical Engineering, 2010 - Now at GE)

Ryan Hart (PhD in Chemical Engineering, 2010 - Now at Exponent)

Hillary Huttenhower (PhD in Chemistry, 2010 - Now at Pratt \& Whitney)

Paul Nielsen (BS in Chemical Engineering, 2011 - Now at University of Texas, Austin)

Sean Faltermeier (BS in Chemical Engineering, 2011 - Now at MIT) 
Dr. Pamela Pollet (Chemistry, Research Scientist)

Dr. Elizabeth Biddinger, (Chemical Engineering, Postdoctoral)

Dr. Rani Jha, (Chemistry, Postdoctoral)

Dr. Manish Talreja, (Chemical Engineering, Postdoctoral)

Dr. Manjusha Verma, (Chemistry, Postdoctoral)

Kyle Flack (PhD Candidate, Chemistry)

Greg Marus (PhD Candidate, Chemical Engineering)

Farhana Momin (MS student, Chemical Engineering)

Emily Nixon (PhD Candidate, Chemistry)

Amy Rohan (PhD Candidate, Chemical Engineering)

Amber Rumple ( $\mathrm{PhD}$ Student, Chemistry)

Swetha Sivaswamy (PhD Candidate, Chemical Engineering)

Jackson Switzer (PhD Candidate, Chemical Engineering)

Ashley Bembry (Sophomore, Chemical Engineering)

Melissa Burlager (Senior, Chemical Engineering)

Jordan Donaldson (Junior, Chemical Engineering)

Poomrapee Jewanarom (Junior, Chemical Engineering)

\section{f. Industrial Collaboration}

As a result of our work on this project we have generated an industrial collaboration with ConocoPhillips, who have agreed to partner with us for the next three years. This not only 
provides for facile technology transfer, but gives us enhanced access to real-world problems and opportunities. And of course, it provides a vehicle for future testing and implementation.

\section{g. Academic Collaboration}

We have collaborated with Francisco Rodríguez and Jose Palomar from Universidad Complutense de Madrid and Universidad Autónoma de Madrid, respectively. They specialize in using COSMO-RS for estimating the thermodynamic properties of the systems based on just the structural information of the components of the system. In this report we have shown how we have successfully integrated the COSMO-RS estimates with the FT-IR results for the calculation of equilibrium constants. The collaboration was not part of the this DOE-funded project but complemented the work in the project. 


\section{c) List of Symbols}

\begin{tabular}{|l|l|}
\hline Symbol & Definition \\
\hline$\lambda_{\max }$ & Wavelength of maximum absorption \\
\hline $\mathrm{K}, \mathrm{K}(\mathrm{T})$ & Equilibrium constant at temp $\mathrm{T}$ \\
\hline $\mathrm{K}_{\mathrm{c}}$ & Equilibrium mole fractions of molecular and ionic liquid \\
\hline $\mathrm{K}_{\gamma}$ & Correction for non-ideality of system \\
\hline$x_{i}$ & Mole fraction of specie $i$ \\
\hline$\gamma_{\mathrm{i}}$ & Activity coefficient of specie $i$ \\
\hline$f_{\mathrm{CO} 2}$ & Fugacity of $\mathrm{CO}_{2}$ \\
\hline$f^{\circ}{ }_{\mathrm{CO} 2}$ & Standard state fugacity of $\mathrm{CO}_{2}$ \\
\hline$a_{i}$ & Activity of specie $i$ \\
\hline $\mathrm{P}$ & Pressure \\
\hline $\mathrm{H}$ & Henry's Law constant \\
\hline $\mathrm{Q}$ & Sensible heat \\
\hline $\mathrm{m}$ & Mass \\
\hline $\mathrm{C}_{\mathrm{P}}$ & Heat capacity \\
\hline$\Delta \mathrm{H}_{\mathrm{rxn}}$ & Heat of reaction \\
\hline$\Delta \mathrm{H}_{\text {dissolution }}$ & Enthalpy of mixing/demixing \\
\hline $\mathrm{T}_{\text {rev }}$ & Reversal temperature \\
\hline $\mathrm{T}_{\text {cap }}$ & Capture temperature \\
\hline $\mathrm{t}_{\mathrm{rxn}}$ & Reaction time \\
\hline $\mathrm{D}_{\text {gas }}$ & Gas diffusivity of $\mathrm{CO}_{2}$ \\
\hline $\mathrm{D}_{\mathrm{IL}}$ & Ionic liquid diffusivity of $\mathrm{CO}_{2}$ \\
\hline$\sigma$ & Characteristic diffusion path length \\
\hline
\end{tabular}

